\title{
Baseline household survey: Buner district
}

Pakistan Initiative for Mothers and Newborns (PAIMAN)

Follow this and additional works at: https://knowledgecommons.popcouncil.org/departments_sbsr-rh

Part of the Family, Life Course, and Society Commons, and the Maternal and Child Health Commons How does access to this work benefit you? Let us know!

\section{Recommended Citation}

Pakistan Initiative for Mothers and Newborns (PAIMAN). 2006. "Baseline household survey: Buner district." Islamabad: Population Council. 


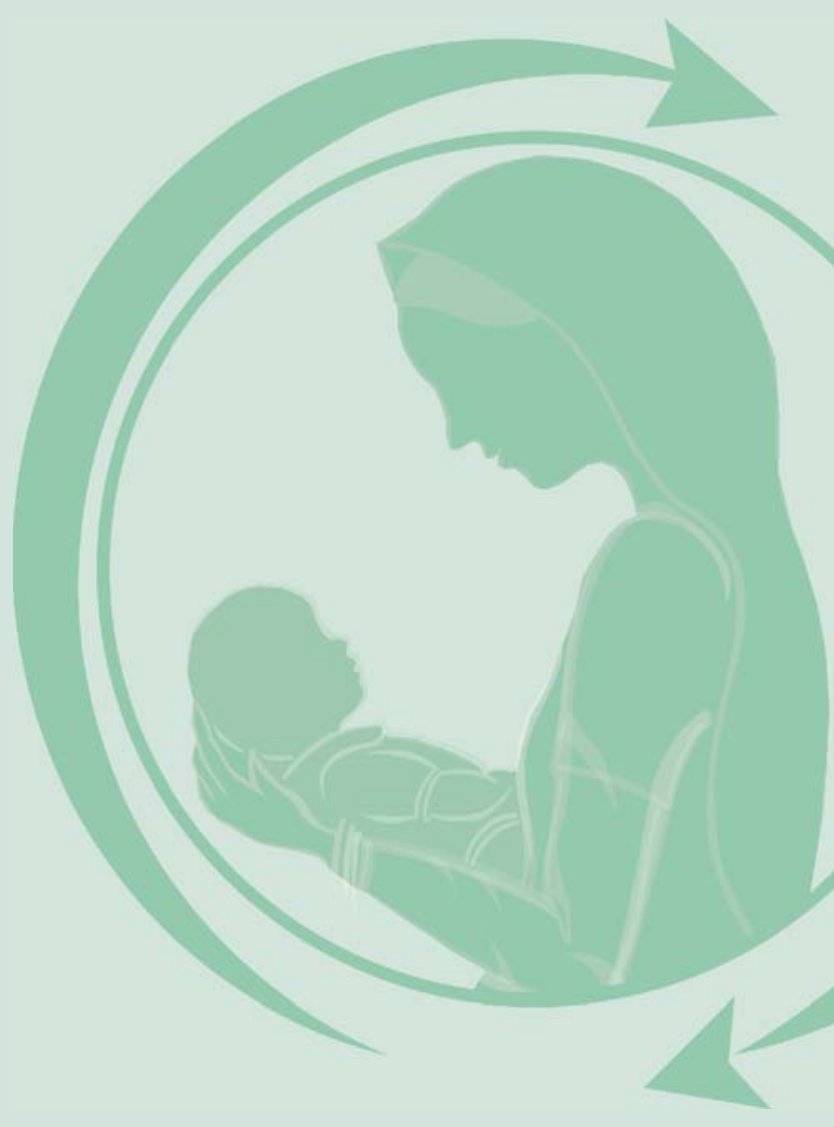

\section{Baseline Household Survey}

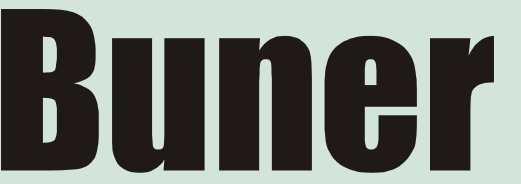

DISTRICT 



\section{Pakistan Initiative for Mothers and Newborns (PAIMAN)}

\section{Buner \\ Baseline Household Survey}

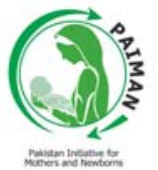




\section{(1) Population Council}

The Population Council, an international, non-profit, non-governmental organization established in 1952, seeks to improve the well-being and reproductive health of current and future generations around the world and to help achieve a humane, equitable, and sustainable balance between people and resources.

The Council analyzes population issues and trends; conducts research in the reproductive sciences; develops new contraceptives; works with public and private agencies to improve the quality and outreach of family planning and reproductive health services; helps governments design and implement effective population policies; communicates the results of research in the population field to diverse audiences; and helps strengthen professional resources in developing countries through collaborative research and programs, technical exchanges, awards, and fellowships.

\section{For inquiries, please contact:}

Population Council

\#7, Street 62, F-6/3, Islamabad, Pakistan

Tel: 92512277439

Fax: 92512821401

Email: info@pcpak.org

web: http://www.popcouncil.org

Layout \& Design : Ali Ammad

Printed by: Crystal Printers, Islamabad

Disclaimer:

"This study/report is made possible by the generous support of the American people through the United States Agency for International Development (USAID). The contents are the responsibility of JSI Research \& Training Institute, Inc. and do not necessarily reflect the views of USAID or the United States Government." 


\section{Contents}

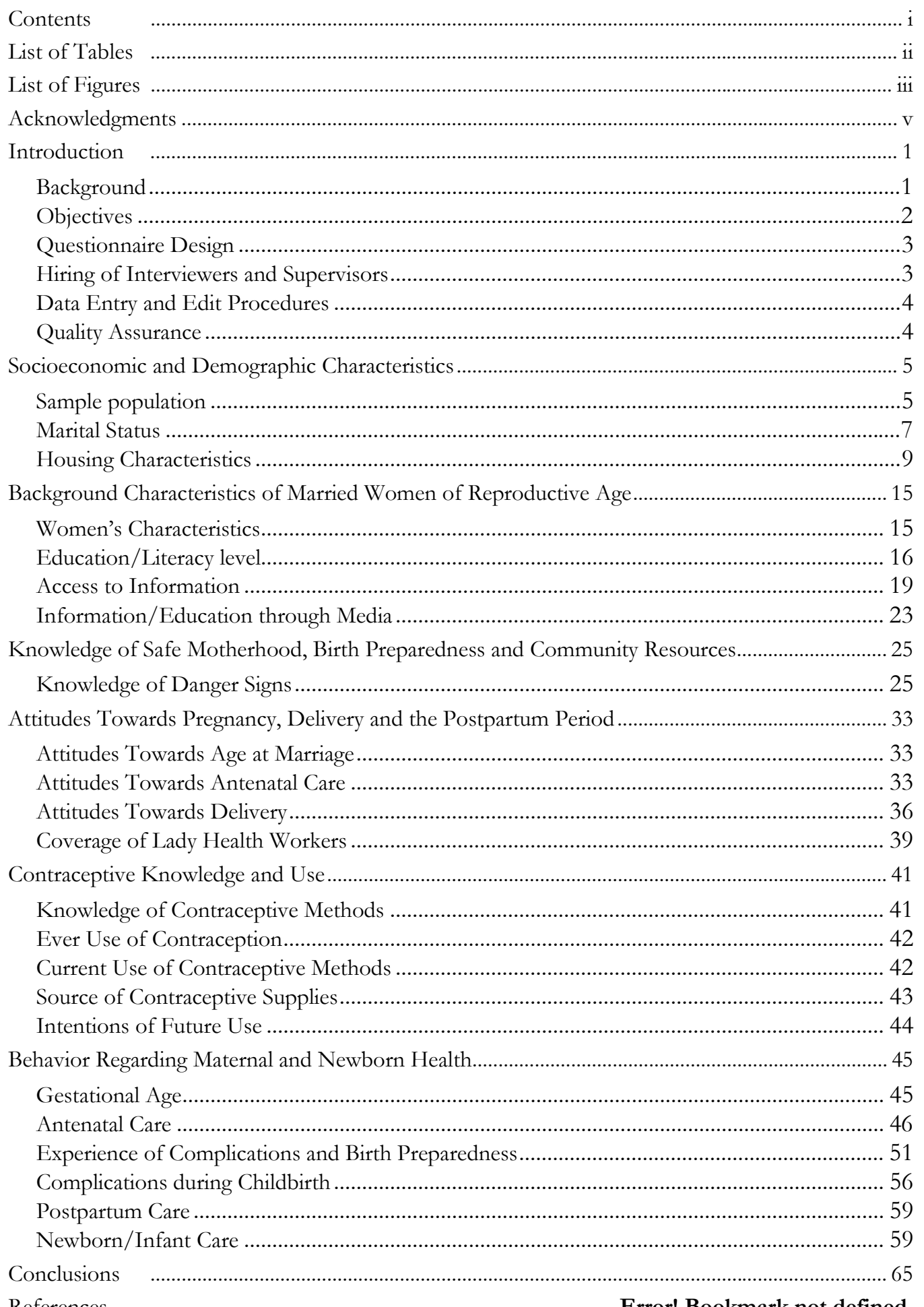




\section{List of Tables}

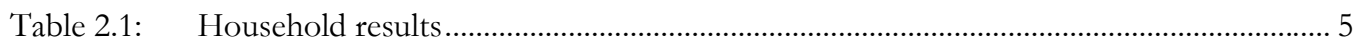

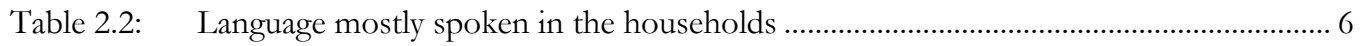

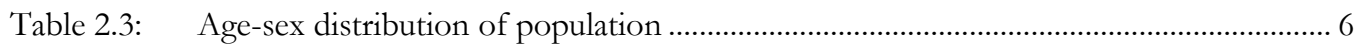

Table 2.4: Household population by age (15 years and above), sex and marital status.................. 7

Table 2.5: Household population by age (10 years and above), sex and educational level............. 8

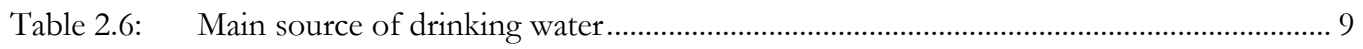

Table 2.7: Type of toilet facility used by household members ........................................................ 10

Table 2.8: $\quad$ Main type of fuel used in the household for cooking...................................................... 10

Table 2.9: $\quad$ Number of rooms used for sleeping by place of residence .......................................... 11

Table 2.10: Ownership of household commodities/land ................................................................ 12

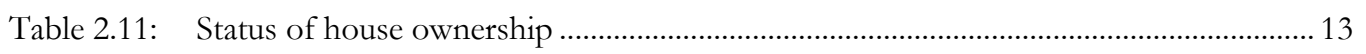

Table 3.1: Current age and age at marriage ................................................................................... 16

Table 3.2: $\quad$ Education and literacy level of married women of reproductive age ........................... 17

Table 3.3: Percentage distribution of married women by number of children ever born, mean number of children ever born, living children and age group ..................................... 18

Table 3.4: Percentage distribution of married women by length of preceding birth interval....... 18

Table 3.4: Frequency of watching television ...................................................................................... 19

Table 3.5: $\quad$ Place where respondents usually watch TV .................................................................... 20

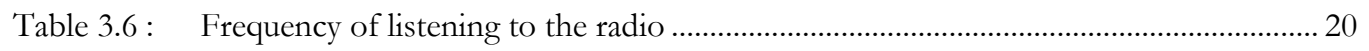

Table 3.7: Place where respondent listens to the radio................................................................. 21

Table 4.1: Knowledge of existence and importance of transport, blood and finances by the

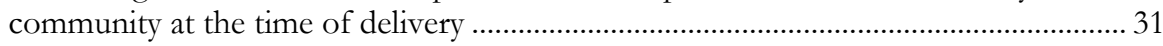

Table 5.1: Importance of antenatal check-ups................................................................................... 33

Table 5.2: Month of the pregnancy when women should receive for antenatal care .................... 34

Table 5.3: Number of antenatal visits considered necessary by respondents................................ 35

Table 5.4: Believe that women should receive delivery services from SBA................................... 36

Table 5.5: Person who decide to take care for the pregnant women............................................. 37

Table 5.6: Necessity of postnatal care ................................................................................................ 38

Table 5.7: Presence of lady health worker in the community ........................................................... 39

Table 5.8: LHW ever visited home during last three months by place of residence ..................... 39

Table 6.1: Ever used FP method by contraceptive ........................................................................ 42

Table 6.2: Method-specific contraceptive prevalence ........................................................................ 42

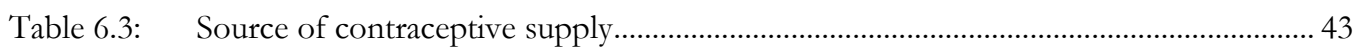

Table 7.1: Pregnancy outcome by gestational age .............................................................................. 46

Table 7.2: Gestational age at first antenatal check-up/number of antenatal check-ups obtained47

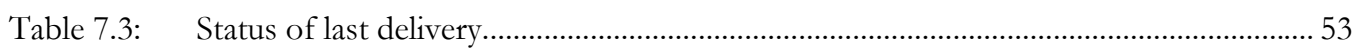

Table 7.4: $\quad$ Experienced complication during Last delivery ........................................................... 56

Table 7.5: Measures taken to address complications .................................................................. 57

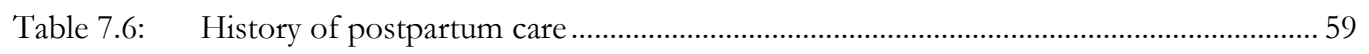

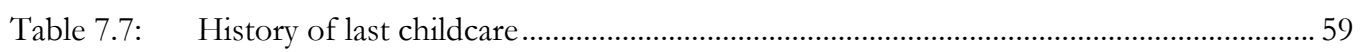




\section{List of Figures}

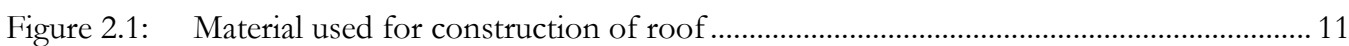

Figure 3.1: Age distribution of currently married women .............................................................. 16

Figure 3.2: $\quad$ Percentage of women who watch TV or listen to the radio.......................................... 19

Figure 3.3: Influence of TV programs on health behaviors of people ........................................... 20

Figure 3.4: Influence of radio on health behaviors, ,...................................................................... 21

Figure 3.5: Frequency of reading newspaper................................................................................ 22

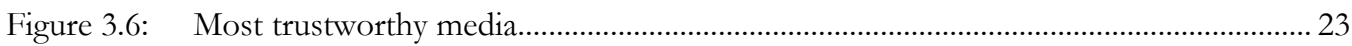

Figure 3.7: Percentage of married women who had heard/read about maternal and newborn health during the last 3 months ................................................................................... 23

Figure 4.1: Knowledge of danger signs during pregnancy that require medical attention ............. 25

Figure 4.2: $\quad$ Percentage of married women by status of knowledge of danger signs during

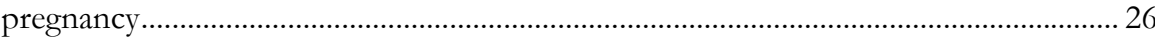

Figure 4.3: Distribution of respondents who had knowledge about complications during delivery

Figure 4.4: Percentage of married women by status of knowledge of danger signs during delivery

Figure 4.5: Percentage of married women who had knowledge about complication during postpartum period

Figure 4.6: Percentage of married women by status of knowledge of danger signs during the postpartum period

Figure 4.7: Distribution of respondents who had knowledge about danger signs in newborns ... 29

Figure 4.8: Percent of married women by status of knowledge of danger signs in newborns ...... 30

Figure 4.9: $\quad$ Source of information about pregnancy......................................................................... 31

Figure 5.1: Percentage of married women who thought it necessary to receive TT shots and take iron/folate tablets during pregnancy ........................................................................ 35

Figure 5.2: Percentage of respondents who believed women in their community seek delivery

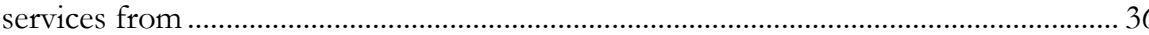

Figure 5.3: $\quad$ Percentage of women by their perception where delivery should take place............... 37

Figure 5.4: Percentage of married women by mode of transport they would use to reach health

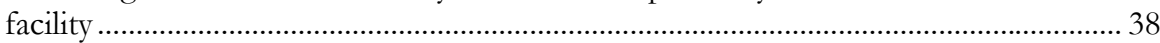

Figure 5.5: Number of postnatal care visits women should have in the community..................... 39

Figure 6.1: Percentage of married women by knowledge of specific contraceptive method ........ 41

Figure 6.2: $\quad$ Percentage of married women by future intention to use contraceptives ................... 44

Figure 7.1: Percentage of pregnant women by their antenatal care status...................................... 46

Figure 7.2: Percentage distribution of married women by persons who accompanied them to

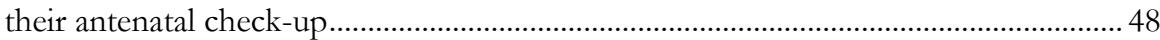

Figure 7.3: $\quad$ Services performed/asked during antenatal check-up................................................ 49

Figure 7.4: Percentage of pregnant women by issues discussed during antenatal check-up......... 49

Figure 7.5: Percentage of married women by status of TT Injections during the last pregnancy. 50

Figure 7.6: Percentage of married women by status of iron/folate tablets during the last

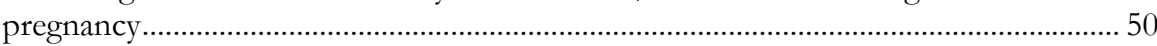

Figure 7.7: Percentage of married women who experienced complications during their last pregnancy 
Figure 7.8: Percentage of married women who made arrangements for their last delivery ........... 52

Figure 7.9: $\quad$ Percentage of pregnancies by outcome .......................................................................... 53

Figure 7.10: Percentage of women by place of delivery.................................................................. 54

Figure 7.11: Percentage of married women by delivery attendant....................................................... 54

Figure 7.12: Percentage of married women by reported main reason to choose a dai as delivery

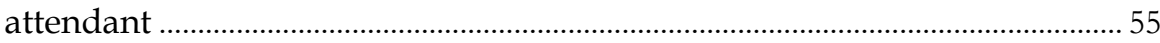

Figure 7.13: Percentage of delivery attendants who reported washed hands before conducting the delivery and type of thread used to tie the cord ....................................................... 55

Figure 7.14: Percentage of delivery attendants who reported instruments for cutting the cord ..... 56

Figure: 7.15: Time taken to reach the health facility for childbirth ................................................. 58

Figure 7.16: Median time to reach the health facility ...................................................................... 58

Figure 7.17: Percent of live birth by their size (small, normal and big) at birth ............................. 60

Figure 7.18: Percentage of babies by time of given bath after birth................................................... 60

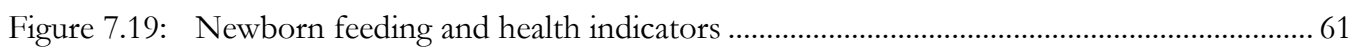

Figure 7.20: Percentage of newborns with danger signs/symptoms soon after delivery ................ 62

Figure 7.21: Percentage of newborns with danger signs/symptoms within 7-days of delivery...... 62

Figure 7.22: Percentage of newborn with measures taken to have complications treated ................63 63

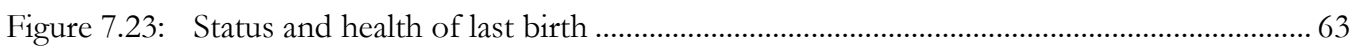




\section{Acknowledgments}

The PAIMAN Baseline Household Survey is a collaborative effort involving many partners, and will be the foundation of the PAIMAN project as a whole. Firstly, we would like to acknowledge our major partners. The United States Agency for International Development (USAID), in particular Mr. Chris McDermott, made funding available for this activity. Dr. Nabeela Ali, Chief of Party for PAIMAN, encouraged the study in general, and greatly facilitated the partnership between the Population Council and NIPS. The role of NIPS was supported under a separate agreement with PAIMAN. The comments, suggestions and feedback received from PAIMAN partners with regard to the design of this activity greatly contributed towards the success of the household survey.

The National Institute of Population Studies (NIPS) ably carried out the fieldwork for this study and was responsible for the completion of a clean dataset. We would like to appreciate the efforts of the Executive Director, Dr. Saeed Shafqat; and the Director Mr. Mahboob Sultan for the timely execution of the fieldwork; Computer Programmer, Mr. Fateh-ud-din, who managed the entry and cleaning of the data and the numerous NIPS staff members who carried out the study.

The Population Council was primarily responsible for designing the study, overseeing the data collection, analysis of data, and writing the reports. Dr. Arshad Mahmood, Director of Monitoring and Evaluation for PAIMAN, used his capable technical and managerial skills to oversee the entire study with enthusiasm and energy. Mr. Peter Miller, Deputy Country Director, contributed substantially in the design phase, and Dr. Zeba Sathar and Mr. Miller contributed towards the report preparation.

The essential work of the study was carried out by several Council staff members at all phases. During the design and pre-testing phases, we would particularly like to acknowledge Shagufta Naheed, Bushra Bano, Tayyaba Gul, and Saima Pervaiz for monitoring fieldwork and ensuring quality data collection in the field. Muhammad Ashraf and Saman Naz assisted in preparing graphs and tables as well as with the writing process. Dr. Arshad Mahmood and Reem Khan jointly prepared the first draft of the baseline survey report, which served as the template for all ten district reports. Shafique Arif, Azeema Faizunisa and Nadia Abid also contributed to the report writing and reviewing process. Reem Khan completed the initial editing, Mehdi Ali Khan designed their layout, Ali Ammad formatted and Ms. Mary DeSouza proof read the district reports.

Finally, we must express our gratitude to the women of Buner, who gave their time freely and cooperated with us in order to make this study possible. We hope to repay them by using the information obtained from them to improve maternal and neonatal health services in the district of Buner. 



\section{Chapter}

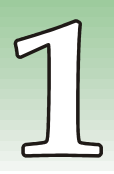

\section{Introduction}

\section{Background}

The Pakistan Initiative for Mothers and Newborns (PAIMAN) is a five-year project funded by the United States Agency for International Development (USAID). PAIMAN is committed to assisting the Government of Pakistan (GoP) in its attempt to implement the full spectrum of interventions necessary to address maternal and neonatal health $(\mathrm{MNH})$ issues.

The consortium is led by John Snow Incorporated (JSI), with partners from Pakistani and international organizations including Aga Khan University, Contech, Greenstar Social Marketing, Johns Hopkins University Center for Communication Program (JHU), PAVHNA, Population Council and Save the Children USA.

USAID has provided a grant to implement PAIMAN in 10 districts of Pakistan's four provinces. These districts are: Rawalpindi, Jhelum, Khanewal, and DG Khan in Punjab; Dadu and Sukkur in Sindh; Jafarabad and Lasbela in Balochistan; and Upper Dir and Buner in the North West Frontier Province. The goal of the project is to reduce maternal, newborn and child mortality in Pakistan. The project is based on the "Pathway to Care and Survival" framework. The five major strategic objectives are to:

1) Increase awareness and promote positive maternal and neonatal health behaviors

2) Increase access (including essential obstetric care) to and community involvement in maternal and child health services, while ensuring that services are successfully delivered through health and ancillary health services

3) Improve service quality in both the public and private sectors, particularly related to the management of obstetrical complications

4) Increase the capacity of Maternal and Newborn Health $(\mathrm{MNH})$ managers and care providers

5) Improve the management and integration of services at all levels

The PAIMAN Project will promote skilled attendants as the long-term goal for all deliveries in Pakistan while acknowledging that maternal and neonatal health outcomes are influenced by factors other than health care. The PAIMAN Project calls for a multi-pronged and integrated strategic approach combining individual health care with public health and community-based interventions. 
To ensure that the success of PAIMAN is properly attained and that the appropriate lessons are learned, PAIMAN has developed a Monitoring and Evaluation Plan. Included in this plan is the establishment of baseline measures for a set of indicators which will be used to evaluate the success of the project. This baseline report explores the level of knowledge of, as well as the attitudes and behaviors towards, maternal and newborn health in the Buner district. The specific objectives of the baseline survey were as follows:

\section{Objectives}

- To measure the Intermediate Result 7 indicators necessary as part of PAIMAN's obligation to USAID.

- To measure PAIMAN indicators for which household survey data are appropriate for measurement and for which sample sizes are feasible.

- To obtain information on maternal and neonatal health along with related issues, which may be of use to district Departments of Health for health management purposes.

- To obtain information needed for the detailed design of the PAIMAN project and, in particular, behavior change communication, public/private partnerships and health systems strengthening.

\section{Methodology}

\section{Study Population}

PAIMAN is primarily a district-level project, intended to improve the health of all pregnant women, women with neonatal children, as well as all neonates of the district over the course of the project. To this end, the study covers community residents - notably mothers and prospective mothers - in order to understand and measure general knowledge and practice in relation to pregnancy, delivery, obstetric and neonatal emergencies etc.

Hence, the study population for the baseline includes all currently married women of reproductive age (15-49 years) living in the selected districts. More specifically, it includes women who have experienced a pregnancy during the last three years. 1.

\section{Sample Design}

The sampling design adopted for the survey is a stratified, systematic sample of households. The universe consists the entire district. The total numbers of 40 villages were selected in the district. The selection procedure is described below:

The 1998 Population Census list of villages was used as the sampling frame for the selection of the rural sample. Villages in rural areas have been treated as primary sampling units (PSU). Sample PSUs have been selected with probability proportional to size (number of households). Households within the sample PSUs were considered secondary sampling units. The enumeration teams then updated the listing of each village before selecting the sampled households. A fixed number of 24 households have been drawn from each sample enumeration village by the systematic random technique. 


\section{Questionnaire Design}

The questionnaire has been developed by the Population Council based on a combination of current general Demographic and Health Survey methodologies and the questionnaire developed by the Population Council for the Safe Motherhood Applied Research and Training (SMART) Project. The questionnaires contain data sufficient to estimate all PAIMAN indicators.

Information on the following is included in the questionnaires:

- Households information

- Socio-economic status of women

- Fertility, pregnancy history and reproductive intentions

- Attitude towards, as well as knowledge and practice of, contraceptive methods

- Attitude towards pregnancy, delivery and the postpartum period

- Current birth preparedness/complications readiness (BP/CR) and knowledge of newborn care

- $\quad$ Current birth practices

- Health-seeking behaviors

- $\quad$ Future BP/CR intentions

- $\quad$ Personal beliefs regarding pregnancy, delivery and the postpartum period

- Common perceptions pertaining to women who are pregnant, delivering or in their postpartum period

- Facilities regarding BP/CR available in the community

- Factors that facilitate or hinder behaviors related to BP/CR

- Media habits

\section{Pre-testing of Questionnaires}

The questionnaires were reviewed by the PAIMAN's M\&E thematic group and other interested stakeholders and were pre-tested in non-PAIMAN districts. The main objective of pre-testing was to examine the suitability and effectiveness of questions in eliciting adequate responses and to find out if there were any linguistic problems faced either by interviewers or by respondents.

Finally, the pre-testing also helped determine the approximate time required to complete a questionnaire. The pre-tests were carried out by the Population Council's female staff members who recorded their experiences with regard to each question. These records were then used to revise and finalize the questionnaire.

\section{Hiring of Interviewers and Supervisors}

Since the respondents in the baseline were to be MWRA and married men, it was decided that female interviewers would be used to interview women and male interviewers for men. Based on the constitution of each team, the required number of female interviewers were hired by the National Institute of Population Studies (NIPS) according to its own internal procedures. 


\section{Training of Interviewers and Supervisors}

The quality of training received by interviewers is reflected in the quality of data they record. In order to ensure that interviews were of a high and uniform quality and that interviewers understood the definitions and concepts behind the language of the questions, training was conducted by the Population Council in collaboration with NIPS. The training took place in Islamabad over two weeks and interviewers were schooled in questionnaire and survey procedures. Interviewers visited 3-4 households to conduct practice interviews;

It was very important for the interviewers to thoroughly understand the methodology and statistical importance of the sampled households. Training regarding the importance of the criterion for the selection of primary sampling units, mapping and listing procedure, sample selection, field operation procedures, as well as the selection of the particular households and respondents was also provided by experts.

\section{Data Entry and Edit Procedures}

Data processing was started from the field level with the checking of the questionnaires. Each team leader completed on-the-spot checks and preliminary editing of questionnaires during the enumeration period. Editing instructions were provided to the team leaders and emphasis was laid on the importance of completing each questionnaire, correctly identifying each eligible respondent and the completeness of household composition.

\section{Quality Assurance}

To ensure the quality of the data, Population Council staff monitored the fieldwork accompanying the field teams. While supervising the fieldwork, the Population Council supervisory staff was also available to provide on-the-spot guidance to interviewers in the event that any part of the questionnaire was unclear to them. This ensured the completeness and accuracy of each questionnaire. 


\section{Chapter}

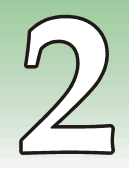

\section{Socioeconomic and Demographic Characteristics}

This chapter presents the demographic and socioeconomic characteristics of the population in the sampled households of Buner. Information was collected on some demographic and socioeconomic characteristics such as the condition of the households, including the source of drinking water, availability of electricity, sanitation facilities, building materials, and possession of household durable goods. This information on the characteristics of the households is essential for the interpretation of survey findings. The definition of the household used for the baseline survey was "a person or a group of persons, related or unrelated, who live together in the same dwelling unit and share a common source of food".

\section{Sample population}

Table 2.1 shows the number of households selected in Buner, as well as the interview status upon completion of the project. A total sample of 960 households was selected.

\section{Table 2.1: $\quad$ Household results}

\begin{tabular}{lrr}
\hline Result & Percent & Number \\
\hline Completed & 97.6 & 937 \\
\hline Refused & 2.1 & 20 \\
\hline Others & 0.3 & 3 \\
Total & 100.0 & 960
\end{tabular}

Table 2.1 indicates the interview completion rate in Buner. Incomplete interviews may have been due to lack of knowledge on behalf of the respondents, or perhaps due to the fact that women were not willing or permitted to share sensitive information with interviewers. However, 937 of the households selected (almost 98 percent) participated in the interview, while only about 2 percent of the chosen households refused to participate. 


\section{Languages Spoken}

Table 2.2 outlines the languages mainly spoken in the households in the district of Buner. An overall picture of the ethnic and linguistic makeup of the district becomes clear by determining the languages spoken in the households.

Table 2.2:

Language mostly spoken in the households

\begin{tabular}{lrr} 
Language & Percent & Number \\
Punjabi & 0.2 & 2 \\
\hline Sindhi & 0.6 & 6 \\
\hline Pushto & 95.5 & 895 \\
\hline Hindko & 2.9 & 27 \\
\hline Others & 0.7 & 7 \\
Total & 100.0 & 937
\end{tabular}

According to the data presented, Pushto is the most widely spoken language in Buner (95.5 percent) followed by Hindko, which is spoken by nearly 3 percent of the population. While Sindhi and Punjabi were spoken by some of the respondents interviewed, they made up a very small portion of the population ( 0.6 percent and 0.2 percent respectively). This would suggest that the population of Buner is largely indigenous, as languages other than Pushto are not widely spoken.

\section{Population Composition}

Table 2.3 shows the population of Buner with regard to age and sex composition. Age and sex are important demographic variables and are the primary basis of demographic analysis. They are the important variables in the study of reproductive health, mortality and fertility.

According to the data presented in table 2.3, there are more males than females in the 14 and under age cohort, whereas the number of females exceeds the number of males in the 15 to 34 age groups.

Table 2.3: $\quad$ Age-sex distribution of population

\begin{tabular}{lrrrrrr}
\multicolumn{1}{c}{ Age } & \multicolumn{2}{c}{ Males } & \multicolumn{2}{c}{ Females } & \multicolumn{2}{c}{ Both Sexes } \\
\multicolumn{1}{c}{ Group } & Number & Percent & Number & Percent & Number & Percent \\
\hline 5 & 776 & 16.5 & 710 & 15.0 & 1486 & 15.7 \\
\hline $5-9$ & 817 & 17.4 & 788 & 16.7 & 1605 & 17.0 \\
\hline $10-14$ & 664 & 14.1 & 609 & 12.9 & 1273 & 13.5 \\
\hline $15-19$ & 513 & 10.9 & 555 & 11.7 & 1068 & 11.3 \\
\hline $20-24$ & 372 & 7.9 & 422 & 8.9 & 794 & 8.4 \\
\hline $25-29$ & 294 & 6.2 & 409 & 8.6 & 703 & 7.5 \\
\hline $30-34$ & 223 & 4.7 & 268 & 5.7 & 491 & 5.2 \\
\hline $35-39$ & 192 & 4.1 & 188 & 4.0 & 380 & 4.0 \\
\hline $40-44$ & 172 & 3.7 & 137 & 2.9 & 309 & 3.3 \\
\hline $45-49$ & 126 & 2.7 & 101 & 2.1 & 227 & 2.4 \\
\hline $50-54$ & 106 & 2.3 & 188 & 4.0 & 294 & 3.1 \\
\hline $55-59$ & 109 & 2.3 & 112 & 2.4 & 221 & 2.3 \\
\hline $60-64$ & 99 & 2.1 & 83 & 1.8 & 182 & 1.9 \\
\hline 65 and older & 243 & 5.2 & 160 & 3.4 & 403 & 4.3 \\
\hline Total & 4706 & 100.0 & 4730 & 100.0 & 9436 & 100.0 \\
\hline
\end{tabular}




\section{Marital Status}

This survey collected information on the marital status of all household members more than 15 years of age. The percentage of males in the 15 to 19 year age group that had never married was much higher (94.2 percent) than the percentage of never married females in the same age group (68.4 percent). The proportion of 15 to 19 year old females who were currently married stood at 31.1 percent, while only 5.7 percent of the males in the same age group were currently married. However, compared to the 1998 Population Census, the figures showed some improvement, as the age of marriage seems to have increased slightly on average. In the 1998 Census, it was determined that 39.5 percent of the females and 10.3 percent of the males in the 15 to 19 year age group were currently married.

Table 2.4: $\quad$ Housebold population by age (15 years and above), sex and marital status

\begin{tabular}{|c|c|c|c|c|c|c|}
\hline \multirow{3}{*}{$\begin{array}{c}\text { Age } \\
\text { Group }\end{array}$} & \multicolumn{3}{|c|}{ Males } & \multicolumn{3}{|c|}{ Females } \\
\hline & Never & Currently & Widow/ & Never & Currently & Widow/ \\
\hline & Married & Married & Divorced & Married & Married & Divorced \\
\hline $15-19$ & 94.2 & 5.7 & 0.2 & 68.4 & 31.1 & 0.5 \\
\hline $20-24$ & 60.8 & 38.4 & 0.8 & 30.6 & 69.1 & 0.2 \\
\hline $25-29$ & 19.2 & 80.8 & 0 & 11 & 88 & 1 \\
\hline $30-34$ & 4.5 & 94.1 & 1.4 & 9.7 & 89.9 & 0.4 \\
\hline $35-39$ & 1.6 & 98.4 & 0 & 4.8 & 93.6 & 1.6 \\
\hline $40-44$ & 1.2 & 96.5 & 2.3 & 4.4 & 91.2 & 4.4 \\
\hline $45-49$ & 3.2 & 96 & 0.8 & 3 & 92.1 & 5 \\
\hline $50-54$ & 0.9 & 97.2 & 1.9 & 2.7 & 87.7 & 9.6 \\
\hline $55-59$ & 0.9 & 93.6 & 5.5 & 2.7 & 83.8 & 13.5 \\
\hline $60-64$ & 0 & 93.9 & 6.1 & 2.4 & 72 & 25.6 \\
\hline 65 and older & 0 & 88.5 & 11.5 & 1.9 & 54.4 & 43.8 \\
\hline Total & 32.1 & 65.7 & 2.2 & 23.3 & 71.1 & 5.6 \\
\hline \multicolumn{7}{|l|}{1998 Census } \\
\hline $15-19$ & 89.6 & 10.3 & 0.1 & 60.3 & 39.5 & 0.3 \\
\hline $20-24$ & 52.5 & 47.3 & 0.2 & 20.5 & 79.1 & 0.4 \\
\hline $25-29$ & 19.1 & 80.6 & 0.3 & 8.7 & 90.3 & 1.0 \\
\hline $30-34$ & 8.7 & 90.9 & 0.4 & 6.8 & 91.5 & 1.7 \\
\hline $35-39$ & 4.7 & 94.9 & 0.4 & 4.9 & 92.3 & 2.8 \\
\hline $40-44$ & 3.9 & 95.3 & 0.8 & 4.0 & 91.4 & 4.6 \\
\hline $45-49$ & 2.4 & 96.1 & 1.5 & 2.5 & 90.5 & 7.1 \\
\hline $50-54$ & 2.8 & 94.8 & 2.4 & 3.1 & 83.3 & 13.7 \\
\hline $55-59$ & 2.2 & 94.0 & 3.8 & 3.3 & 77.8 & 18.9 \\
\hline $60-64$ & 3.0 & 90.8 & 6.2 & 5.3 & 63.3 & 31.4 \\
\hline 65 and Above & 4.4 & 82.4 & 13.2 & 6.8 & 46.2 & 47.0 \\
\hline Total & 31.6 & 66.6 & 1.8 & 18.8 & 74.8 & 6.5 \\
\hline
\end{tabular}




\section{Education Attainment}

The percentage of males that received no education seems to be consistently lower than the percentage of women who received no education with an increase in age. For example, in the 20 to 24 year age group, nearly a quarter of the males interviewed indicated that they received no education, whereas three quarters of the women interviewed indicated the same thing. The percentage of women that received no education increases with age after the 10 to 14 year age group.

Table 2.5: $\quad$ Household population by age (10 years and above), sex and educational level

\begin{tabular}{|c|c|c|c|c|c|}
\hline $\begin{array}{l}\text { Age } \\
\text { Group }\end{array}$ & $\begin{array}{c}\text { No } \\
\text { Education }\end{array}$ & $\begin{array}{c}1-5 \\
\text { Years }\end{array}$ & $\begin{array}{l}6-10 \\
\text { Years }\end{array}$ & $\begin{array}{c}11 \text { and more } \\
\text { Years }\end{array}$ & Total \\
\hline \multicolumn{6}{|l|}{ Males } \\
\hline $10-14$ & 20.6 & 65.8 & 13.6 & 0.0 & 519 \\
\hline $15-19$ & 27.1 & 24.2 & 46.4 & 2.3 & 380 \\
\hline $20-24$ & 24.2 & 16.9 & 42.7 & 16.1 & 257 \\
\hline $25-29$ & 25.2 & 15.3 & 42.5 & 17.0 & 167 \\
\hline $30-34$ & 34.1 & 11.2 & 34.5 & 20.2 & 129 \\
\hline $35-39$ & 44.8 & 8.3 & 32.8 & 14.1 & 143 \\
\hline $40-44$ & 52.3 & 12.8 & 22.1 & 12.8 & 78 \\
\hline $45-49$ & 51.6 & 10.3 & 31.7 & 6.3 & 84 \\
\hline $50-54$ & 69.8 & 4.7 & 18.9 & 6.6 & 74 \\
\hline $55-59$ & 73.4 & 5.5 & 10.1 & 11.0 & 65 \\
\hline $60-64$ & 80.8 & 5.1 & 7.1 & 7.1 & 84 \\
\hline 65 and older & 89.3 & 4.5 & 4.5 & 1.6 & 160 \\
\hline Total & 39.0 & 20.5 & 18.7 & 21.9 & 3297 \\
\hline \multicolumn{6}{|l|}{ Females } \\
\hline $10-14$ & 56.2 & 36.9 & 6.9 & 0.0 & 531 \\
\hline $15-19$ & 64.7 & 19.6 & 14.8 & 0.9 & 424 \\
\hline $20-24$ & 74.2 & 12.8 & 8.3 & 4.7 & 306 \\
\hline $25-29$ & 82.4 & 10.5 & 5.4 & 1.7 & 225 \\
\hline $30-34$ & 89.2 & 7.5 & 3.0 & 0.4 & 175 \\
\hline $35-39$ & 91.5 & 4.8 & 2.1 & 1.6 & 146 \\
\hline $40-44$ & 94.9 & 3.6 & 1.5 & 0.0 & 104 \\
\hline $45-49$ & 98.0 & 2.0 & 0.0 & 0.0 & 99 \\
\hline $50-54$ & 95.2 & 3.7 & 1.1 & 0.0 & 115 \\
\hline $55-59$ & 97.3 & 2.7 & 0.0 & 0.0 & 100 \\
\hline $60-64$ & 98.8 & 1.2 & 0.0 & 0.0 & 62 \\
\hline 65 and older & 100.0 & 0.0 & 0.0 & 0.0 & 83 \\
\hline Total & 66.7 & 13.4 & 4.2 & 15.8 & 3471 \\
\hline
\end{tabular}




\section{Housing Characteristics}

\section{Source of Drinking Water}

Respondents were asked to indicate their main source of drinking water. A large segment of the population (41 percent) cited government supply (tap water) as their main source, while 12 percent indicated that they used a communal water source. Indoor wells and motorized/hand pumps (inside) were also cited as sources of drinking water (12 percent and 8 percent respectively).

Interestingly, nearly 4 percent of the population also indicated that they obtained their drinking water from nearby rivers/canals/streams, while about 2 percent from pool/pond water. Such open water sources are unsafe for consumption as they may lead to the spread of water based diseases.

Therefore, approximately 5 percent of the population of Buner is at risk of contracting serious waterbased diseases, putting the lives of expectant mothers and young children at risk. In regards to pregnancy and neonatal care, the source of drinking water can indicate the level of hygiene and comfort available to an expectant mother or a newborn child. It also determines the socio-economic status of the household, and therefore to some extent also the education background.

However, while the rest of the water sources may be safe for consumption, the quality of water being consumed from these other sources may remain questionable.

Table 2.6: $\quad$ Main source of drinking water

\begin{tabular}{lrr} 
Source & Percent & Number \\
Govt. supply (tap water inside) & 40.7 & 381 \\
\hline Govt. supply (communal) & 11.7 & 110 \\
\hline Motorized/hand pump (inside) & 8.1 & 76 \\
\hline Motorized/Hand pump (outside) & 2.6 & 24 \\
\hline Well (inside) & 12.0 & 112 \\
\hline Well (outside) & 8.8 & 82 \\
\hline Tube-well & 1.3 & 12 \\
\hline River/canal/stream & 3.7 & 35 \\
\hline Pooled/pond water & 1.7 & 16 \\
\hline Others & 9.5 & 89 \\
Total & 100.0 & 937
\end{tabular}




\section{Toilet Facilities}

Along with the source of drinking water, toilet facilities are a major indicator of a household's socioeconomic status and therefore the level of hygiene, sanitation and comfort available to an expectant or new mother, along with her newborn children. The type of toilet facility a household has access to directly reflects the quality of sanitation, which has a more direct affect on mortality than does socioeconomic status (Martin, Linda et al, 1983, pp. 425). Households lacking hygienic toilet facilities have a higher risk of disease and infection, which in turn puts the health of newborn children, as well as their mothers, at risk.

Table 2.7: $\quad$ Type of toilet facility used by household members

\begin{tabular}{lrr} 
Toilet Facility & Percent & Number \\
\hline Flush to sewerage & 4.3 & 40 \\
\hline Flush connected to septic tank & 24.3 & 228 \\
\hline Flush connected to open drain & 1.4 & 13 \\
\hline Raised latrine & 17.6 & 165 \\
\hline Pit latrine & 14.6 & 137 \\
\hline In fields & 35.2 & 330 \\
\hline Others & 2.6 & 24 \\
Total & 100.0 & 937
\end{tabular}

According to the data presented in table 2.7, the largest percentage of people in Buner had no toilet facilities in their homes and used fields (35 percent), followed by 24 percent who had flushes connected to septic tanks. Raised/pit latrines are also very widely used in the districts of (18 percent and 15 percent respectively).

\section{Fuel Used for Cooking}

A question regarding the type of fuel being used in household kitchens was also asked in the baseline survey. According to the data, 98 percent of the respondents in Buner use firewood for cooking purposes, while 1.9 percent use gas cylinders. This data suggests that Buner is a less developed and more traditional society.

Table 2.8: $\quad$ Main type of fuel used in the housebold for cooking

\begin{tabular}{lrr} 
Type of Fuel & Percent & Number \\
Fire wood & 97.8 & 916 \\
\hline Gas cylinder & 1.9 & 18 \\
\hline Others & 0.3 & 3 \\
\hline Total & 100.0 & 937
\end{tabular}




\section{Materials used for the House Roof}

The materials used for the roof and walls of a household are major indicators of the socio-economic status of that household, as well as the living standards of the people residing there. The more secure the materials, the higher the level of comfort and living standard for residents and the lower the risk of disease and infection.

About 60 percent of the women interviewed indicated that the material used for their roofs was wood, bamboo and mud. Such materials are not very secure, and therefore suggest that the district of is lower socio-economic level. Approximately a quarter (27 percent) of the population cited concrete as being the material from which their roofs were made. Finally, 12.8 percent of the respondents indicated that their roofs were made from iron sheets, and 0.1 percent-cited girders and T-iron as the main material from which their roofs were constructed.

Figure 2.1: $\quad$ Material used for construction of roof

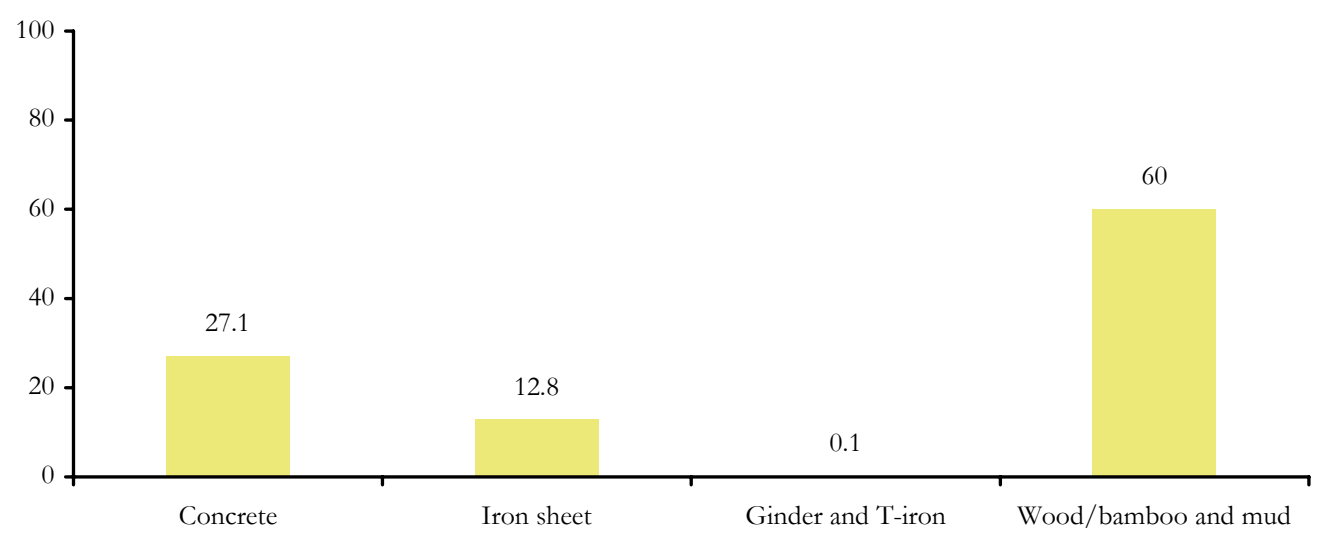

\section{Number of Rooms for Sleeping}

The number of separate rooms available for sleeping in each household is an important indicator of sanitation and hygiene levels. Overcrowding in households may lead to the spread of infections and diseases, which puts the lives of expectant/young mothers and of their newborn children at risk.

Table 2.9:

Number of rooms used for sleeping by place of residence

\begin{tabular}{lrr}
\hline Rooms & Percent & Number \\
0 & 0.3 & 3 \\
\hline 1 & 28.7 & 269 \\
\hline 2 & 36.2 & 339 \\
\hline 3 & 20.1 & 188 \\
\hline 4 & 7.4 & 69 \\
\hline $5+$ & 7.3 & 68 \\
Total & 100.0 & 936
\end{tabular}


In the district of Buner, 36 percent of the population indicated that they had two rooms for sleeping, followed by 29 percent who stated that they only had one room for the same purpose. Approximately 20 percent claimed to have three rooms, while 7.4 percent and 7.3 percent of the respondents claimed to have four and five rooms, respectively. Findings show that in district Buner 4.8 people are living per room.

\section{Household possessions}

Household possessions are perhaps one of the most effective ways of determining the socioeconomic level of a household. Often, it is easier to obtain information on household possessions than to ask for details about the household income, which respondents may be less willing to provide for various reasons.

The list of household possessions in Table 2.10 are setting-specific and will therefore be quite accurate in determining the socio-economic status of the households. The presence of durable goods in the household, such as a radio, television, telephone, refrigerator, motorcycle, and private car is another indicator of the household's socioeconomic status. Moreover, particular goods have specific benefits; for example, the ownership of a radio or television is a measure of access to mass media and exposure to innovative ideas; telephone ownership measures access to an efficient means of communication; refrigerator ownership means the life of wholesome food is prolonged and ownership of private transport allows greater access to many services away from the local area.

Table 2.10: Ownership of household commodities/land

\begin{tabular}{|c|c|c|}
\hline Household items & Percent & Number \\
\hline Electric iron & 48.1 & 451 \\
\hline Electric fan & 70.3 & 659 \\
\hline Sewing machine & 41.9 & 393 \\
\hline Radio or cassette player & 46.7 & 438 \\
\hline Chair/table & 56.2 & 527 \\
\hline Television & 20.0 & 187 \\
\hline Telephone & 27.5 & 258 \\
\hline Watch/clock & 80.0 & 750 \\
\hline VCR/VCP/VCD/CD player & 8.4 & 79 \\
\hline Refrigerator/deep freezer & 22.5 & 211 \\
\hline Air cooler & 3.6 & 34 \\
\hline Air conditioner & 0.5 & 5 \\
\hline Computer & 3.4 & 32 \\
\hline Bicycle & 6.9 & 65 \\
\hline Motorcycle & 3.7 & 35 \\
\hline Car/Jeep & 6.4 & 60 \\
\hline Tractor/truck & 3.3 & 31 \\
\hline HH owned any agriculture land & 50.6 & 474 \\
\hline Agriculture land major source of livelihood & 34.4 & 322 \\
\hline
\end{tabular}


According to table 2.10, less than half of the population owned objects such as electric irons, sewing machines, radios and cassette players. Furthermore, less than a quarter of the women interviewed owned televisions, VCR/VCP/VCD/CD players and refrigerators. Finally, less than 4 percent of the sample population claimed to own air conditioners, air coolers and computers.

Respondents were also asked to indicate if they owned any agricultural land. More than half (51 percent) of the respondents answered in the affirmative, while 34 percent indicated that agriculture was their major source of livelihood. This data suggests that Buner is a largely agricultural society and may therefore be more traditional than other PAIMAN districts.

\section{Ownership of the House}

Table 2.11 reflects the ownership of the house. Nearly 81 percent of the respondents interviewed indicated that they owned the homes they lived in, while approximately 4 percent lived in rented homes. About 13.5 percent of the respondents lived in rent-free accommodations.

Table 2.11: $\quad$ Status of house ownership

\begin{tabular}{lrr}
\hline Status & Percent & Number \\
Owner occupied & 80.7 & 755 \\
\hline Rented & 4.1 & 38 \\
\hline Rent free & 13.5 & 126 \\
\hline Others & 1.8 & 17 \\
Total & 100.0 & 936
\end{tabular}





\section{Chapter 5}

\section{Background Characteristics of Married Women of Reproductive Age}

Information regarding the basic background characteristics of respondents is essential for the interpretation of survey findings. This chapter describes the basic background characteristics including age, education level, and place of residence of the respondents. It also describes detailed information on the educational status of respondents and their husbands, literacy levels, and exposure to mass media. Only currently married women aged 15-49 were interviewed for this portion of the survey.

\section{Women's Characteristics}

\section{Age Distribution of Married Women}

Table 3.1 shows the percentage distribution of currently married women by age and the age at marriage in the district of Buner. The age distribution of the women interviewed shows that 25 percent of the respondents were in the 25-29 year age group, followed by 21 percent who were in the 20-24 year age group. Only 6 percent of the women interviewed were in the 45 to 49 year age group. The figure 3.1 is a visual depiction of the age distribution of currently married women at the time of survey. Overall the mean age of married women of reproductive age is estimated to be 31 years in Buner.

The mean age at marriage of currently married women interviewed is estimated to be 16.1 years. Table 3.1 shows that about 62 percent of the respondents interviewed indicated that their age at marriage was between 15 to 19 years of age. A quarter of the respondents indicated that they were less than 15 years old at the time of marriage. The data suggest that a very large portion of the female population married at a young age and therefore may not have had a chance to obtain an education. The younger the age at marriage, the less education a woman is likely to receive. As a result, she has less decision-making power and therefore may be dependent on others to make decisions for her.

Due to the fact that nearly a quarter of the respondents interviewed in Buner were married before the age of 15 , the level of education obtained by these women is likely to be very low. 
Table 3.1: $\quad$ Current age and age at marriage

\begin{tabular}{|c|c|c|c|}
\hline \multicolumn{2}{|c|}{ Background profile } & Percent & Number \\
\hline \multirow{7}{*}{ Age of respondent } & $15-19$ & 11.4 & 144 \\
\hline & $20-24$ & 20.6 & 260 \\
\hline & $25-29$ & 24.7 & 313 \\
\hline & $30-34$ & 16.7 & 211 \\
\hline & $35-39$ & 12.6 & 160 \\
\hline & $40-44$ & 7.9 & 100 \\
\hline & $45-49$ & 6.1 & 77 \\
\hline \multirow{4}{*}{ Age at marriage } & $<15$ & 24.2 & 306 \\
\hline & $15-19$ & 62.0 & 784 \\
\hline & $20-24$ & 11.8 & 149 \\
\hline & $25+$ & 2.1 & 26 \\
\hline
\end{tabular}

Figure 3.1: $\quad$ Age distribution of currently married women

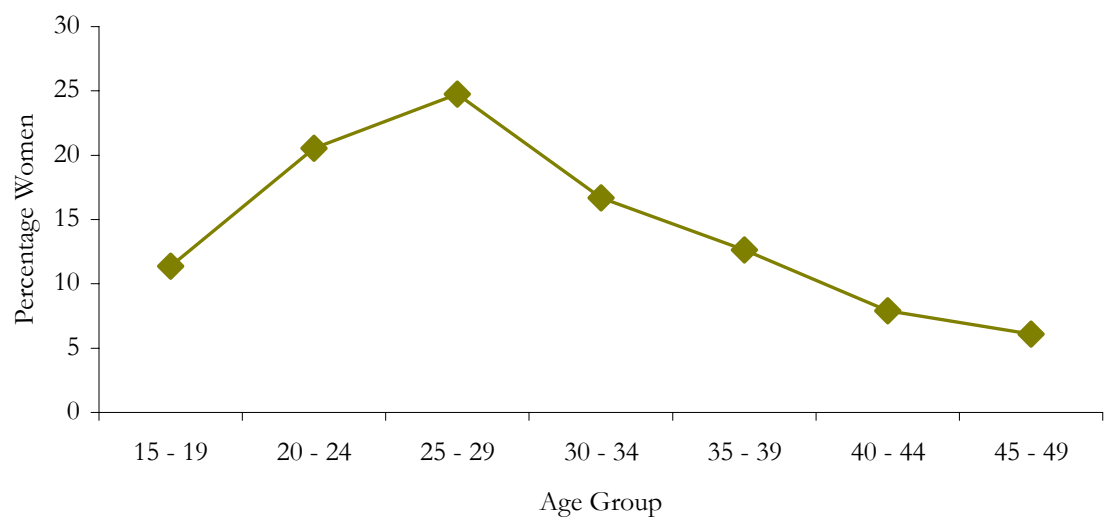

\section{Education/Literacy level}

The level of education obtained by a woman can be a good indicator of her status in society as well as the independent decision-making power available to her. It is presumed that the higher the level of education obtained by a woman, the more say she has in matters concerning her health and that of her children. In regards to maternal health, a higher literacy rate in women can result in an increased use of contraceptives, higher awareness of complications during and after pregnancy, a strong understanding of neonatal and newborn health, and finally a more complete understanding of safe birth practices. 
Table 3.2:

Education and literacy level of married women of reproductive age

\begin{tabular}{llrr} 
Background Profile & & Percent & Number \\
& No education & 86.6 & 1,096 \\
\cline { 2 - 4 } Level of education & Up to primary & 8.5 & 108 \\
\cline { 2 - 4 } & Up to middle & 2.1 & 26 \\
\cline { 2 - 4 } & Up to secondary & 2.1 & 26 \\
\cline { 2 - 4 } & Secondary + & 0.7 & 9 \\
\hline \multirow{3}{*}{ Respondent's literacy } & Literate & 12.6 & 159 \\
\cline { 2 - 4 } & Illiterate & 87.4 & 1,106 \\
\hline \multirow{3}{*}{$\begin{array}{l}\text { Husband's Level of } \\
\text { education }\end{array}$} & No education & 41.7 & 527 \\
\cline { 2 - 4 } & Up to primary & 12.0 & 152 \\
\cline { 2 - 4 } & Up to middle & 13.1 & 166 \\
\cline { 2 - 4 } & Up to secondary & 19.7 & 249 \\
\cline { 2 - 4 } & Secondary + & 13.1 & 166 \\
\cline { 2 - 4 } & Don't know & 0.4 & 536 \\
\hline \multirow{2}{*}{ Husband's literacy } & Literate & 58.2 & 529 \\
\cline { 2 - 4 } & Illiterate & & 51.8 \\
\hline
\end{tabular}

According to table 3.2, more than 86 percent of the women interviewed indicated that they had received no education at all, while only 8.5 percent reportedly went up to primary school. Less than 1 percent of the women indicated that they went beyond secondary school. Respondents were also asked to indicate their husband's level of literacy. The data presented in the table 3.2 shows that 41.7 percent had received no education at all, whereas 12 percent went up to primary school, 20 percent completed secondary school, and slightly over 13 percent went beyond secondary school.

It has also been shown that the mortality rates among children with mothers who have six or more years of education are considerably lower than the mortality rates among children with uneducated mothers (Martin, 1983). Educated women are more likely to recognize signs of illness in their children, actively seek assistance from a doctor, and administer the treatment in the manner required. Educated women are also more likely to return to a doctor in the event that the treatment administered failed to take effect. Therefore, the proactive nature of educated women with regard to the health of their children lowers the morbidity and mortality rates of infants and young children (Caldwell, 1986).

The level of education of fathers also affects the mortality rates amongst children. This is partly an indication of socio-economic level, as typically the more education the father of a child has, the higher his socio-economic status and standard of living are likely to be. However, the effect educated fathers have on the mortality rates of children is lower than the effect an educated mother has in Pakistan. (Mahmood, 1992).

The ability to read is an important personal asset allowing women and their husbands increased access to various opportunities. By gathering information regarding the distribution of literacy of the respondents surveyed, maternal and newborn health communicators are better able to reach their target population with their messages. The literacy rate for currently married women in Buner is 12.6 
percent, while over 87 percent are illiterate. Meanwhile, the literacy rate for men is 58.2 percent, with over 41 percent being illiterate.

\section{Children Ever Born and Living}

Table 3.3 outlines the number of children ever born to the respondents interviewed, along with the mean number of children based on the PAIMAN baseline survey and compared to the 1998 Population census.

Table 3.3: $\quad$ Percentage distribution of married women by number of children ever born, mean number of children ever born, living children and age group

\begin{tabular}{crrrrrrrrrr} 
& \multicolumn{4}{c}{ Number of Children Ever Born } & \multicolumn{3}{c}{ No. of } & \multicolumn{3}{c}{ Mean number of Children } \\
Age & \multicolumn{1}{c}{0} & 1 to 2 & 3 to 4 & 5 or & Total & Women & PAIMAN Baseline & 1998 Population Census \\
Group & & & & more & & & Ever born & Living & Ever born & Living \\
\hline $15-19$ & 56.9 & 40.3 & 2.1 & 0.7 & 100 & 144 & 0.6 & 0.6 & 2.2 & 1.3 \\
\hline $20-24$ & 18.8 & 55.0 & 22.3 & 3.8 & 100 & 260 & 1.8 & 1.7 & 2.8 & 1.9 \\
\hline $25-29$ & 6.1 & 26.2 & 45.4 & 22.4 & 100 & 313 & 3.3 & 3.1 & 4.6 & 3.3 \\
\hline $30-34$ & 5.2 & 9.5 & 31.8 & 53.6 & 100 & 211 & 4.6 & 4.3 & 5.9 & 4.5 \\
\hline $35-39$ & 5.0 & 3.1 & 13.8 & 78.1 & 100 & 160 & 5.8 & 5.3 & 6.2 & 5.1 \\
\hline $40-44$ & 2.0 & 3.0 & 14.0 & 81.0 & 100 & 100 & 6.5 & 6.1 & 7.3 & 6.1 \\
\hline $45-49$ & 3.9 & 3.9 & 9.1 & 83.1 & 100 & 77 & 6.7 & 6.3 & 6.9 & 6.0 \\
\hline Total & 13.8 & 24.8 & 24.7 & 36.7 & 100 & 1265 & 3.7 & 3.4 & 4.8 & 3.7
\end{tabular}

The number of children ever born rises with the age of the respondent in the "five or more children" category. Overall, the mean number of children ever born seems to have decreased since the 1998 Population Census, dropping from 4.8 to 3.7 children. Nevertheless, the mean number of living children has also dropped from 3.7 to 3.4 percent. This decline is observed in all the age groups.

\section{Preceding Birth Interval}

The length of the preceding birth interval is very important as it directly affects the health and mortality of both mother and child. A mother with repeated pregnancies, especially at short intervals, does not have sufficient time for recovery both physically and nutritionally and is therefore more likely to have pregnancy losses and babies of a lower birth weight. Table 3.4 shows that almost 14.2 percent of the last births occurred at an interval less than 19 months of birth interval, 16.5 percent at 19-24 months and 29 percent have 25-36 months of interval between the last birth and the second last birth in Buner.

Table 3.4:Percentage distribution of married women by length of preceding birth interval

\begin{tabular}{lrr}
\hline Length of Preceding Birth Interval & Number & Percent \\
\hline Less than 12 Months & 16 & 2.7 \\
\hline 13-18 Months & 69 & 11.5 \\
\hline 19-24 Months & 99 & 16.5 \\
\hline 25-36 Months & 175 & 29.1 \\
\hline More than 36 Months & 242 & 40.3 \\
\hline Total & 601 & 100
\end{tabular}




\section{Access to Information}

In the baseline survey, respondents were asked several questions regarding access and exposure to television, radio and newspapers. One of the main objectives of the baseline survey was to determine the knowledge of married women on different maternal and newborn health issues and the source of that knowledge. This information is useful in determining which media channels should be employed in the dissemination of maternal and newborn health information to target audiences. Moreover, it is important to measure the likelihood of reaching target audiences, as well as to determine which media channels are most effective when it comes to reaching that target audience.

\section{Access to Media (Television, Radio and Newspaper)}

Mass media is regularly used to campaign various issues, including those related to the health of mothers and newborns. In the past, radio was the most popular form of communication (Syed, 1979). However, according to the survey findings, television seems to have become a more popular source of information.

\section{Television}

According to Figure 3.2, approximately 9 percent of the respondents in the district of Buner indicated that they watched television, while about 13 percent indicated that they listened to the radio.

Therefore, this data would suggest that television and radio may not be very effective means of communication in the district of Buner.

Figure 3.2: $\quad$ Percentage of women who watch TV or listen to the radio

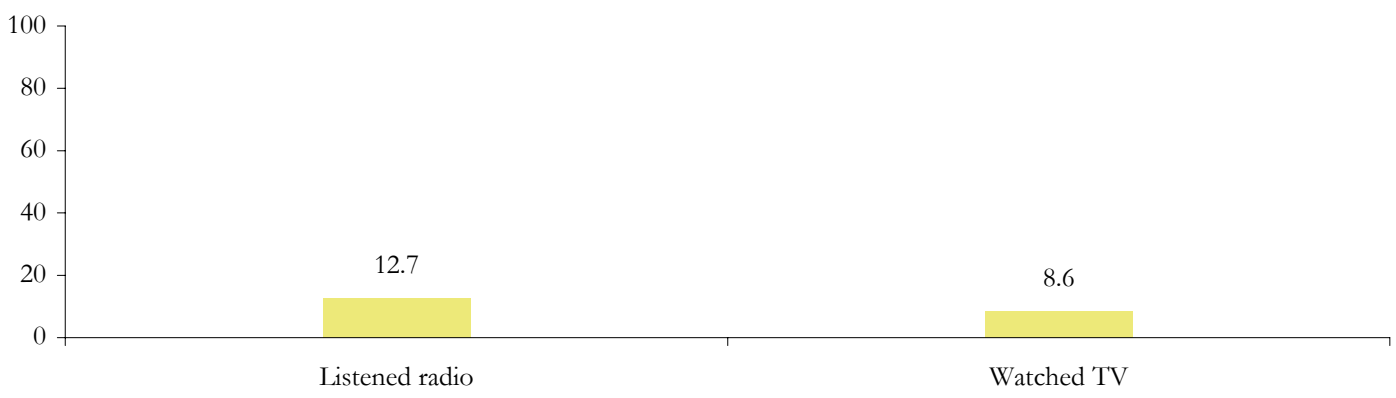

Respondents were then asked to indicate the frequency with which they watch television. About 55 percent of the respondents indicated that they watched TV on a daily basis, while 2.8 percent stated that they did so at least once a week. Approximately 41 percent stated that they rarely watched television.

Table 3.4: $\quad$ Frequency of watching television

\begin{tabular}{lrr} 
Frequency & Percent & Number \\
Almost daily & 55.0 & 60 \\
\hline At least once a week & 2.8 & 3 \\
\hline At least once a month & 0.9 & 1 \\
\hline Rarely & 41.3 & 45 \\
Total & 100.0 & 109
\end{tabular}


From the respondents who do watch television, 97.2 percent indicated that they have a television at home. Less than 1 percent have access a TV at a relative's house. Access to television is synonymous with access to information, and women who do watch television on a daily basis are likely to have more knowledge and information regarding health issues. With increased awareness, women may be able to make better decisions without having to rely on others

Table 3.5:

Place where respondents usually watch TV

\begin{tabular}{lrr} 
Place & Percent & Number \\
\hline At home & 97.2 & 106 \\
\hline At relative's house & 0.9 & 1 \\
\hline Others & 1.8 & 2 \\
Total & 100.0 & 109
\end{tabular}

Respondents were also asked to indicate if they believed television to be influential when it came to people's health behaviors. Nearly 59 percent of those who were interviewed believed that TV had a "great deal" of influence on the health behaviors of people, whereas 5.5 percent believed that it had "no influence at all".

Figure 3.3: $\quad$ Influence of TV programs on health behaviors of people

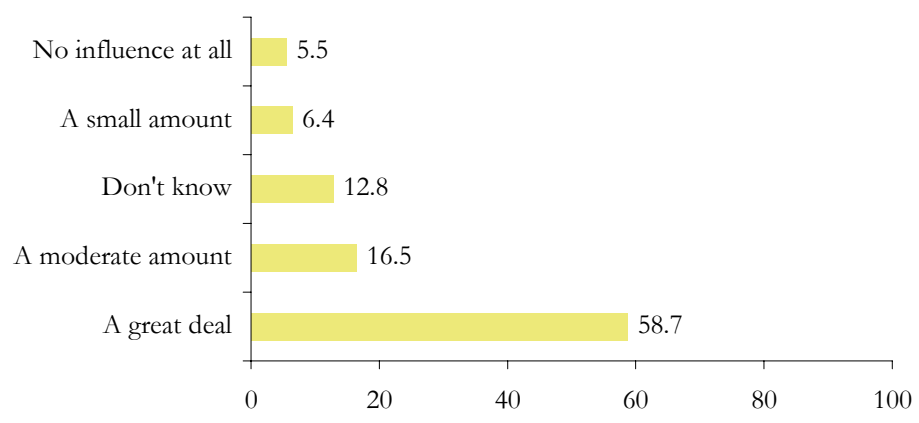

\section{Radio}

Much like television, radio is also a tool through which messages may be relayed to a relatively large audience. However, according to figure 3.2, only 12.7 percent of the respondents in the district of Buner reportedly listened to the radio. In fact, from that 12.7 percent, only half listened to the radio on a daily basis, while 48.1 percent indicate that they "rarely" listened to the radio. Therefore, it can be determined that radio is not the most efficient mean through which a large audience may be reached.

Table 3.6: $\quad$ Frequency of listening to the radio

\begin{tabular}{lrr} 
Frequency & Percent & Number \\
Almost daily & 50.0 & 80 \\
\hline Alt least once a week & 1.9 & 3 \\
\hline Rarely & 48.1 & 77 \\
Total & 100 & 160
\end{tabular}


Respondents were asked to indicate the place at which they most often listened to the radio. Out of the portion of the sample population that does listen to the radio, about 99 percent indicated that they have access to a radio at home, while the rest cited the work place as the main location at which they listen to the radio.

Table 3.7: Place where respondent listens to the radio

\begin{tabular}{|lrr|}
\hline Place & Percent & Number \\
\hline At home & 98.8 & 158 \\
At work place & 1.3 & 2 \\
Total & 100 & 160 \\
\hline
\end{tabular}

Finally, respondents were asked to indicate the level of influence radio has on the health behaviors of people. From the respondents who did listen to the radio, half (50.6 percent) indicated that radio had a "great deal" of influence, while about 8.1 percent believed it had "no influence at all".

Figure 3.4: Influence of radio on health behaviors,

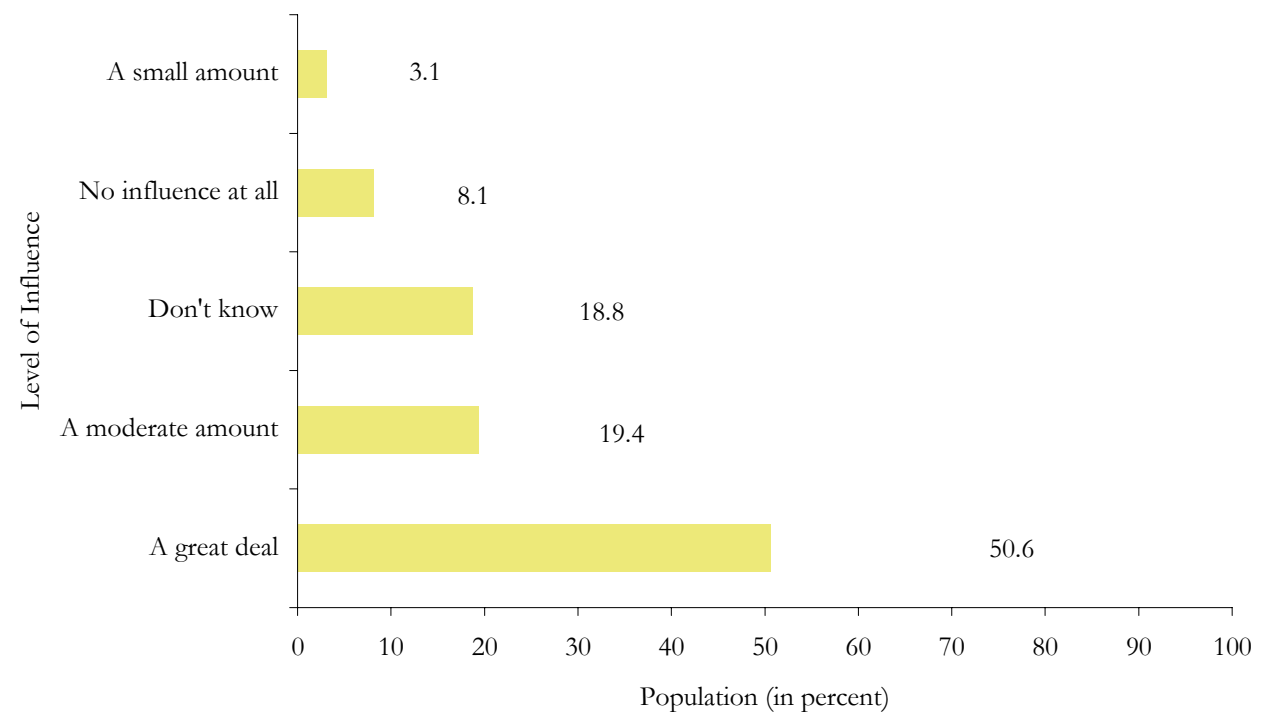




\section{Newspapers}

According to figure 3.5, approximately 94.4 percent of the respondents in the district of Buner indicated that they never read the newspaper, while less than 1 percent stated that they read the newspaper on a daily basis. In a district that is largely illiterate, print media is quite ineffective in promoting any messages geared towards a large audience, such as those regarding maternal and newborn health.

Figure 3.5: $\quad$ Frequency of reading newspaper

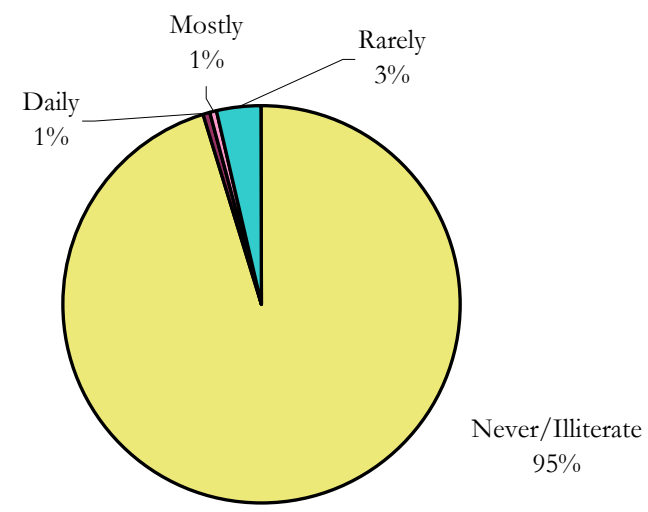

Overall, it was determined that only about 22.5 percent of the respondents in the district of Buner are exposed to some sort of media, while the remainder cannot be reached via television, radio or print media. About 77.5 percent of the respondents indicated that they had no access to any form of media, and therefore must be reached though a different approach. These approaches may include inter-personal communication through community workers, community gatherings, speeches and health education sessions.

Respondents were asked to indicate the media channel that they thought was most trustworthy. Interestingly, as presented in figure 3.6, the largest portion of the women interviewed (64.9 percent) was not sure which media channel they considered most trustworthy. About 18 percent believed television was the most trustworthy form of media, while almost 15 percent felt the same way about radio. Less than 2 percent of the women regarded print media as being the most trustworthy.

Unfortunately, such sentiments make it very difficult to educate a population through the use of TV as campaigns that are most effective through this media channel may not be received well by districts such as Buner. 
Figure 3.6: $\quad$ Most trustworthy media

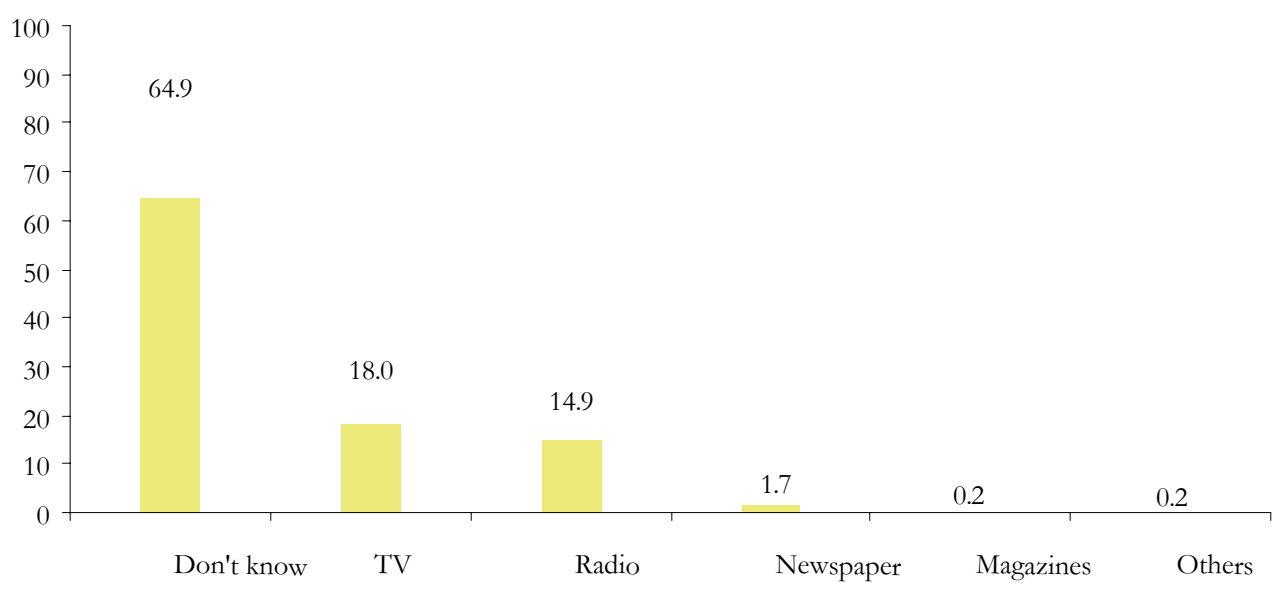

\section{Information/Education through Media}

Before moving on to questions regarding attitudes towards pregnancy, delivery and postpartum, respondents were asked to comment on whether or not they had heard or read anything about maternal and newborn mortality within the past three months. Figure 3.7 shows that about 5 percent of the women interviewed indicated that they had heard/read something regarding newborn health, while 5.8 percent stated having read/heard something about maternal health.

Respondents were then asked to indicate if they had heard an NGO/Community worker or a religious leader speak about maternal and newborn health. The data collected in response to this question indicated that less than 1 percent of the population ( 0.6 percent) had heard NGO/Community workers speak about maternal and newborn health, whereas nearly 2 percent (1.7 percent) had heard a religious leader address the same issue.

Figure 3.7: $\quad$ Percentage of married women who had heard/ read about maternal and newborn health during the last 3 months

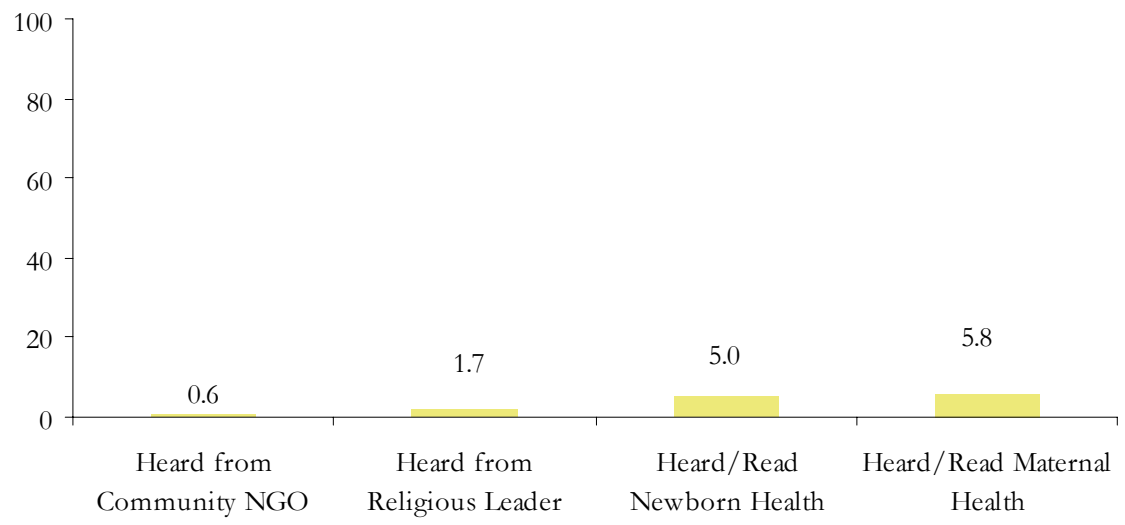


It becomes evident from the data above that the percentages of married women who had heard anything about maternal or newborn health are very low for the district of Buner, indicating the absence of proactive education and awareness in such areas of Pakistan. Hence, it would be a challenge o convey messages regarding maternal and newborn health. 


\section{Chapter 4}

\section{Knowledge of Safe Motherhood, Birth Preparedness and Community Resources}

This chapter explores the level of understanding women have of safe motherhood practices, birth preparedness and the use of community resources. It examines the level of health awareness women in the district possess and thus provides an explanation for the maternal and newborn mortality rates. Respondents were asked questions regarding knowledge of complications during pregnancy, delivery, the postpartum period and newborn health. They were also asked about the community resources available to them within the community. The findings of those responses are presented in this chapter.

\section{Knowledge of Danger Signs}

\section{Knowledge of Danger Signs during Pregnancy}

Figure 4.1 outlines the various complications that may occur during pregnancy. Respondents were asked to indicate which complications they believed were dangerous and required medical attention. Surprisingly, a considerable portion of the sample population was unaware of serious complications that could occur during pregnancy. For example, only 26.9 percent of the respondents reported "severe abdominal pain" as being a serious complication.

Figure 4.1: $\quad$ Knowledge of danger signs during pregnancy that require medical attention

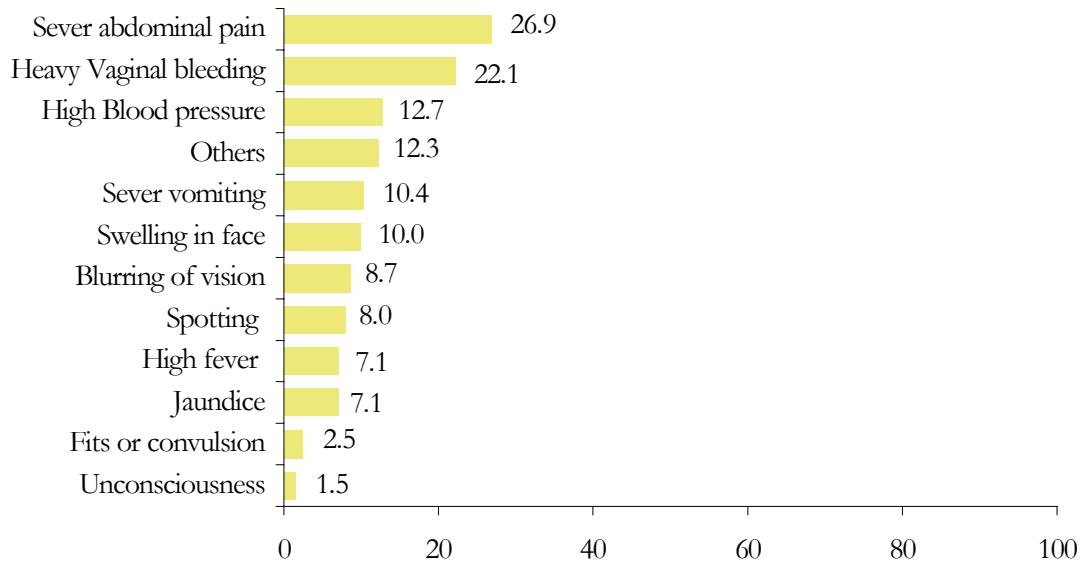

Similarly, 22 percent believed "heavy vaginal bleeding" was a complication, and only 12.7 percent were aware of "high blood pressure" as being a danger sign. Finally, only 1.5 percent of the 
population knew that "unconsciousness" was a complication that could occur during pregnancy, and requires immediate medical attention.

Figure 4.2: $\quad$ Percentage of married women by status of knowledge of danger signs during pregnancy

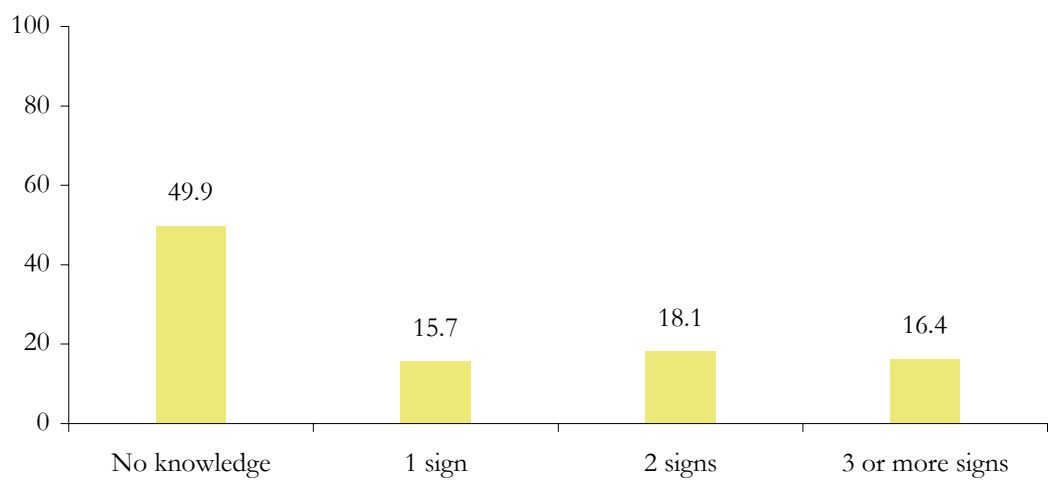

Figure 4.2 indicates the percentage of women who know of one, two and three or more danger signs during pregnancy, along with those who had no knowledge of complications that could arise during pregnancy. In the district of Buner, half the respondents interviewed had no knowledge whatsoever regarding the danger signs that may appear during pregnancy. Only 16 percent were able to name one danger sign, while 16 percent were able to name three or more danger signs. This data suggests that women in the districts of Buner are not educated enough in terms of birth preparedness and complication readiness, and may therefore be putting not only their lives, but also those of their unborn children at risk.

\section{Knowledge of Danger Signs during Childbirth/Delivery}

As in the case of pregnancy, many women are not aware of the complications that may arise during delivery. As a result, many women are not taken to a hospital in the event that such a complication should occur. Figure 4.3 depicts the level of the respondents' understanding of complications during delivery. Once again, a very small portion of the population was aware of the various danger signs that may appear during delivery. For example, only about a quarter of the women interviewed recognized "prolonged labor" as a complication, while 23 percent believed that "bleeding before labor" was a complication. Finally, less than 8 percent believed that premature rupture of membranes and mal-positioning were danger signs. 
Figure 4.3: $\quad$ Distribution of respondents who had knowledge about complications during delivery

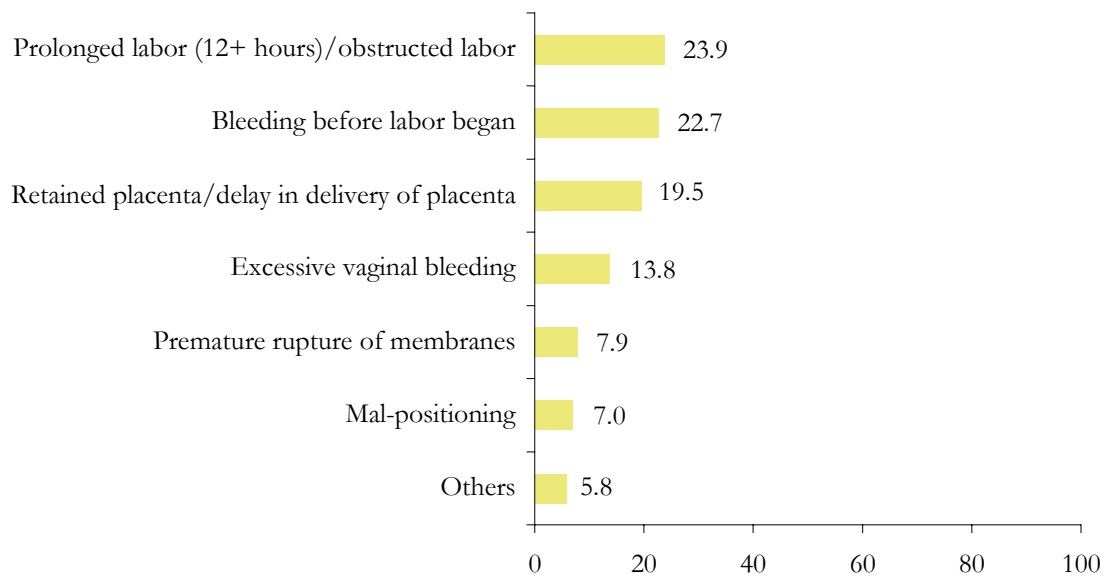

Furthermore, respondents were asked to name all the danger signs they knew of, which may occur during delivery. According to the data presented in figure 4.4, 47 percent of the respondents had no knowledge of any danger signs to look out for during the delivery, while less than 10 percent of the women knew of 3 or more danger signs during childbirth.

Figure 4.4: $\quad$ Percentage of married women by status of knowledge of danger signs during delivery

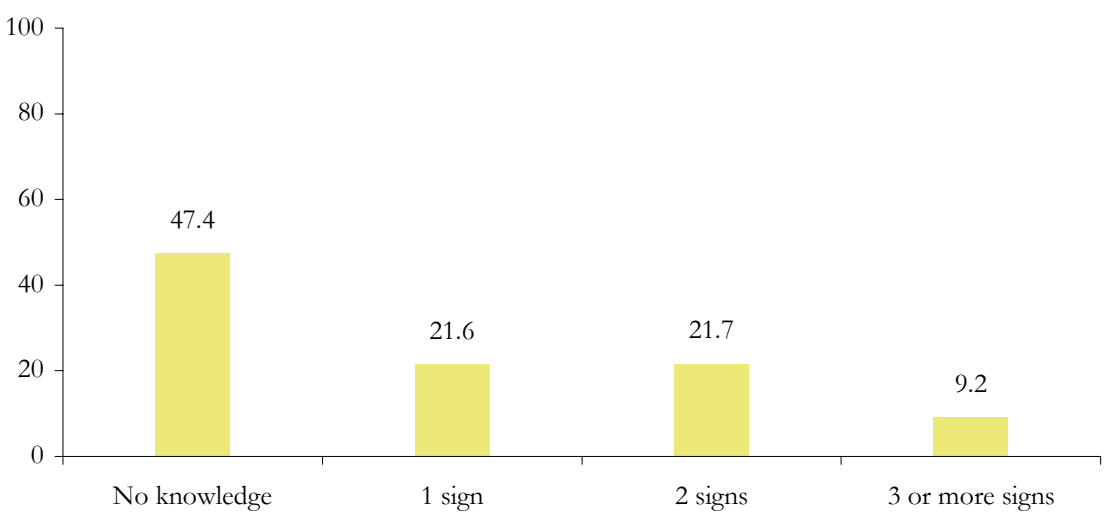

This data suggests that there is considerable room for improvement when it comes to an increase in education and awareness in regards to health education. Innovative approaches are therefore needed to make these communities more aware of issues regarding maternal and newborn health.

\section{Knowledge of Danger Signs during the Postpartum Period}

In the baseline survey, the postpartum period is defined as the 40 days after childbirth. Postpartum hemorrhage is the most significant cause of maternal morality in developing countries. Although baseline survey findings indicate that excessive vaginal bleeding is the most known danger sign during the postpartum period, not all women were aware of this fact. This calls for some innovative 
approaches to make communities knowledgeable regarding the danger signs during the postpartum period. If mothers are not medically fit and completely healthy during the postpartum period, they are unlikely to take adequate care of their newborns.

While only 37 percent of the respondents interviewed were aware of "excessive vaginal bleeding" and "high fever" (16 percent) as being serious complications, many were unable to name other danger signs which could put their health at risk. For example, only 6.3 percent knew that "fits and convulsions" were danger signs, while just over 5 percent believed that a "prolapsed uterus" was a complication.

Figure 4.5: $\quad$ Percentage of married women who had knowledge about complication during postpartum period

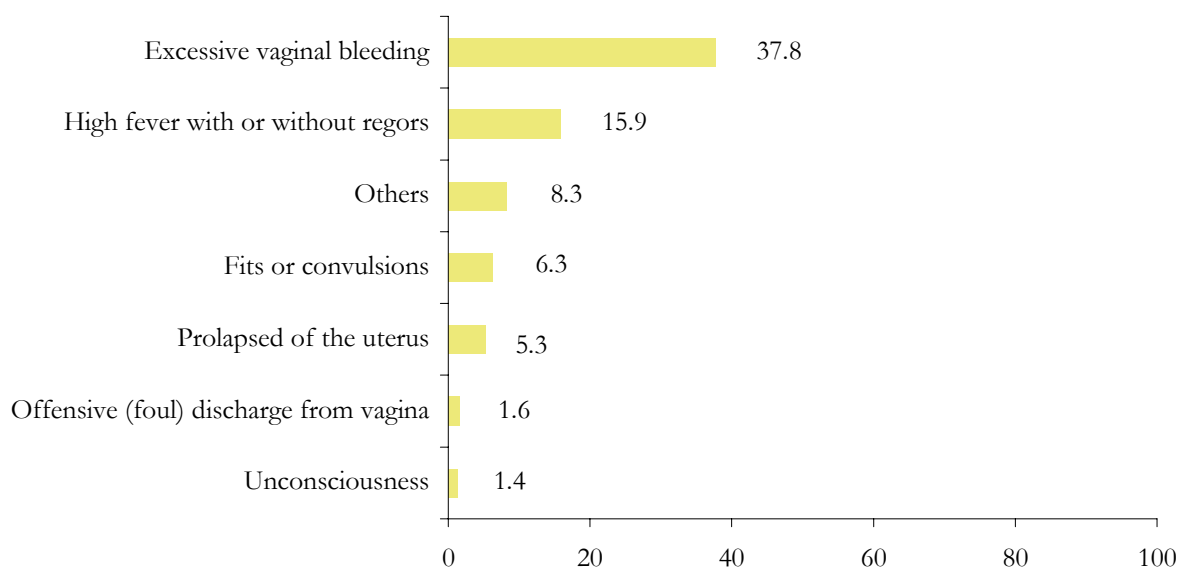

In fact, when respondents were asked to name danger signs that may be noted during the postpartum period, nearly 54 percent were unable to name even a single one. About 27 percent were able to name just one danger sign during postpartum period, and only 3 percent of the respondents were able to name three or more danger signs. This lack of awareness is shocking, as it suggests that women who may be experiencing such symptoms remain unaware of the impact these complications have on their health, and may therefore fail to seek adequate treatment. Such lack of action is very likely to result in maternal mortality or morbidity. 
Figure 4.6: $\quad$ Percentage of married women by status of knowledge of danger signs during the postpartum period

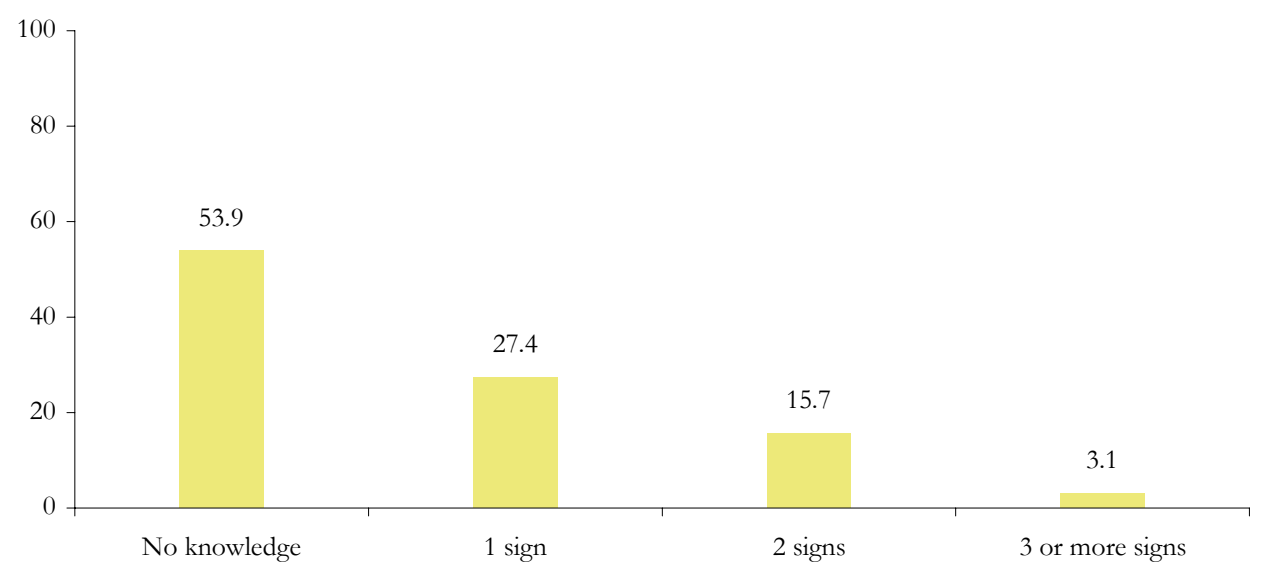

\section{Knowledge of Danger Signs in the Newborn}

Unfortunately, many women are also unaware of the danger signs that may appear in newborns, especially in the first seven days after the childbirth. The newborn period is defined as the first four weeks after birth.

Figure 4.7: $\quad$ Distribution of respondents who had knowledge about danger signs in newborns

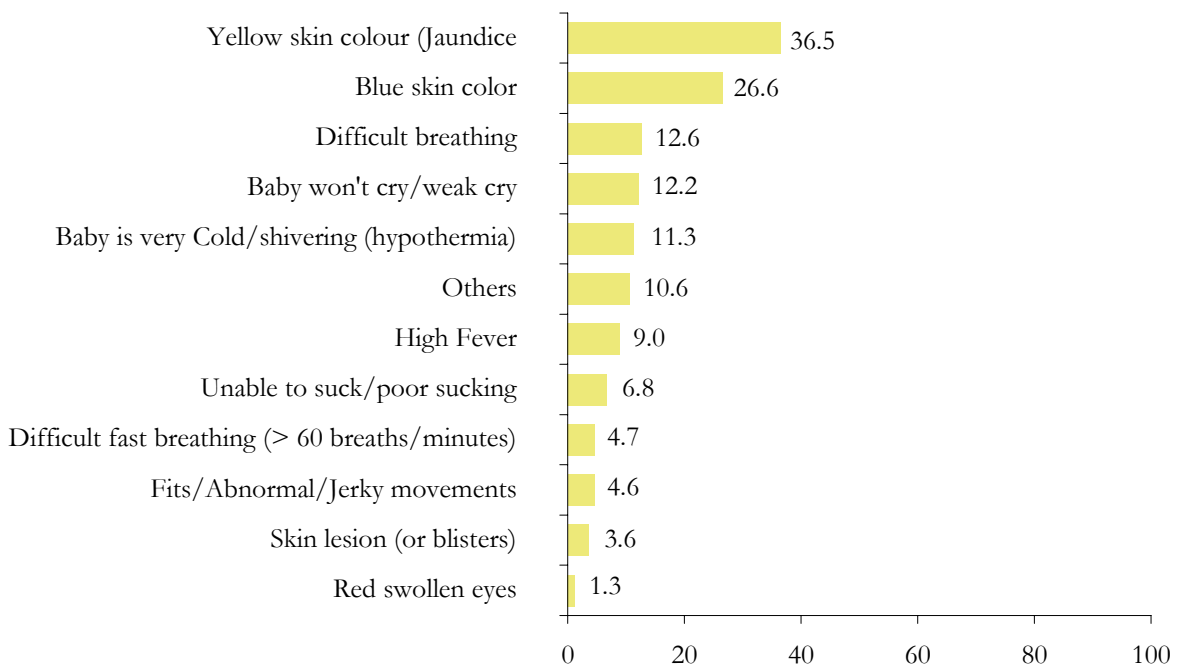

Respondents were asked to name all the danger signs that may appear in a newborn. Figure 4.7 shows that amongst the more commonly known complications, "yellow skin (jaundice)" was the most wellknown danger sign in newborns, as over 36 percent of the women interviewed knew about it. "Blue skin color" (27 percent), "difficulty breathing" (13 percent) and "weak cry" (12 percent) were also among the better-known complications. Less than 10 percent of the women knew about "high fever", "fits/jerky movements", "skin lesions" and "red/swollen eyes" as being danger signs to look out for in newborn babies. 
Figure 4.8 shows that a large percentage of the respondents in Buner (43 percent) were unable to name any danger signs at all. About 17 percent named one complication, 22 percent were able to name two, while only 19 percent of the women interviewed named three or more danger signs that can be noted in newborns.

Figure 4.8: $\quad$ Percent of married women by status of knowledge of danger signs in newborns

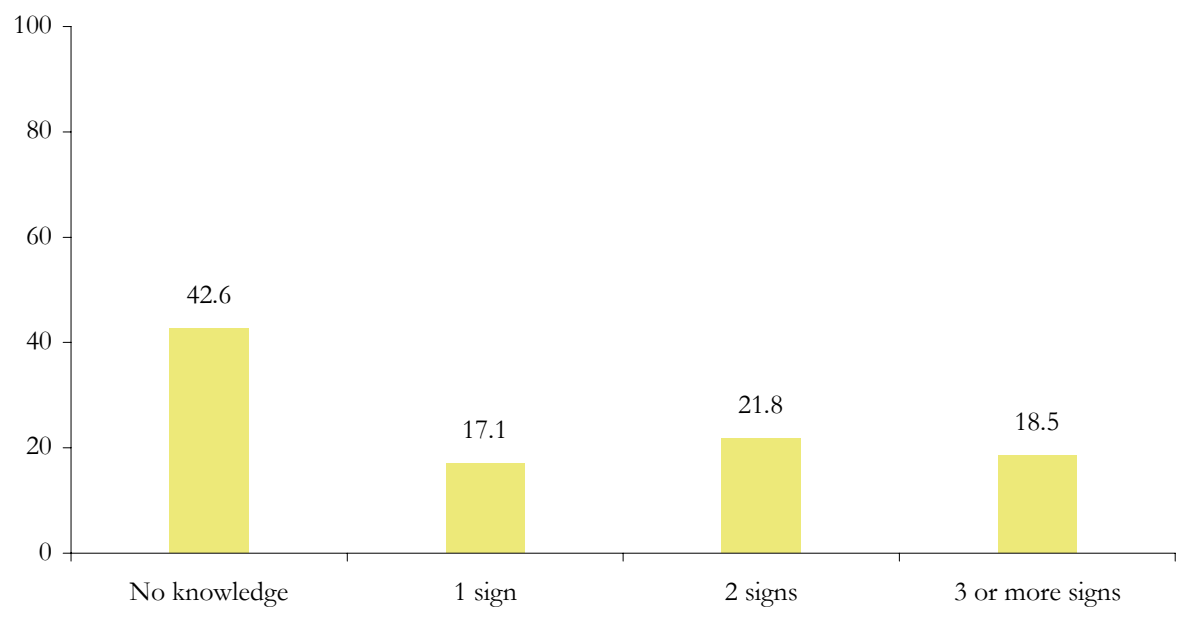

\section{Source of Information Regarding Danger Signs}

Finally, respondents were asked to indicate where they received their information regarding complications during pregnancy, delivery and postpartum period. About 72 percent of the respondents indicated that they received their information from friends, neighbors and relatives, while 18 percent stated that their in-laws were their main source of information. Just over 6 percent stated that they obtained their information from BHUs/RHCs/MCH centers, while only about 4 percent receive their information from DHQs/THQs. Only 2 percent cited LHWs as their main source of information, while TBAs, nurses/LHWs, private hospitals/clinics and midwifes accounted for less than 1 percent each as main sources of information. 
Figure 4.9: $\quad$ Source of information about pregnancy

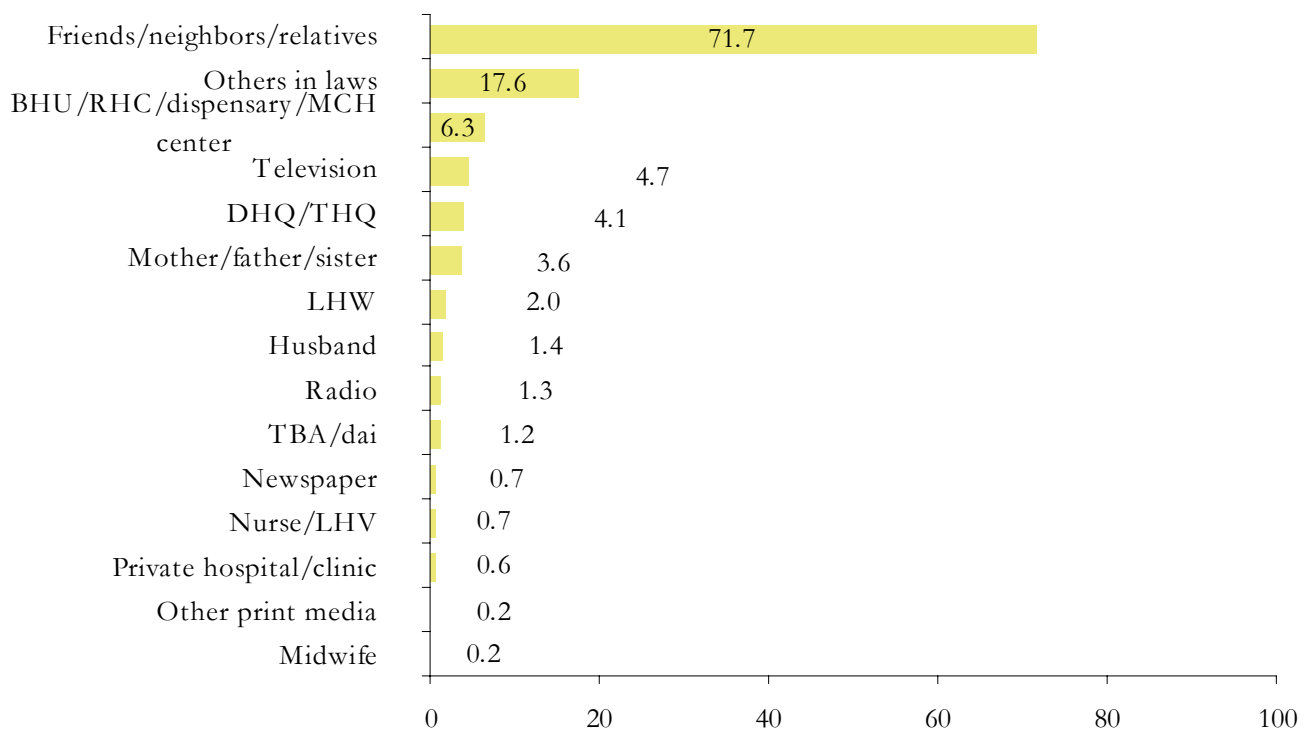

The fact that most respondents reportedly obtained information about pregnancy through in-laws, family members and friends shows that many women may not be getting accurate information. Also, many women are not receiving reliable information regarding the health and medical side of a pregnancy from a doctor's perspective.

\section{Knowledge of Community Schemes for the Welfare of Women and Newborns}

In addition to asking questions on the knowledge of danger signs, married women were asked whether they were aware of any existing schemes in their respective communities that would help ensure a safe and healthy delivery. The baseline focused on schemes pertaining to transportation, blood arrangements and funding, all services which help ensure that there are no delays during the delivery time. Failure to arrange transport on time to a health facility is a major cause of delay and can often lead to maternal and newborn mortality. Unfortunately, many households are unable to do so due to a lack of transportation in their communities.

Table 4.1: $\quad$ Knowledge of existence and importance of transport, blood and finances by the community at the time of delivery

\begin{tabular}{lrr}
\multicolumn{1}{c}{ Committee Services } & Percent & Number \\
Existence of transport by the community at delivery & 1.6 & 20 \\
\hline Important to have community provided transport facility & 99.8 & 1260 \\
\hline Existence of blood by the community at time of delivery & 1.0 & 13 \\
\hline Important to have community provided blood facility & 99.9 & 1261 \\
\hline Existence of money by community at the time of delivery & 1.1 & 14 \\
\hline Important to have community provided money facility & 99.6 & 1257 \\
\hline
\end{tabular}


According to table 4.1, most of the population (over 99 percent) stressed the importance of community provided transport facilities, as well as arrangements for blood and money in the case of an emergency. However, less than 2 percent of the respondents indicated that such facilities and arrangements existed in their communities. This becomes a major obstacle to safe birth practices, as women are then forced to deliver at home, and may be exposed to infections and complications. Birth preparedness promotes the arrangement of such aspects. 


\section{Chapter}

\section{Attitudes Towards Pregnancy, Delivery and the Postpartum Period}

This chapter explores the attitudes of married women towards pregnancy, delivery and the postpartum period. Determining these attitudes and beliefs can lead to the development of new strategies and methods that bring about a change in the traditional ways of thinking.

\section{Attitudes Towards Age at Marriage}

Respondents were asked if they felt women should get married soon after puberty. About 36 percent of the respondents interviewed believed that women should be married soon after puberty, while 46.6 percent of the population felt that women should not be married at that age. About 13 percent had no opinion, while nearly 4 percent did not know how to answer that question. A deeper look into this issue would show that many families do not value education and choose marriage before providing girls and women with schooling. As a result, women are married at an early age, and often completely forgo the opportunity to obtain any education whatsoever. As well, there is a link between the amount of education obtained by women and the fertility rate of a country (Sathar et al, 1988). The younger the age at marriage, the higher the fertility rate tends to be. Therefore, in order to lower the fertility rate, it is important to delay the age at marriage for women.

\section{Attitudes Towards Antenatal Care}

Next, respondents were asked to indicate if they believed antenatal check-ups were necessary during pregnancy. Table 5.1 outlines the responses provided. While a very large percentage of the women (69.4 percent) felt it necessary to seek antenatal care, a sizable portion of the women (18 percent) indicated that antenatal care was not necessary.

Table 5.1:

Importance of antenatal check-ups
\begin{tabular}{|lrr} 
Have antenatal check-up & Percent & Number \\
Yes & 69.4 & 878 \\
\hline No & 17.9 & 227 \\
\hline Don't know & 12.6 & 160 \\
\hline Total & 100.0 & 1,265 \\
\hline
\end{tabular}

Antenatal care also encourages mothers to be more aware of their own health as well as the health of their newborn babies. When asked to state the month of pregnancy in which a woman should receive 
antenatal care, the responses received varied. The table 5.2 outlines the different responses and opinions.

Table 5.2:

Month of the pregnancy when women should receive for antenatal care

\begin{tabular}{|c|c|c|}
\hline Month & Percent & Number \\
\hline 1 & 3.6 & 32 \\
\hline 2 & 6.6 & 58 \\
\hline 3 & 16.2 & 142 \\
\hline 4 & 5.7 & 50 \\
\hline 5 & 5.8 & 51 \\
\hline 6 & 1.9 & 17 \\
\hline 7 & 0.5 & 4 \\
\hline 8 & 0.6 & 5 \\
\hline 9 & 1.4 & 12 \\
\hline As soon as possible after pregnancy & 9.7 & 85 \\
\hline When check-up is needed & 37.1 & 325 \\
\hline Don't know & 10.9 & 96 \\
\hline Total & 100.0 & 877 \\
\hline
\end{tabular}

About 26.4 percent of the respondents interviewed believed that a woman should receive an antenatal check-up in the first trimester, with 16 percent indicating that the check-up should be made in the third month of pregnancy. Approximately 13.4 percent indicated that the antenatal check-up should be in the second trimester, while about 2.5 indicated that it should occur in the third trimester. Nearly 10 percent of the women stated that an antenatal check-up should be made as soon as possible after pregnancy. However, a very large portion of the women (37 percent) believed that women should receive an antenatal check-up only when needed.

The next question respondents were asked was in regard to the number of antenatal visits a woman should ideally receive during her pregnancy. The highest portion (approximately 8 percent each) believed that at least three or four antenatal visits should be received during pregnancy. However, over half the women interviewed (57 percent) indicated that antenatal check-ups were not necessary, and should only be sought when needed. This gives rise to the question of access to antenatal care and the obstacles that stand in the way of women. Traditional and financial barriers, along with lack of transport may stand in the way. 
Table 5.3: $\quad$ Number of antenatal visits considered necessary by respondents

\begin{tabular}{|c|c|c|}
\hline Number & Percent & Number \\
\hline 1 & 1.9 & 17 \\
\hline 2 & 3.3 & 29 \\
\hline 3 & 8.6 & 75 \\
\hline 4 & 8.0 & 70 \\
\hline 5 & 2.2 & 19 \\
\hline 6 & 3.2 & 28 \\
\hline 7 & 1.5 & 13 \\
\hline 8 & 2.9 & 25 \\
\hline 9 & 2.2 & 19 \\
\hline 10 & 0.1 & 1 \\
\hline 13 & 0.3 & 3 \\
\hline 22 & 0.1 & 1 \\
\hline When check-up is needed & 56.6 & 496 \\
\hline Don't know & 9.2 & 81 \\
\hline Total & 100.0 & 877.0 \\
\hline
\end{tabular}

Figure 5.1: $\quad$ Percentage of married women who thought it necessary to receive TT shots and take iron/folate tablets during pregnancy

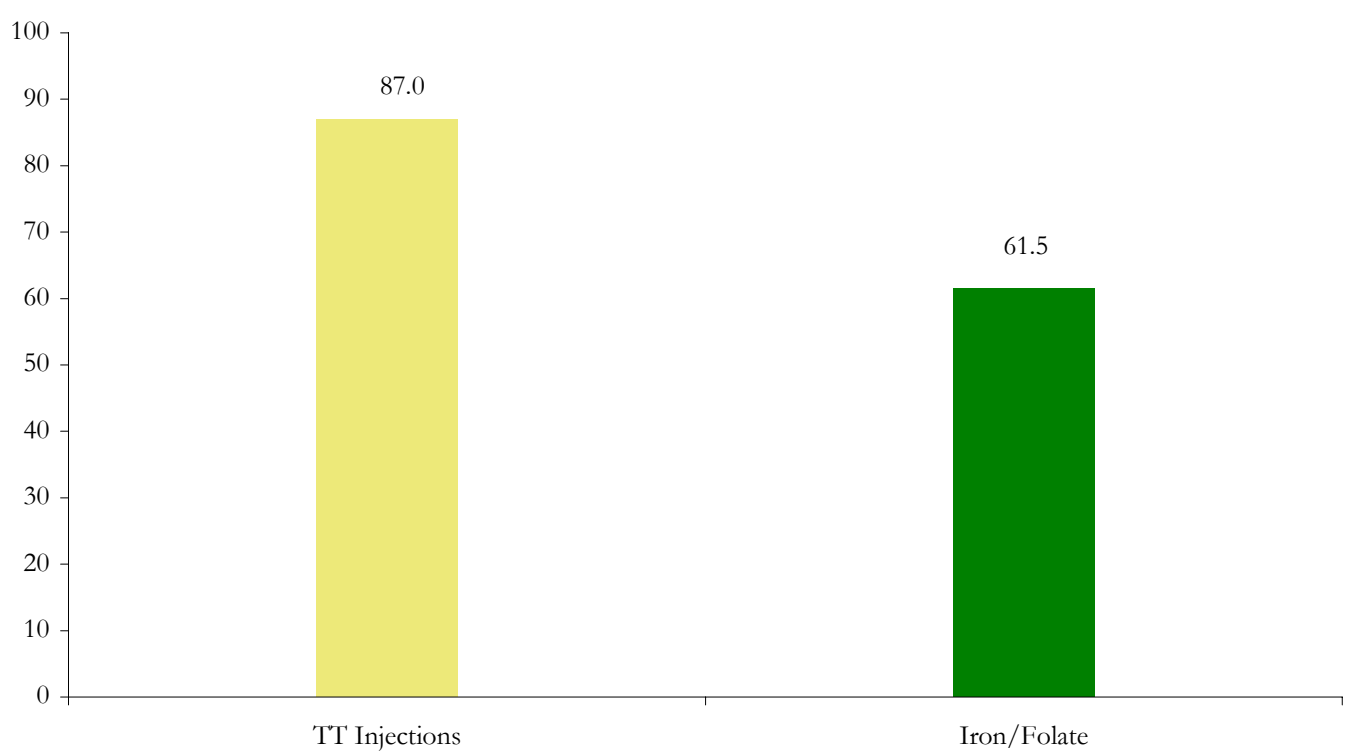

Figure 5.1 presents the percentage of respondents who believe that TT shots and iron/folate supplements are necessary during pregnancy. Almost 87 percent of the respondents in Buner understood the importance of T'T shots during pregnancy, while 61.5 percent felt the same way about 
iron/folate supplements. This suggests that a sizable portion of the population feels that TT shots and iron/folate supplements are unnecessary during pregnancy.

\section{Attitudes Towards Delivery}

Many families prefer the traditional practice of employing Traditional Birth Attendants (TBAs) or Dais to assist with deliveries. These TBAs/Dais have vast experience but no formal training and therefore do not qualify as skilled birth attendants. However, many families do not realize the impact a lack of training can have on childbirth, and chose to opt for TBAs over health professionals.

Table 5.4: $\quad$ Believe that women should receive delivery services from $S B A$

\begin{tabular}{|c|c|c|}
\hline Number & Percent & Number \\
\hline Yes & 80.6 & 1,016 \\
\hline No & 7.1 & 90 \\
\hline Don't know & 12.3 & 155 \\
\hline Total & 100.0 & 1,261 \\
\hline
\end{tabular}

Interestingly, almost 81 percent of the respondents indicated that women should receive delivery services from a SBA, whereas only 7 percent were against the idea.

Respondents were also asked to indicate if they knew of women in their community who received delivery services from SBAs. Almost 37 percent indicated that "most" of the women in their community went to SBAs at the time of delivery, while 12 percent stated that "all" women in the community sought the assistance of SBAs. However, the same percent (12 percent) indicated that none of the women in the community received delivery services from a SBAs.

Figure 5.2: $\quad$ Percentage of respondents who believed women in their community seek delivery services from SBA

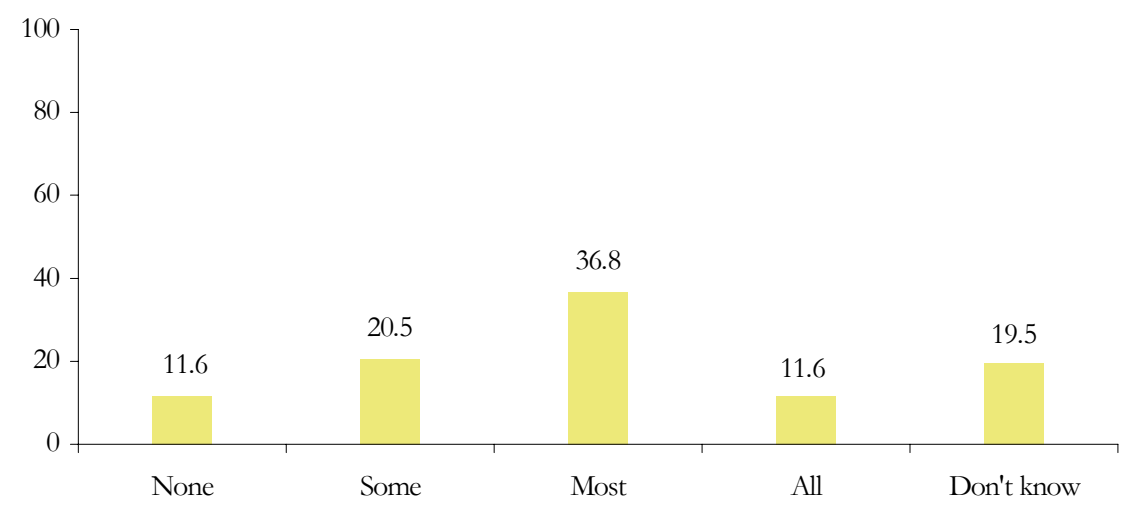

Figure 5.3 depicts the response provided by the respondents regarding their preferred place for delivery. When asked where they felt a delivery should take place, over half the population (57 percent) indicated that a delivery should occur at home, whereas 40 percent believed that it should take place in hospital. The data for Buner is held in contrast with the data obtained for less traditional areas where people generally feel deliveries should take place at a hospital. 
Figure 5.3: $\quad$ Percentage of women by their perception where delivery should take place

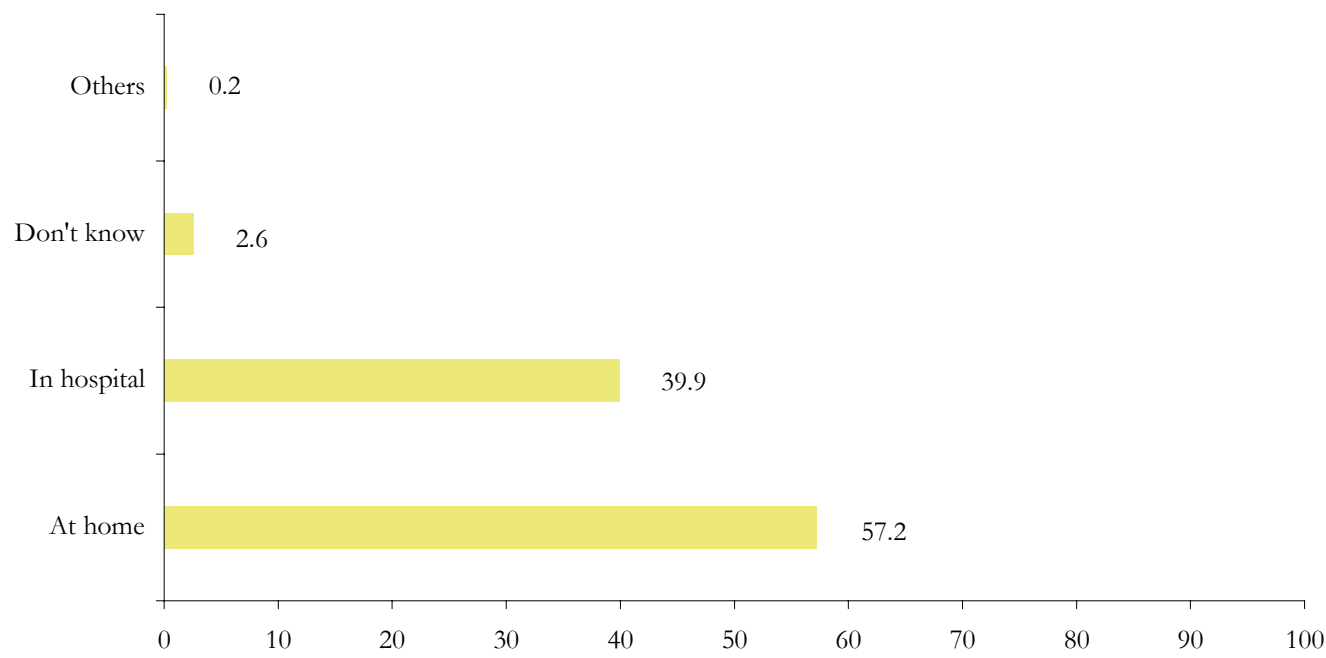

One reason, which explains why some women still want to deliver at home, is that they are not able to make decisions independently. Often, women are dependant upon their husbands or in-laws when it comes to major decisions. Respondents were asked to indicate who they believe should take care and charge of a pregnant woman. Less than 1 percent of the Buner (0.6 percent) indicated that a pregnant woman herself should be able to decide when to go to a hospital in order to seek medical attention. However, 80 percent indicated that the family members of the pregnant woman should be the ones who decide when to obtain care for her, while 15 percent indicated that the husband should be the decision-maker when it comes to a pregnant woman's health.

Table 5.5: $\quad$ Person who decide to take care for the pregnant women

\begin{tabular}{lrr}
\multicolumn{1}{c}{ Person } & Percent & Number \\
Pregnant woman & 0.6 & 7 \\
\hline Husband & 15.4 & 195 \\
\hline Other family members & 80.4 & 1,017 \\
\hline Friend/Neighbor/Relative & 0.2 & 3 \\
\hline TBA/Dai & 0.8 & 10 \\
\hline Others & 0.7 & 9 \\
\hline Don't know & 1.9 & 24 \\
Total & 100.0 & 1,265
\end{tabular}

Since women may not always be able to make their own decisions, they are often unable to seek medical care when they deem necessary, and usually do not make decisions such as those regarding the location of delivery. Therefore, while many women may like to get assistance from a SBA, most are unable to do so due to a lack of decision-making power. 
Figure 5.4: $\quad$ Percentage of married women by mode of transport they would use to reach health facility

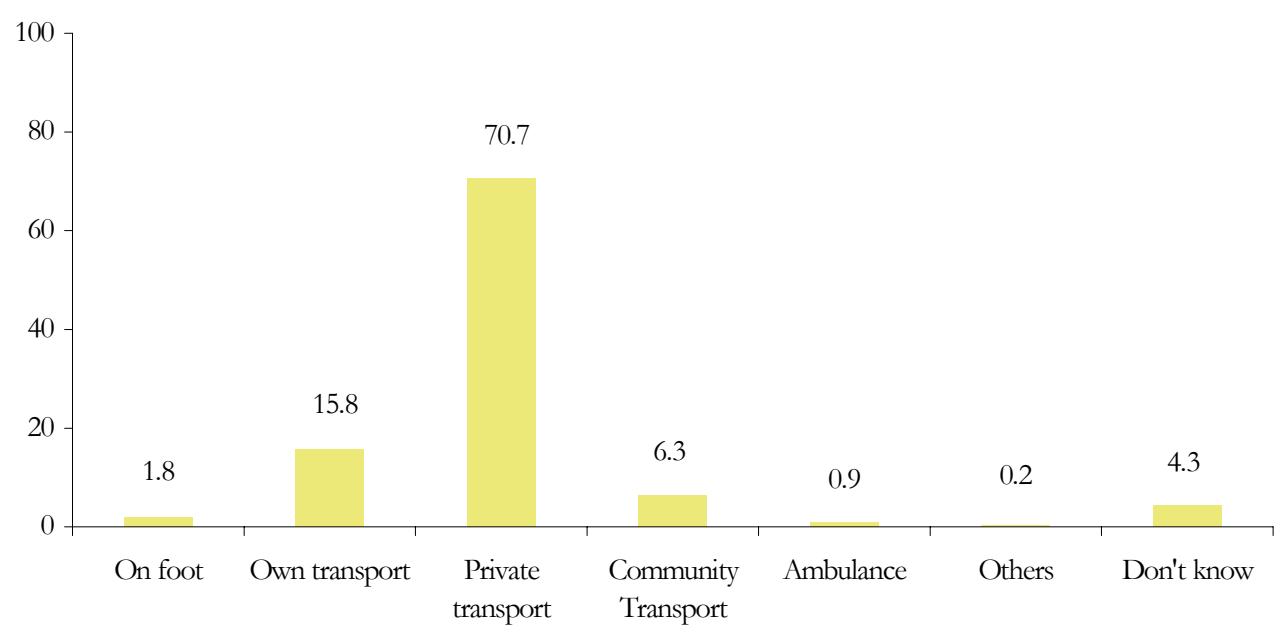

Figure 5.4 depicts the percentage of married women based on the mode of transport they planned on using in order to reach a health facility for their delivery. In the district of Buner , 71 percent indicated that they would use private transport in order to get to a health facility, while 16 percent indicated that they would use their own transportation. Just over 6 percent cited community transport as their main source of transportation, while nearly 2 percent indicated that they had no means of transport whatsoever and would walk to a health facility at the time of delivery. About 4 percent of the population had not yet decided which mode of transportation to employ in order to reach a health facility at the time of delivery.

While private transport is better than relying on community transport, and certainly much better than walking to a health facility, it cannot be completely relied upon. Transportation to a health facility is a major delay in the delivery process, and may be very harmful to both the mother and the unborn baby. As well, many families often fail to arrange transport for pregnant women, thus having to rely on unreliable private transport.

\section{Attitudes Towards Postpartum and Neonatal Care}

The importance of postnatal care is often undervalued. Postnatal care ensures that both mother and newborn are in good health, and monitors the recovery process of new mothers.

Table 5.6:

Necessity of postnatal care

\begin{tabular}{lrr}
\multicolumn{1}{c}{ Need postnatal care } & Percent & Number \\
Yes & 29.2 & 370 \\
\hline No & 55.3 & 700 \\
\hline Don't know & 15.4 & 195 \\
Total & 100.0 & 1,265
\end{tabular}

Only about 29 percent of the women interviewed indicated that women should receive postnatal care, whereas 55 percent stated that postnatal care was not necessary. These numbers prove that women are not aware of the complications that can arise following birth and may ignore symptoms. A large number of maternal deaths occur during the 48 hours after birth (JHPIEGO, 2004). "In spite of the high risk associated with the postpartum period, women seem to know very little about health practices during this period” (JHPIEGO, 2004). Since about 15 percent of pregnant women require 
emergency obstetric care to prevent mortality, it is important to have regular postnatal check-ups. A lack of knowledge during the postpartum period may influence inappropriate or delayed care seeking, which may result in maternal morbidity or mortality.

Figure 5.5: $\quad$ Number of postnatal care visits women should have in the community

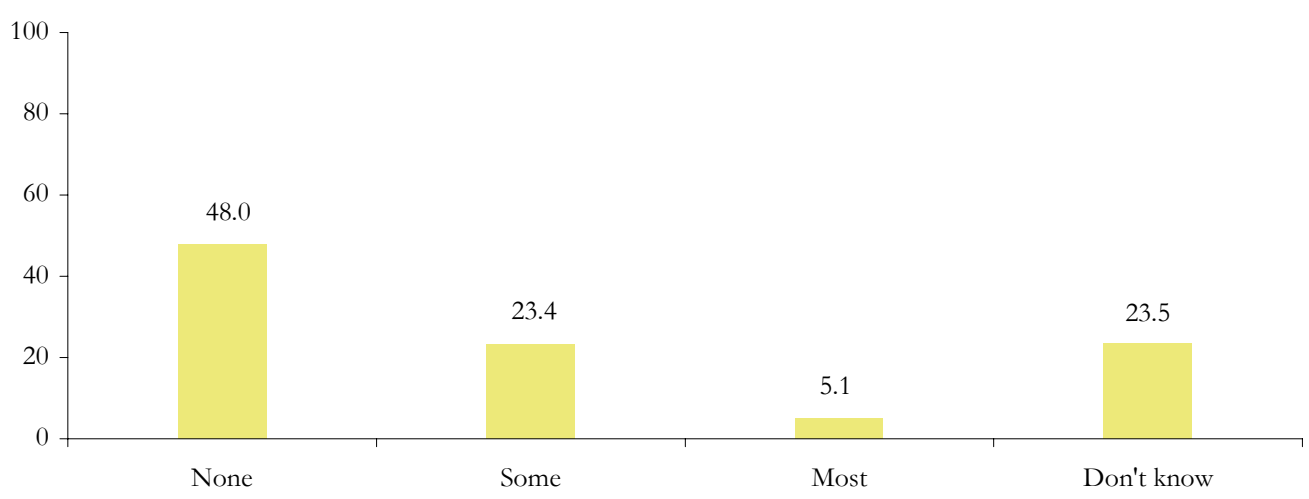

When asked if women in the community sought postnatal care, 48 percent of the respondents believed that none of the women in their communities received postnatal care, while only 5 percent indicated that "most" women in their communities did.

\section{Coverage of Lady Health Workers}

Respondents were asked to indicate if a Lady Health Worker (LHW) had been to their community within the last three months. The table outlines the responses given. Nearly 31 percent of the women interviewed indicated that a LHW had in fact been to their communities within the past three months, whereas 56 percent indicated that no LHW had visited their community.

Table 5.7: $\quad$ Presence of lady health worker in the community

\begin{tabular}{lrr}
\multicolumn{1}{c}{ Has LHW in the area } & Percent & Number \\
Yes & 30.8 & 390 \\
\hline No & 56.3 & 712 \\
\hline Respondent herself is LHW & 0.6 & 7 \\
\hline Don't know & 12.3 & 156 \\
Total & 100.0 & 1,265
\end{tabular}

Similarly, respondents were also asked to state if a LHW had visited their homes within the past three months. Interestingly, over half the women interviewed ( 52 percent) indicated that a LHW had been to their homes, whereas 48 percent indicated that no LHW had visited them at their homes.

Table 5.8: $\quad$ LHW ever visited home during last three months by place of residence

\begin{tabular}{lrrr} 
& Ever visited & Percent & Number \\
Yes & 52.1 & 203 \\
\hline No & 47.9 & 187 \\
Total & 100.0 & 390
\end{tabular}





\section{Chapter}

Contraceptive Knowledge and Use

Respondents were asked to name the ways in which a couple could delay or avoid a pregnancy. If the respondent did not spontaneously mention a particular method, the interviewer described different methods and asked the respondent to indicate if she recognized them. In the questionnaire, descriptions were included for six modern contraceptive methods and two traditional methods.

\section{Knowledge of Contraceptive Methods}

Many women are unaware of the different types of contraceptives that may be used to delay or prevent pregnancy. As women do not always have full control over the number of children they want to have, contraception is an important tool that helps give women that freedom of choice.

Figure 6.1: $\quad$ Percentage of married women by knowledge of specific contraceptive method

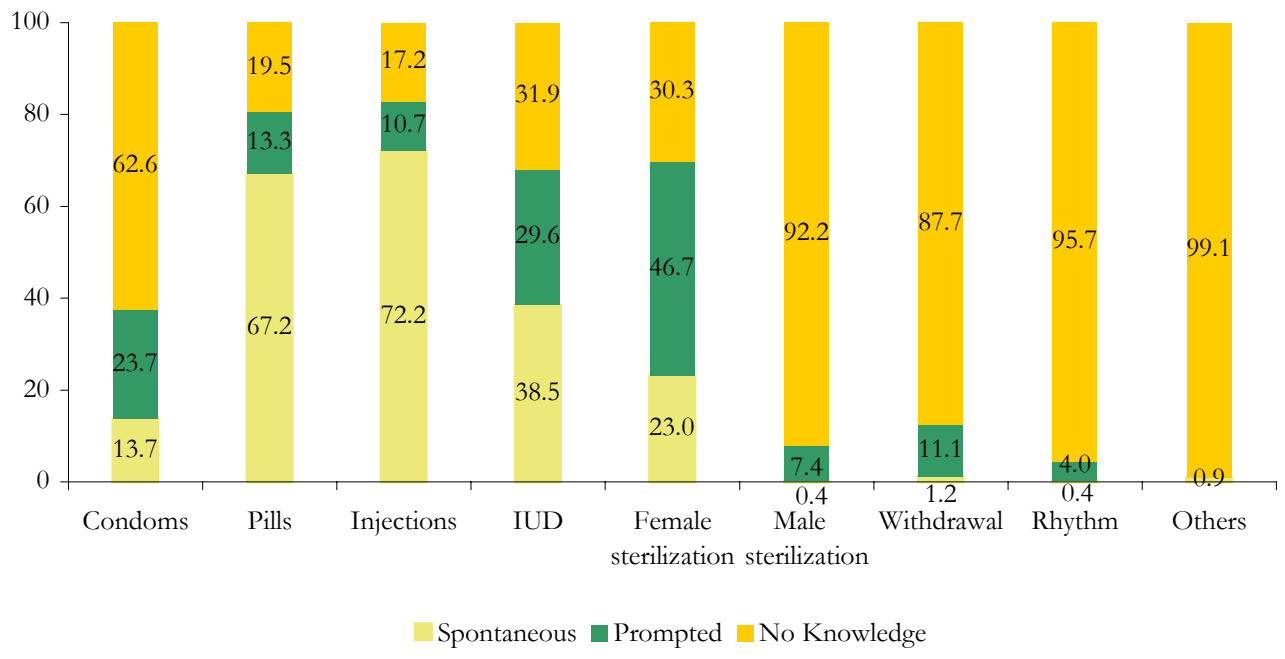

Figure 6.1 presents the most commonly known contraceptive methods in the district of Buner. Injections were the most widely known contraceptive method ( 72.2 percent), followed by pills ( 67.2 percent). Respondents also mentioned IUDs (38.5 percent), female sterilization (23 percent) and condoms (13.7 percent) as popular family planning methods. Male sterilization, withdrawal and rhythm methods were not very well known to most of the respondents interviewed. 


\section{Ever Use of Contraception}

Respondents were then asked to indicate if they had ever used any means of contraception. About 17.5 percent of the sample population indicated that they had used injections, 11 percent claimed to have used contraceptive pills, while 6 percent used condoms. Male sterilization was the least common form of contraception, followed by the rhythm method, while injections seemed to be the most popular form of contraception. Overall 30 percent of the married women have ever used any type of contraceptive method.

Table 6.1: $\quad$ Ever used FP method by contraceptive

\begin{tabular}{lrr} 
Contraceptive method & Percentage & Number \\
Any method & 30.1 & 381 \\
\hline Condoms & 6.2 & 78 \\
\hline Pills & 11.0 & 139 \\
\hline Injections & 17.5 & 222 \\
\hline IUD & 4.6 & 58 \\
\hline Female sterilization & 1.4 & 20 \\
\hline Male sterilization & 0.1 & 1 \\
\hline Withdrawal & 1.7 & 22 \\
\hline Rhythm & 0.5 & 6 \\
\hline
\end{tabular}

\section{Current Use of Contraceptive Methods}

Contraceptive prevalence is defined as the proportion of currently married women aged 15-49 years who were using some method of family planning at the time of the survey. According to the data presented in table 6.2, 13.4 percent of the population currently uses some form of contraception, whereas 12.7 percent of that figure uses modern contraceptive methods.

Table 6.2: $\quad$ Method-specific contraceptive prevalence

\begin{tabular}{lr}
\multicolumn{1}{c}{ Contraceptive Method } & Percentage \\
Any method & 13.4 \\
\hline Any modern method & 12.7 \\
\hline Any traditional method & 0.5 \\
\hline Condom & 2.0 \\
\hline Pill & 2.8 \\
\hline Injectables & 4.8 \\
\hline IUD & 1.8 \\
\hline Female Sterilization & 1.4 \\
\hline Male sterilization & 0.1 \\
\hline Withdrawal & 0.4 \\
\hline Rhythm & 0.1 \\
\hline Other & 0.2 \\
\hline Not currently using & 86.6 \\
\hline Number & 1,265
\end{tabular}


Once again, injectables seemed to be the most popular form of contraception used by 4.8 percent of the respondents, followed by the pill at 2.8 percent, condoms at 2 percent and IUDs, used by just under two percent of the population. Nearly 87 percent of the respondents indicated that they do not currently use any form of contraception.

\section{Source of Contraceptive Supplies}

Respondents were then asked where they obtained their contraception. About a quarter of the population that uses contraception indicated that they obtained their contraception from $\mathrm{BHU} / \mathrm{RHC} / \mathrm{Dispensaries/MCH}$ centers, while about 18 percent each obtained theirs from DHQ/THQ or medical stores.

Table 6.3: $\quad$ Source of contraceptive supply

\begin{tabular}{|c|c|c|}
\hline Source/Place & Percent & Number \\
\hline LHW & 4.3 & 7 \\
\hline TBA/dai & 2.5 & 4 \\
\hline BHU/RHC/dispensary/MCH center & 24.8 & 40 \\
\hline $\mathrm{DHQ} / \mathrm{THQ}$ & 18.0 & 29 \\
\hline Private clinic/hospital & 6.8 & 11 \\
\hline Midwife & 1.2 & 2 \\
\hline Nurse/LHV & 4.3 & 7 \\
\hline Medical store & 18.6 & 30 \\
\hline General store/shop & 9.9 & 16 \\
\hline Others & 8.7 & 14 \\
\hline Don't know & 0.6 & 1 \\
\hline Total & 100.0 & 161 \\
\hline
\end{tabular}

According to the data presented, LHWs were a source of contraception for about 4.3 percent of the population, TBA/Dais 2.5percent, and midwives accounted for 1.2 percent.

Interestingly, less than 1 percent of the respondents indicated that they did not know the source from which they obtained contraception. This seems to suggest that women who are using contraception have the decision-making power to use contraception as well as the freedom to obtain it, without being dependant upon their husbands and families. 


\section{Intentions of Future Use}

The figure depicts the future intention of married women to use contraception. A quarter (24 percent) of the respondents intend to use contraception in the future, while 32 percent do not intend to do so. Close to half the women interviewed (44 percent) were unsure of their future intentions when it came to contraception. This uncertainly may be due to the fact that contraception is sometimes considered dangerous, harmful, wrong or even un-Islamic. However, this portion of the population is a potential target audience for campaigns which encourage an increase in contraceptive use through awareness and education.

Figure 6.2: $\quad$ Percentage of married women by future intention to use contraceptives

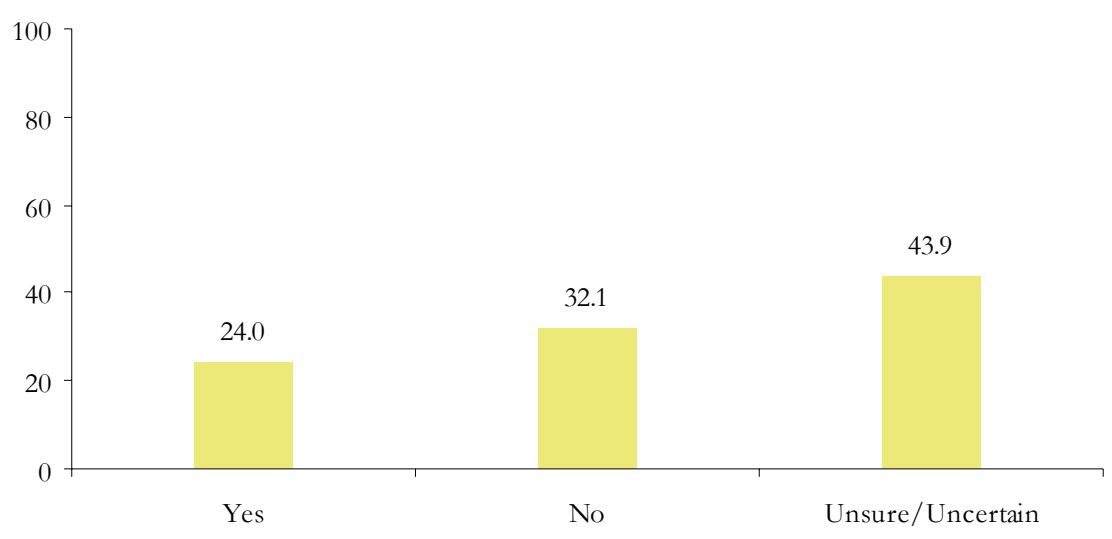




\title{
Chapter
}

\section{Behavior Regarding Maternal and Newborn Health}

\begin{abstract}
Many of the women who were interviewed were currently pregnant and had not yet experienced the full range of events that take place over the nine-month gestational period. However, women who have recently given birth were able to provide a full range of information on these events, and thus constitute an important part of the sample population for understanding the attitude and behavior on maternal and newborn health. This chapter pertains to the respondents' last pregnancy, given that it was within the past three years. Respondents were asked several questions regarding their experience during their last pregnancy, including antenatal and delivery care, complications of pregnancy and delivery, postnatal care, and problems in accessing health care.
\end{abstract}

Information on antenatal care, delivery services and postnatal care is of immense value in identifying subgroups of women who do not utilize such services, and it is useful in planning for future improvements in the services. Delivery services are described according to the person assisting and the rate of caesarean section. Information on postnatal care was collected for women who did not give birth in a health facility, and it describes the time elapsed since delivery when postnatal care was received, as well as from whom it was received.

Information regarding complications during pregnancy, childbirth, and the postpartum period, as well as complications in newborn was collected from these women. This information helps identify groups who are underserved.

\section{Gestational Age}

The respondents were asked to indicate gestational age at the time at which the pregnancy ended. Table 7.1 shows that of those pregnancies that ended in live births, almost 67 percent of them were born after completing nine months of gestational period, whereas about 3 percent of the pregnancies ended before the nine month gestational period. It also shows that 60 percent of the spontaneous abortions occurred within the first trimester and forty percent within the second trimester. Stillbirths occurred throughout the nine-month gestational period, with the most occurring in the tenth month of pregnancy. 
Table 7.1: $\quad$ Pregnancy outcome by gestational age

\begin{tabular}{|c|c|c|c|}
\hline \multirow{3}{*}{$\begin{array}{l}\text { Gestational Age when } \\
\text { Pregnancy Ended }\end{array}$} & \multicolumn{3}{|c|}{ Outcome of last pregnancy } \\
\hline & \multirow[t]{2}{*}{ Live Birth } & \multirow[t]{2}{*}{ Still birth } & Spontaneous \\
\hline & & & Abortions \\
\hline First Trimester of Pregnancy & & & 58.5 \\
\hline Second Trimester of Pregnancy & & & 41.5 \\
\hline 7 & 0.9 & 20 & \\
\hline 8 & 1.5 & 15 & \\
\hline 9 & 67.2 & 30 & \\
\hline 10 & 30.4 & 35 & \\
\hline Total & 100 & 100 & 100 \\
\hline Number of Pregnancies & 667 & 20 & 40 \\
\hline
\end{tabular}

\section{Antenatal Care}

In this survey, antenatal care was defined according to the type of provider, the number of visits made, and the stage of pregnancy at the time of the first visit, including whether tetanus toxoid injection and iron/folate tablets were received. The baseline survey also included questions regarding the antenatal care received by the respondent during the last pregnancy.

Figure 7.1: $\quad$ Percentage of pregnant women by their antenatal care status

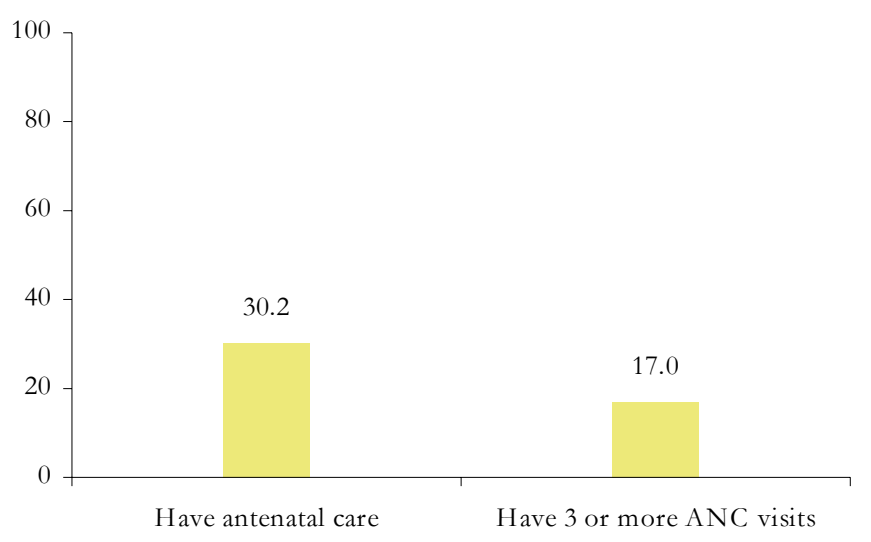

In the district of Buner, 30 percent of the respondents indicated that they received antenatal care during pregnancy, while nearly 70 percent failed to obtain any antenatal care whatsoever.

Table 7.2 outlines the time at which the respondent first obtained antenatal care during pregnancy. The largest portion of respondents received antenatal care within the first four months of pregnancy, with the most (18 percent) indicating that they obtained care in their third month. As well, respondents were asked to indicate the number of times they received antenatal check-ups during the course of their pregnancy. A large portion (23 percent) indicated that they had three antenatal checkups, followed by 20 percent each who received one and two check-ups during their pregnancy. 
From the respondents interviewed, approximately 6 percent were unable to recall the gestational age of pregnancy at the first antenatal visit, while 5 percent were unsure of the number of antenatal checkups they received during the course of their pregnancy.

Table 7.2: $\quad$ Gestational age at first antenatal check-up/ number of antenatal check-ups obtained

\begin{tabular}{|c|c|c|c|}
\hline \multicolumn{2}{|l|}{ Check-ups } & Percent & Number \\
\hline \multirow{11}{*}{$\begin{array}{l}\text { Gestational age of pregnancy at } \\
\text { first antenatal care }\end{array}$} & 1 & 7.7 & 17 \\
\hline & 2 & 12.2 & 27 \\
\hline & 3 & 18.1 & 40 \\
\hline & 4 & 10.9 & 24 \\
\hline & 5 & 8.1 & 18 \\
\hline & 6 & 8.1 & 18 \\
\hline & 7 & 8.1 & 18 \\
\hline & 8 & 9.0 & 20 \\
\hline & 9 & 9.5 & 21 \\
\hline & 10 & 1.8 & 4 \\
\hline & Don't know & 6.3 & 14 \\
\hline \multirow{10}{*}{$\begin{array}{l}\text { No. of times have antenatal } \\
\text { check-ups during pregnancy }\end{array}$} & 1 & 20.4 & 45 \\
\hline & 2 & 19.5 & 43 \\
\hline & 3 & 23.1 & 51 \\
\hline & 4 & 9.5 & 21 \\
\hline & 5 & 6.3 & 14 \\
\hline & 6 & 7.2 & 16 \\
\hline & 7 & 0.9 & 2 \\
\hline & 8 & 3.2 & 7 \\
\hline & 9 & 1.8 & 4 \\
\hline & Don't know & 5.0 & 11 \\
\hline Total & & 100.0 & 221 \\
\hline
\end{tabular}

Figure 7.2 is a visual depiction of the people who most often accompany a pregnant woman to antenatal check-ups. In the district of Buner, 43 percent of the respondents indicated that their mother-in-law accompanied them to the health facility, followed by 32 percent who stated that their husbands accompanied them. Family members accompanied 21 percent of the respondents with 1 percent indicating that they went unaccompanied. 
Figure 7.2: $\quad$ Percentage distribution of married women by persons who accompanied them to their antenatal check-up

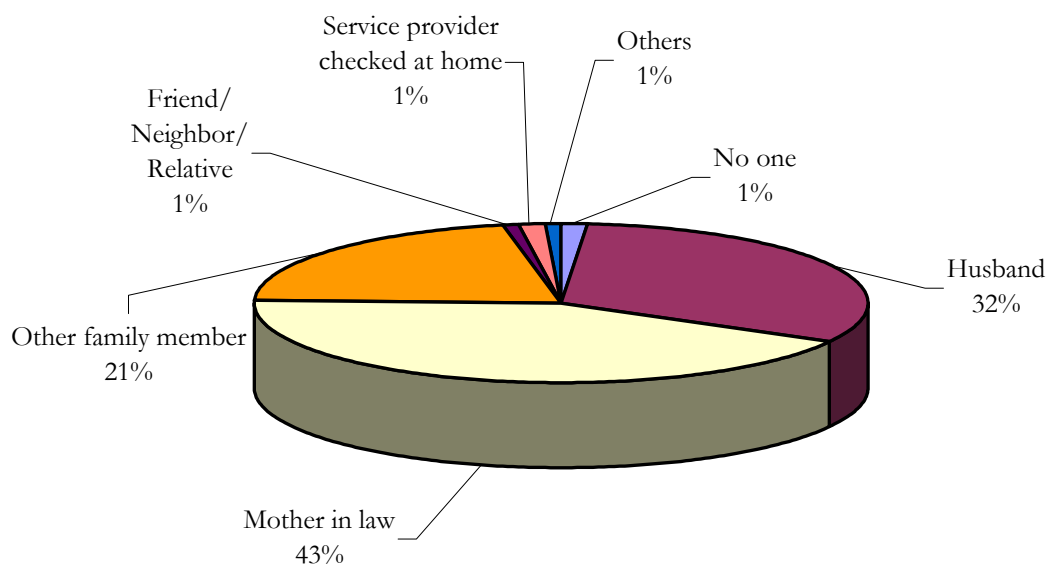

\section{Components of Antenatal care}

In Pakistan, it is recommended that every pregnant woman receive the following services: height and weight measurements, blood pressure measurement, iron tablets, tetanus toxoid immunization, and abdominal examination. In any antenatal care visit, a woman should be informed of the danger signs of pregnancy, have her weight measured, and provide blood and urine samples for testing.

Antenatal care can improve certain outcomes through the detection and management of possible complications. However, although antenatal care has not been shown to reduce rates of maternal mortality, it may improve birth weight. Antenatal care can prevent, identify and treat iron deficiency and anemia in a pregnant mother.

Figure 7.3 indicates the services performed for respondents during their antenatal check-ups. Most respondents indicated that their health care provider measured their blood pressure (60 percent), asked about their obstetric history (57 percent), completed blood and urine tests (43 percent and 49 percent respectively), and checked for anemia (47 percent). However, only 38 percent indicated that an ultrasound was performed on them, while only 24 percent had their weight measured. 
Figure 7.3: $\quad$ Services performed/asked during antenatal check-up

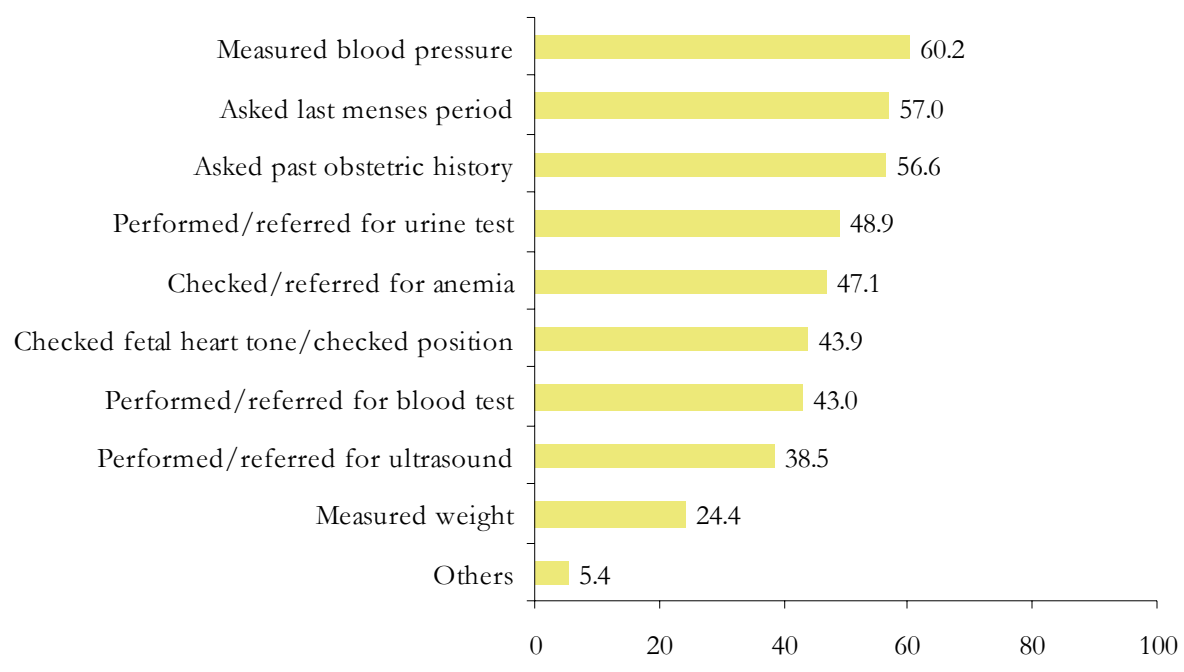

The next part of the survey required women to indicate the topics discussed with them during their antenatal check-ups. Over half (59 percent) the respondents indicated that their health providers discussed nutrition with them, whereas less than half (46 percent) indicated that the topic of 'T'T injections was discussed with them. Unfortunately, other important topics were not discussed enough during the antenatal check-ups. These topics included breastfeeding, which was discussed with only 19 percent of the women, danger signs ( 9 percent) and birth preparedness ( 9 percent).

Figure 7.4: $\quad$ Percentage of pregnant women by issues discussed during antenatal check-up

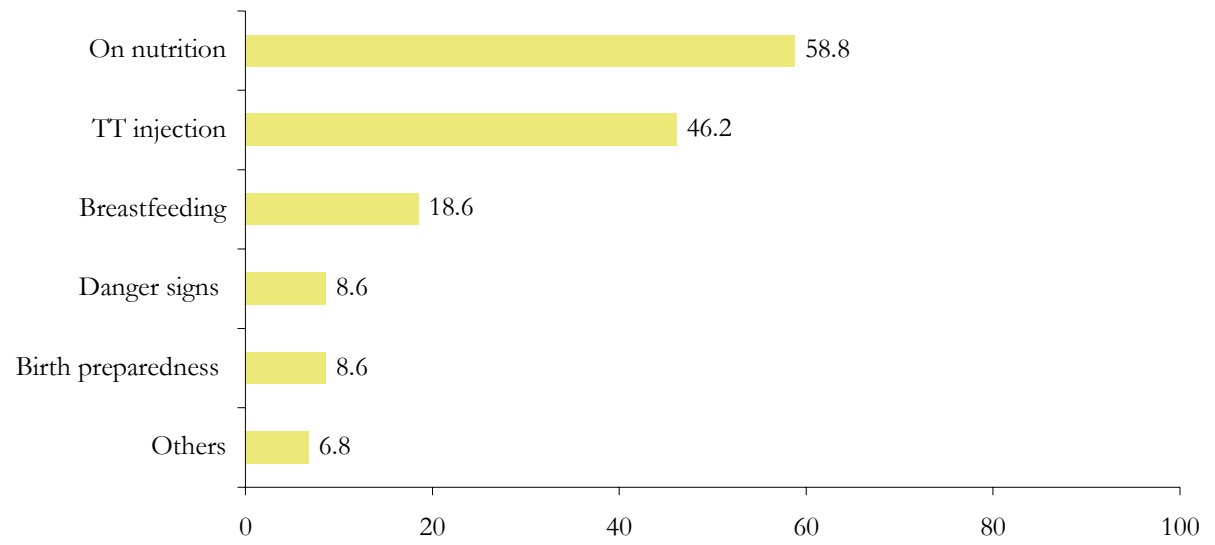




\section{TT Injections and Iron/Folate Tablets}

Respondents were also asked to state whether they took iron and folate supplements and received TT shots during the last pregnancy. The immunization of pregnant women is enforced by a program coordinated by the Expanded Program on Immunization (EPI) and the Maternal and Child Health Care $(\mathrm{MCH})$ departments at the district level. The program recommends that women receive two tetanus toxoid (TT) injections during their first pregnancy. Booster injections are given once during each subsequent pregnancy to maintain full protection. In recent years, TT immunization has also been given to women before marriage, so that any pregnancy occurring within three years of their marriage would be protected against tetanus.

Figure 7.5: $\quad$ Percentage of married women by status of TT Injections during the last pregnancy

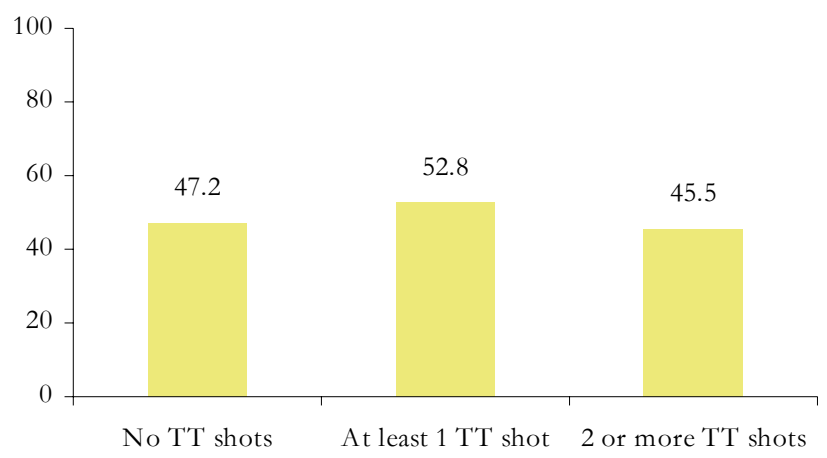

Figure 7.6: $\quad$ Percentage of married women by status of iron/folate tablets during the last pregnancy

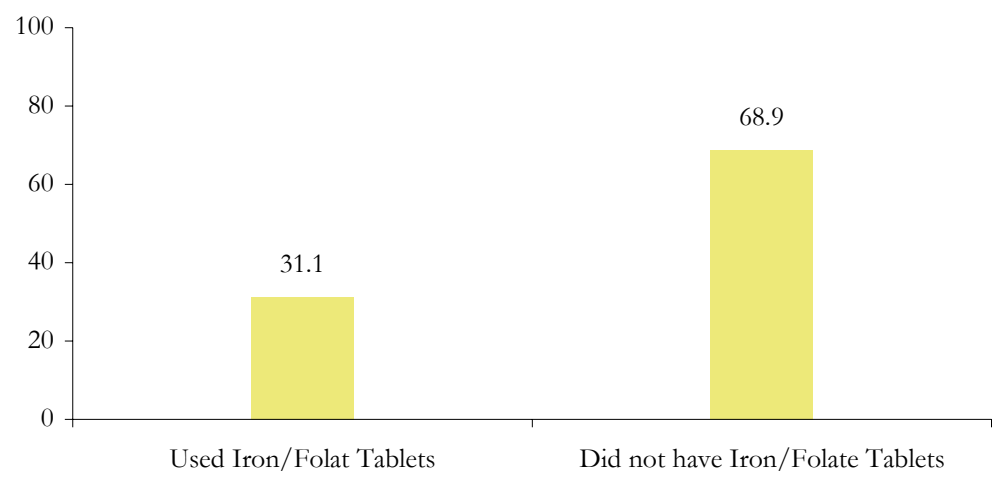

According to figures 7.5 and 7.6, less than half of the women (45.5 percent) interviewed received 2 doses of TT shots during pregnancy and only 31 percent took iron/folate supplements. This means that nearly half of the women did not receive any TT shots during their pregnancy, and 69 percent did not take iron/folate supplements. Women may not have the decision-making power to obtain these supplements and vaccinations, and may be dependent upon husbands or family members/in-laws to make these important decisions for them. Also the availability of these services may be a problem in these areas. 


\section{Experience of Complications and Birth Preparedness}

\section{Complications During Pregnancy}

To identify complications associated with pregnancy, women were asked about certain signs and symptoms that they had experienced in association with their last pregnancy during the past three years.

Interestingly, slightly less than half the respondents reported any complications during pregnancy. The most commonly reported complications were "severe abdominal pain" (29 percent), "severe headache" (17 percent), "severe/ prolonged vomiting" (15 percent) and "blurring of vision" (14 percent).

Figure 7.7: $\quad$ Percentage of married women who experienced complications during their last pregnancy

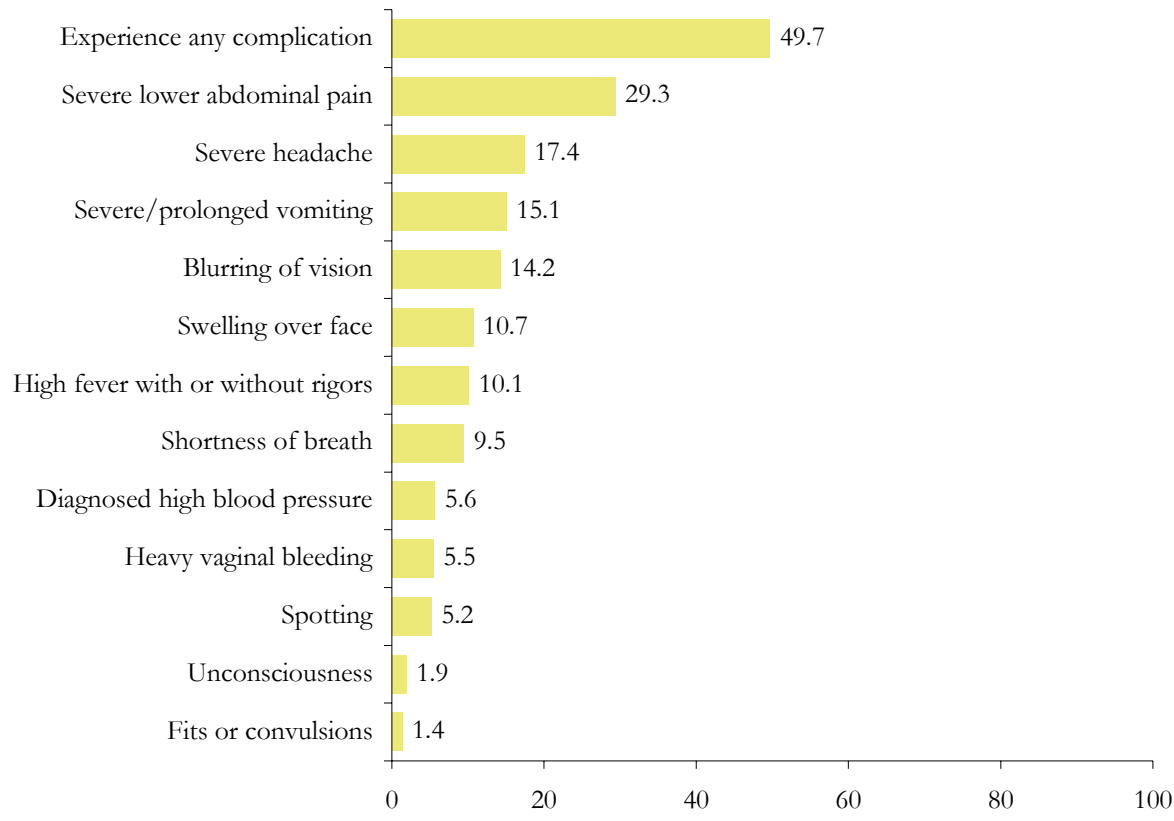

Around 10 percent of the women interviewed reported "swelling on face", "high fever" and "shortness of breath". Other danger signs were not commonly reported. While a few women reported "heavy vaginal bleeding, spotting and high blood pressure", it is possible that most respondents assume such symptoms are part of the pregnancy process and may therefore fail to report these complications. 


\section{Preparedness for Childbirth}

To ensure the safety of the mother and newborn at the time of delivery, certain preparations need to be made. These include deciding who is going to assist in the delivery, where the delivery is going to take place, how the woman is going to get to this place, and how much the delivery is going to cost. Delivery services, especially emergency obstetric care, are critical for pregnant women. Emergency care is important if pregnant mother experience obstructed labor, pregnancy-induced hypertension, eclampsia or severe untreated anemia. Obstructed or prolonged labor is one of the most serious complications that can cause maternal death. Obstetric care can also prevent or treat complications that affect the neonate, such as birth asphyxia.

In the baseline survey, respondents were asked whether they had discussed any of these specific topics during pregnancy. The questions asked assessed the arrangements that were made for the time of delivery, and the removal of various delays, which may affect the health of both mother and baby. Respondents were asked if they had made necessary arrangements regarding transport, money, blood, location and hours of operation of the nearest hospital, as well as clothes for the newborn baby. In the district of Buner, over half (54 percent) the women interviewed indicated that they had located a nearby hospital, and 39 percent had determined the cost/delivery fees. As well, 39 percent stated that they had arranged for money for a normal delivery, while 31 percent claimed to have arranged for money in the event that an emergency should occur.

Figure 7.8: $\quad$ Percentage of married women who made arrangements for their last delivery

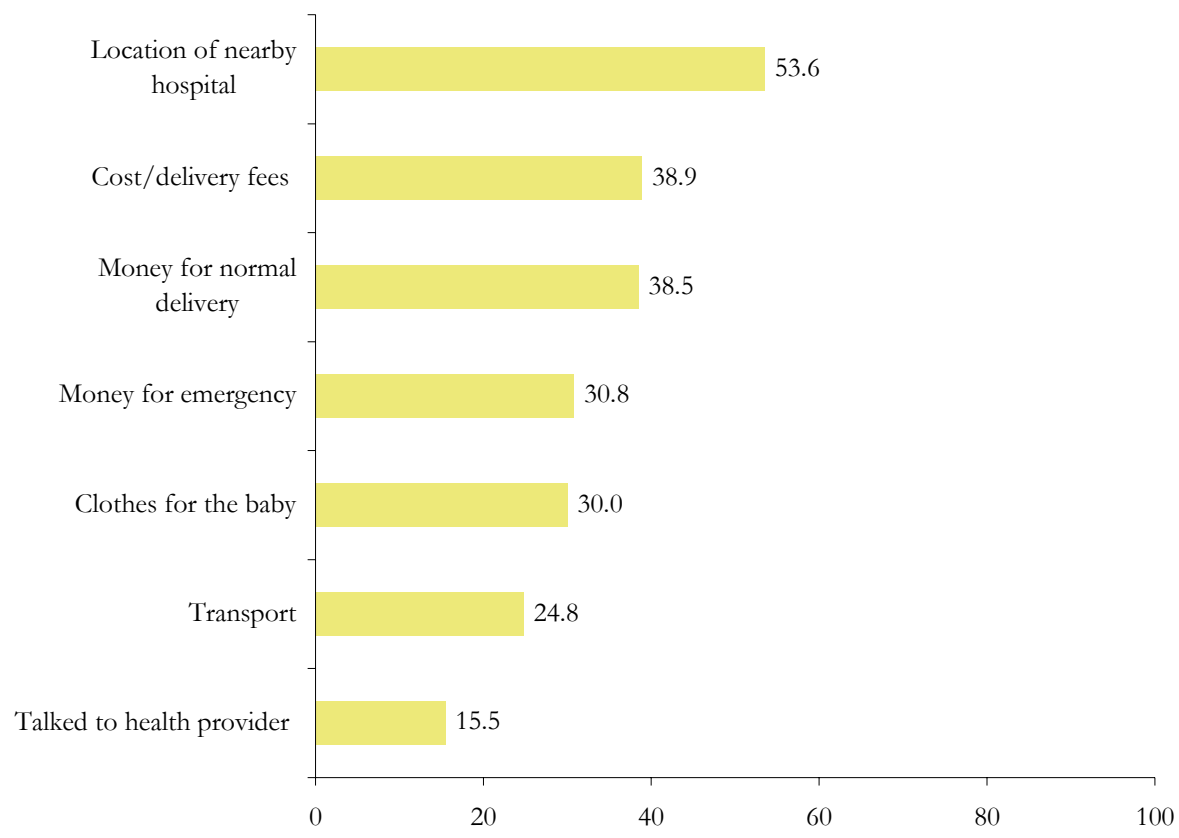

Only 25 percent however, had arranged for transport at the time of delivery, even though a lack of transportation is often a very common delay that may jeopardize the health of both mother and baby. 


\section{Delivery Characteristics}

When asked about the status of the delivery, 91 percent of the women interviewed indicated that they had normal vaginal deliveries, whereas 3.2 percent had assisted deliveries. Only 0.4 percent claimed to have delivered via Caesarean section. Almost 6 percent of the women interviewed indicated that their pregnancies ended in spontaneous abortions. There were no induced abortions reported. This may be due to the fact that spontaneous abortions are more socially acceptable than induced ones and are therefore misreported by women.

Table 7.3:

Status of last delivery

\begin{tabular}{lcr}
\multicolumn{1}{c}{ Status } & Percent & Number \\
\hline Normal vaginal delivery & 90.8 & 661 \\
\hline Assisted vaginal delivery & 3.2 & 23 \\
\hline Caesarean section & 0.4 & 3 \\
\hline Spontaneous abortion & 5.6 & 41 \\
Total & 100.0 & 728
\end{tabular}

As well, 92 percent of the deliveries ended in live births, whereas 2.7 percent resulted in stillbirths. 5.4 percent of the population reported spontaneous abortions.

Figure 7.9: $\quad$ Percentage of pregnancies by outcome

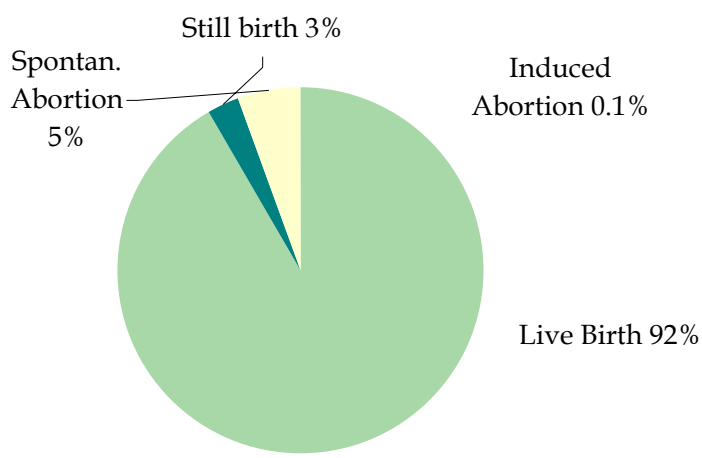




\section{Place of delivery}

Respondents were asked to indicate the location at which their previous delivery took place. Of the respondents interviewed, 65 percent stated that they delivered at home, whereas 19 percent cited the DHQ/THQ as their place of delivery. Private hospitals and clinics were the locations for 8 percent of the deliveries.

Figure 7.10: $\quad$ Percentage of women by place of delivery

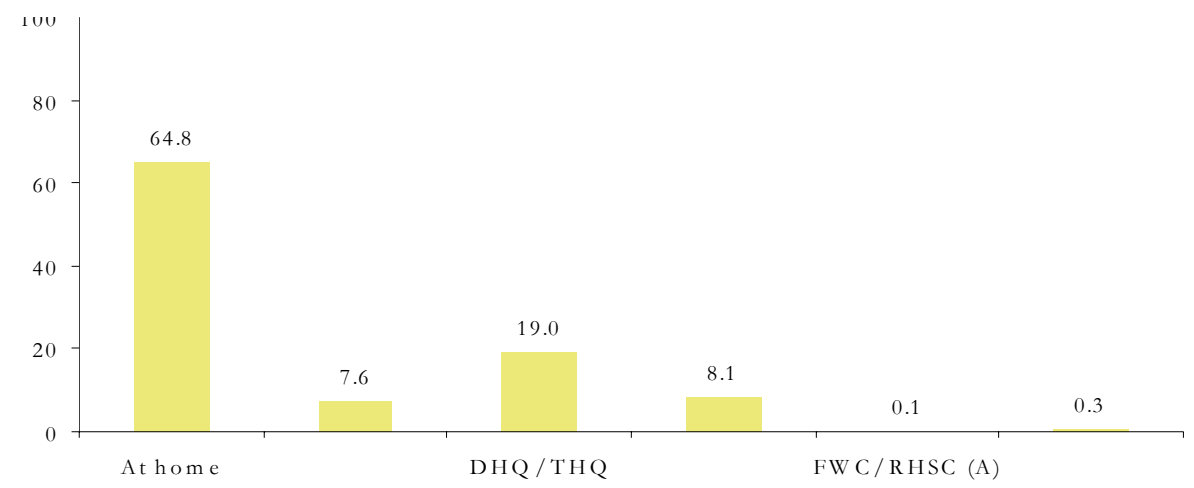

Financial constraints may be the leading cause for women delivering at home, in spite of their desire to deliver their babies at a health facility. Also, women may not be allowed to deliver at a health facility by their husbands, in-laws or family members.

\section{Assistance during Delivery}

This portion of the survey determined the type of assistance women received during their delivery. Two thirds ( 65 percent) of the respondents indicated that a female relative assisted with their delivery, while 16 percent of the deliveries were carried out by TBAs/Dais. Nurses undertook only 5.2 percent of the deliveries, and less than 1 percent ( 0.9 percent) were carried out by lady doctors. This suggests that over 80 percent of the deliveries are carried out by women who have either no experience, or no formal training, and would therefore not be able to handle any complications that may arise.

Figure 7.11: $\quad$ Percentage of married women by delivery attendant

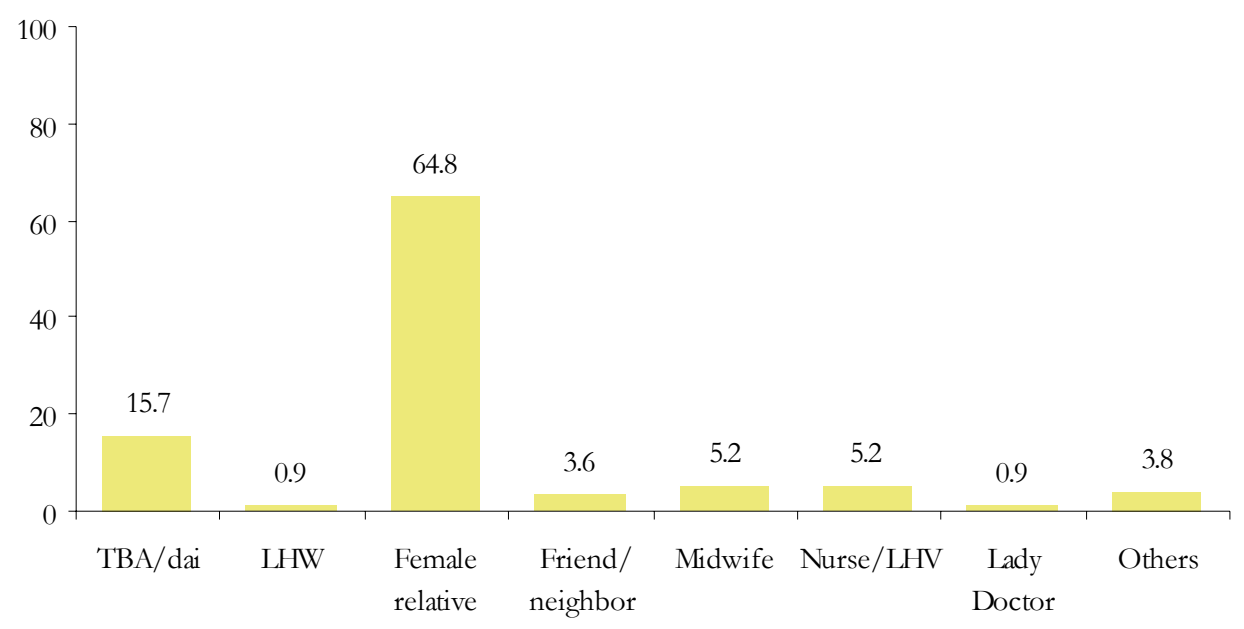


Figure 7.12: $\quad$ Percentage of married women by reported main reason to choose a dai as delivery attendant

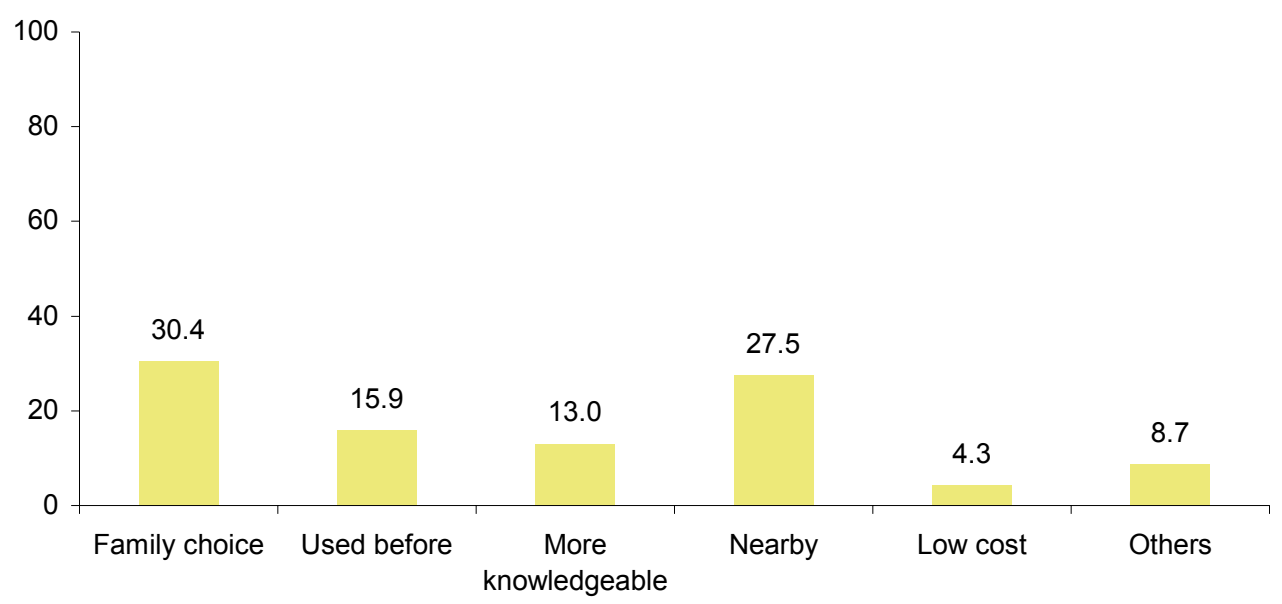

When asked why they chose a TBA/dai as a delivery attendant, 30 percent of the respondents indicated that family choice was the reason, followed by 28 percent who cited geographical convenience as the main reason. Nearly 16 percent indicated that they had used a TBA/Dai before, while 13 percent believed that TBAs/Dais were more knowledgeable.

\section{Clean Delivery Practices}

Respondents were asked to state if the TBAs followed safe health practices such as washing their hands with soap prior to deliveries and using clean delivery practice. Less than three quarters (72 percent) of the women interviewed indicated that their TBA/Dai did in fact wash her hands with soap prior to delivering the newborn baby.

Figure 7.13: $\quad$ Percentage of delivery attendants who reported washed hands before conducting the delivery and type of thread used to tie the cord

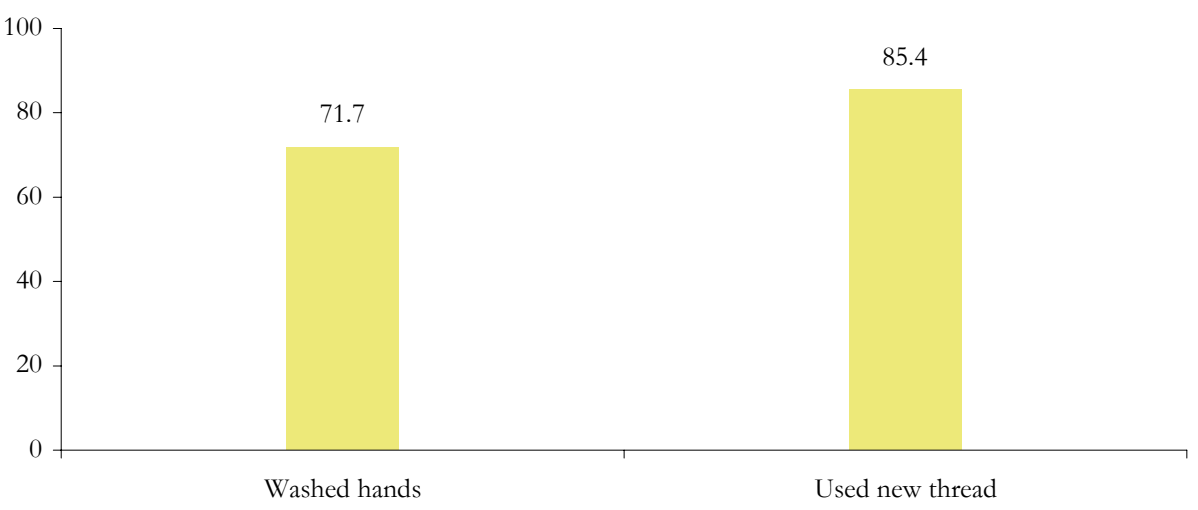


Figure 7.14: $\quad$ Percentage of delivery attendants who reported instruments for cutting the cord

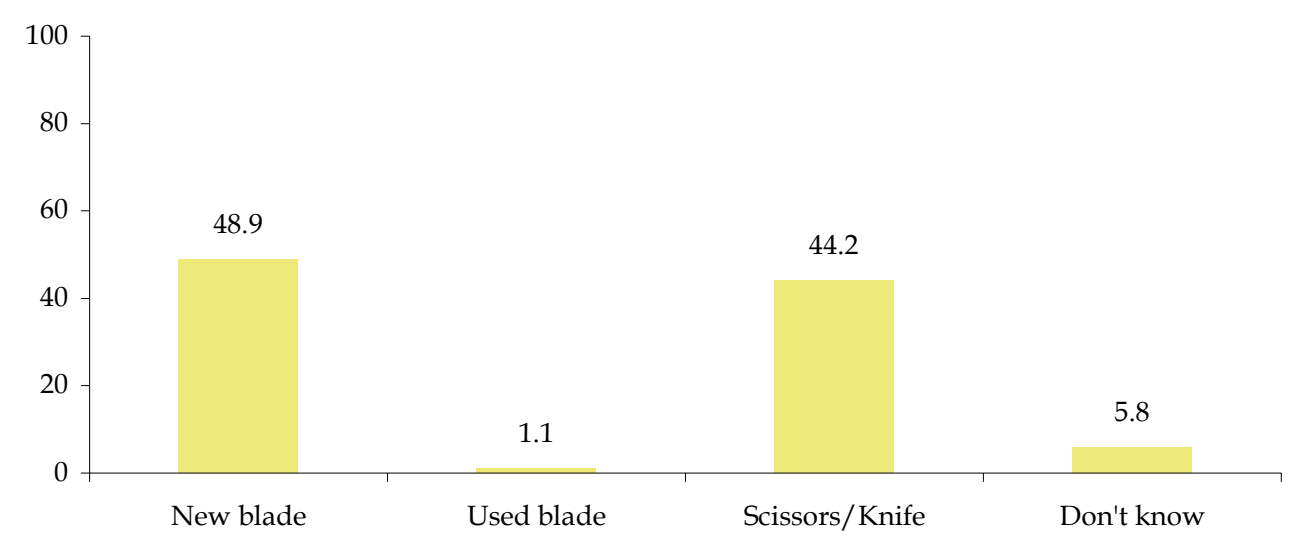

Furthermore, while 48.9 percent of the delivery attendants used new blades for cutting the cord, one percent used an old blade and 44.2 percent used scissors/knives. Nearly 6 percent were not sure what instrument was used to cut the cord at the time of delivery (figure 7.14). Figure 7.13 also shows that in 85.4 percent of the cases the cord was tied with a new piece of thread.

\section{Complications during Childbirth}

During the baseline survey, severe complications during childbirth were also discussed and respondents were asked to indicate the complications they may have experienced. The highest percentage of respondents (18 percent) reported having “excruciating abdominal pain," while 7.3 percent and 7.1 percent of the population reported "prolonged/obstructed labor" and "premature rupture of membranes" respectively. "Bleeding prior to labor", "delay in delivery", and "excessive postpartum bleeding" were amongst the other complications that were experienced.

\section{Table 7.4: $\quad$ Experienced complication during Last delivery}

\begin{tabular}{|c|c|c|}
\hline Complications & Percentage & Number \\
\hline Prolonged/obstructed labor & 7.3 & 53 \\
\hline Bleeding before labor began & 4.9 & 36 \\
\hline Excruciating abnormal pain & 17.5 & 128 \\
\hline Premature rupture of membranes & 7.1 & 52 \\
\hline Delay in delivery of placenta/retained placenta & 3.0 & 22 \\
\hline Excessively postpartum bleeding on day of deli./abort. & 2.6 & 19 \\
\hline Tear in vagina, cervix or uterus & 1.1 & 8 \\
\hline Prolapsed of the uterus & 1.0 & 7 \\
\hline Fever & 1.2 & 9 \\
\hline Abnormal position fetus & 1.8 & 13 \\
\hline
\end{tabular}




\section{Decision-making within family}

Delays in seeking care, in reaching adequate health facilities and in receiving appropriate care at health facilities are recognized barriers to care for pregnant women and these factors may be especially pronounced for young and old pregnant mothers. Timely and appropriate care provides an opportunity to prevent or manage the direct causes of maternal mortality such as hemorrhage, obstructed labor, infection and hypertensive disorders. It also reduces fetal and neonatal deaths related to obstetric complications. According to table 7.5, more than 30 percent of the respondents indicated that the mother-in-law was the one who made the decision regarding maternal health. Twenty-one percent indicated that their husbands made these important decisions, while only 14 percent of the respondents stated that they themselves made the decision regarding health care.

Table 7.5:

Measures taken to address complications

\begin{tabular}{|c|c|c|c|}
\hline \multicolumn{2}{|c|}{ Measures taken } & Percent & Number \\
\hline \multirow{5}{*}{$\begin{array}{l}\text { Person who made decision to } \\
\text { seek health care }\end{array}$} & Self & 14.3 & 15 \\
\hline & Husband & 21.0 & 22 \\
\hline & Mother in law & 30.5 & 32 \\
\hline & Other family member & 27.6 & 29 \\
\hline & Others & 6.7 & 7 \\
\hline \multirow{5}{*}{$\begin{array}{l}\text { Mode of transport to reach health } \\
\text { care service }\end{array}$} & Service provider visited at home & 27.6 & 29 \\
\hline & On foot & 4.8 & 5 \\
\hline & Own transport & 23.8 & 25 \\
\hline & Private transport & 39.0 & 41 \\
\hline & Community Transport & 4.8 & 5 \\
\hline Total & & 100.0 & 105 \\
\hline
\end{tabular}

\section{Availability of Transport}

The mode of transport to get the health facility was also an issue that was discussed during the survey. In table 7.5, the highest percentage of people (39 percent) indicated that they used private transportation in order to reach a health facility, while 24 percent had their own transportation. Nearly 5 percent indicated that they had no means of transportation available to them and would walk to a health facility at the time of delivery.

Whatever the mode of transport the respondent used, more than 9 percent of the pregnant women were able to reach the facility within 15 minutes. Eighteen percent reached it between 16-30 minutes while 30 percent took between $1-2$ hours to reach the facility. More than 9 percent of the pregnant women took more than 2 hours to reach the health facility. Figure 7.15 shows the distribution of respondents by the time they took to reach the facility. 
Figure: 7.15: $\quad$ Time taken to reach the bealth facility for childbirth

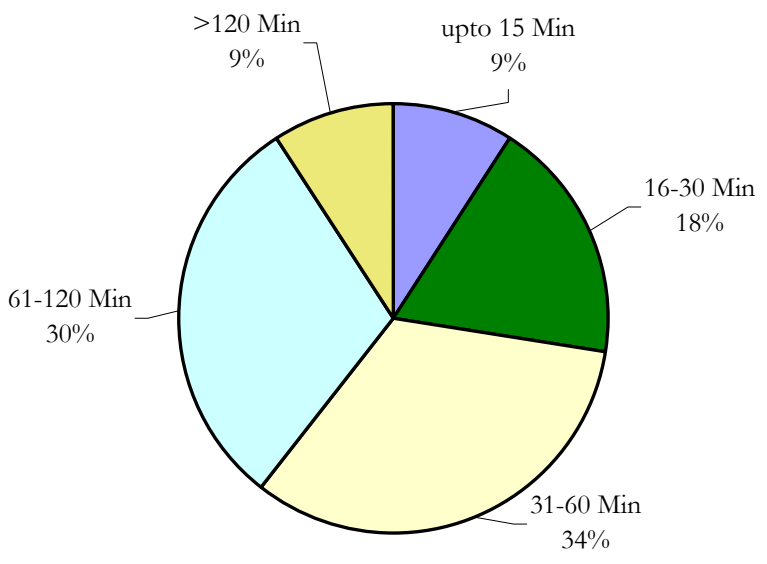

Figure 7.16 depicts the median time taken to "find the transport", after getting the transport and "reaching the hospital" and finally to "obtaining services after reaching the health facility". Overall, it shows that it took more than 30 minutes to find the transport and almost 60 minutes of traveling to reach the health facility. After reaching the health facility it took not more than 5 minutes to obtain the delivery services at the health facility. It means that overall it took more than 1 hour and 35 minutes from the decision making to getting the delivery services in Buner.

Figure 7.16: $\quad$ Median time to reach the bealth facility

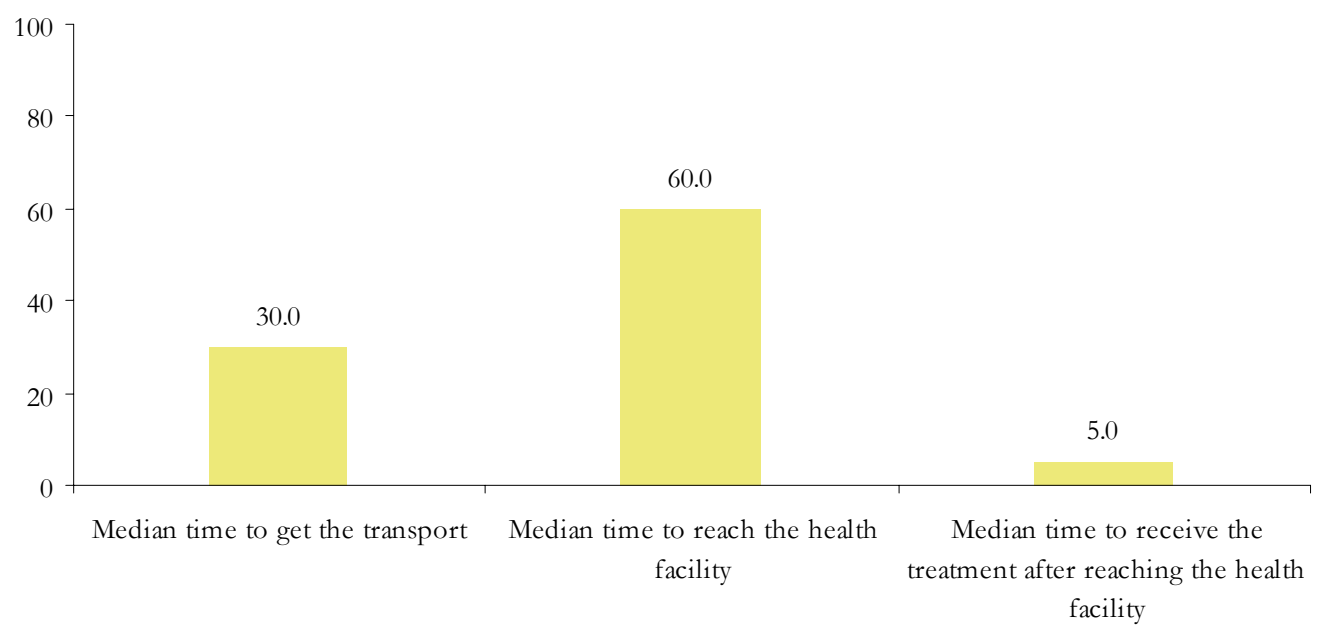




\section{Postpartum Care}

The postpartum period is a critical time for mothers and newborns. Respondents were asked about the quality and level of postpartum care they received after their last delivery.

Table 7.6:

History of postpartum care

\begin{tabular}{|c|c|c|c|}
\hline \multicolumn{2}{|c|}{ History } & Percent & Number \\
\hline \multirow{3}{*}{ Have a postnatal check-ups } & Yes & 3.3 & 23 \\
\hline & No & 92.9 & 638 \\
\hline & Delivered in hospital & 3.8 & 26 \\
\hline $\begin{array}{l}\text { No. of days after delivery, have first } \\
\text { check-up }\end{array}$ & Same day & 21.7 & 5 \\
\hline \multirow{2}{*}{$\begin{array}{l}\text { Experience complications during } \\
\text { postpartum period }\end{array}$} & Yes & 14.8 & 108 \\
\hline & No & 85.2 & 621 \\
\hline Total & & 100.0 & 729 \\
\hline
\end{tabular}

Surprisingly, 93 percent of the women interviewed indicated that they had no postnatal check-ups, while only about 3.3 percent indicated that they did receive postnatal care. As well, from those that did receive postnatal care, only 22 percent received check-ups on the day of delivery.

\section{Newborn/Infant Care}

The care provided to a newborn upon birth is crucial to the baby's health. Survey questions regarding initial infant care help determine the cause of newborn morbidity and mortality.

\section{Child Care during Delivery}

Respondents were asked to indicate where their child was placed immediately after delivery. A majority of the respondents ( 32 percent) indicated that the newborn was placed on a piece of cloth immediately after delivery, while 27 percent indicated that the child was placed with the mother. About 16 percent stated that the baby was put on a mattress and 5 percent said that the newborn was placed on the floor after delivery. It has been suggested that poverty, lack of education and awareness, as well as insufficient training and resources are the leading causes of infant mortality (Simmons, 1979). Since most babies are, in fact, delivered at home with the assistance of untrained midwives as discussed previously, the care provided to infants may not always be of good quality. Therefore, it is important to record the percentage of women following harmful or unhealthy procedures in order to understand the root causes of infant mortality.

Table 7.7: $\quad$ History of last childcare

\begin{tabular}{llrr}
\multirow{2}{*}{ History } & & Percent & Number \\
& On floor & 5.0 & 33 \\
\cline { 2 - 4 } & On mattress & 16.0 & 106 \\
\cline { 2 - 4 } Placed child immediately after delivery & On a piece of cloth & 32.1 & 213 \\
\cline { 2 - 4 } & Put with the mother & 26.7 & 177 \\
\cline { 2 - 4 } & Others & 16.6 & 110 \\
\cline { 2 - 4 } & Don't know & 3.8 & 25 \\
\hline \multirow{3}{*}{ Child dried up/cleaned before giving bath } & Yes & 90.2 & 598 \\
\cline { 2 - 4 } & No & 2.3 & 15 \\
\cline { 2 - 4 } & Don't know & 7.5 & 50 \\
\hline
\end{tabular}


Figure 7.17 shows the distribution of size of the babies at birth. It shows that 82 percent of the newborns were of normal size whereas 12 percent were smaller and 6 percent were bigger than the normal size of the babies.

Figure 7.17: $\quad$ Percent of live birth by their size (small, normal and big) at birth

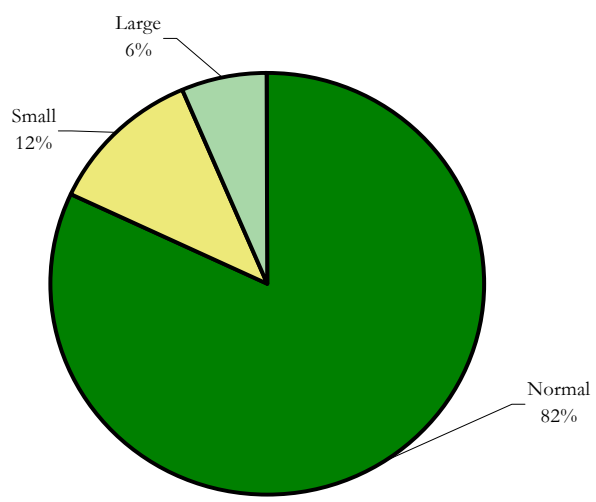

\section{Colostrum and Breastfeeding}

Respondents were asked if they gave their newborn babies colostrum. Nearly three quarters (72 percent) of the women indicated that they did in fact give their babies colostrum leaving about onefourth ( 28 percent) of the women who did not. Furthermore, only 19 percent indicated that they had a medical/physical examination carried out on their newborn baby, while the rest of the women failed to do so. This could be very dangerous especially if parents are unable to recognize complications or danger signs in their newborns.

All the women were also asked to report the time when they first gave a bath to the newborn. Figure 7.18 shows that only 35 percent of the babies were given a bath after 6 hours of birth. It also shows that more than 39 of the babies were given a bath within the first hour after birth. Figure 7.18 shows the distribution of babies by their bath time after birth.

Figure 7.18: $\quad$ Percentage of babies by time of given bath after birth

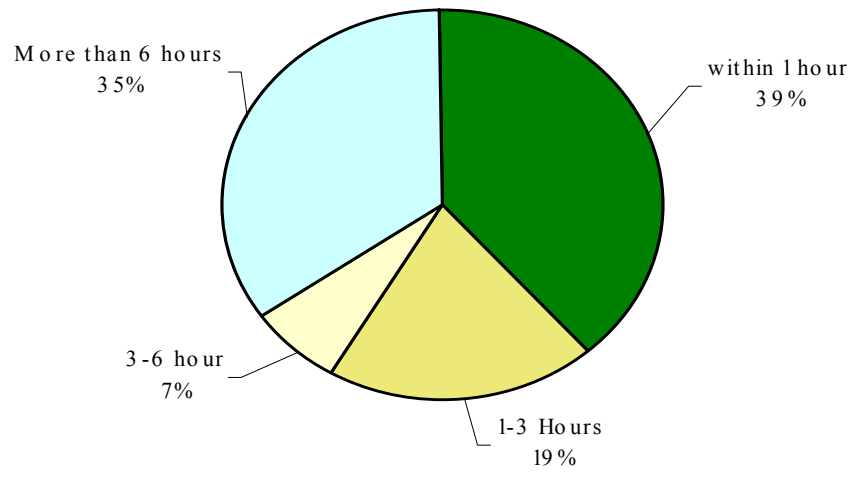


Respondents were also asked to indicate if they gave their newborn babies anything aside from breast milk within the first three days after delivery. About 86 percent indicated that they did feed their babies substances other than breast milk.

\section{Newborn Medical Check-ups}

Respondents were asked to indicate if any physical and/or medical examinations were conducted on their newborn baby. Figure 7.19 shows that only 19 percent of the babies were medically examined after birth. When asked if they had ever noticed any danger signs and symptoms in their newborns soon after delivery, a very small percentage of respondents indicated that they had noticed anything. "Yellow skin (jaundice)" was the most commonly noted symptoms, reported by only 4 percent of the population. "Difficulty breathing" and "weak cry" were also noted by only about 3 percent of the population. This suggests that respondents are either unable to recognize danger signs in their newborns, or failed to report them accurately.

Furthermore, when asked if they noted any danger signs and symptoms in their newborns seven days after delivery, respondents once again indicated that "yellow skin (jaundice)" was the most commonly noted symptom, reported by about 12 percent of the population.

Figure 7.19: $\quad$ Newborn feeding and health indicators

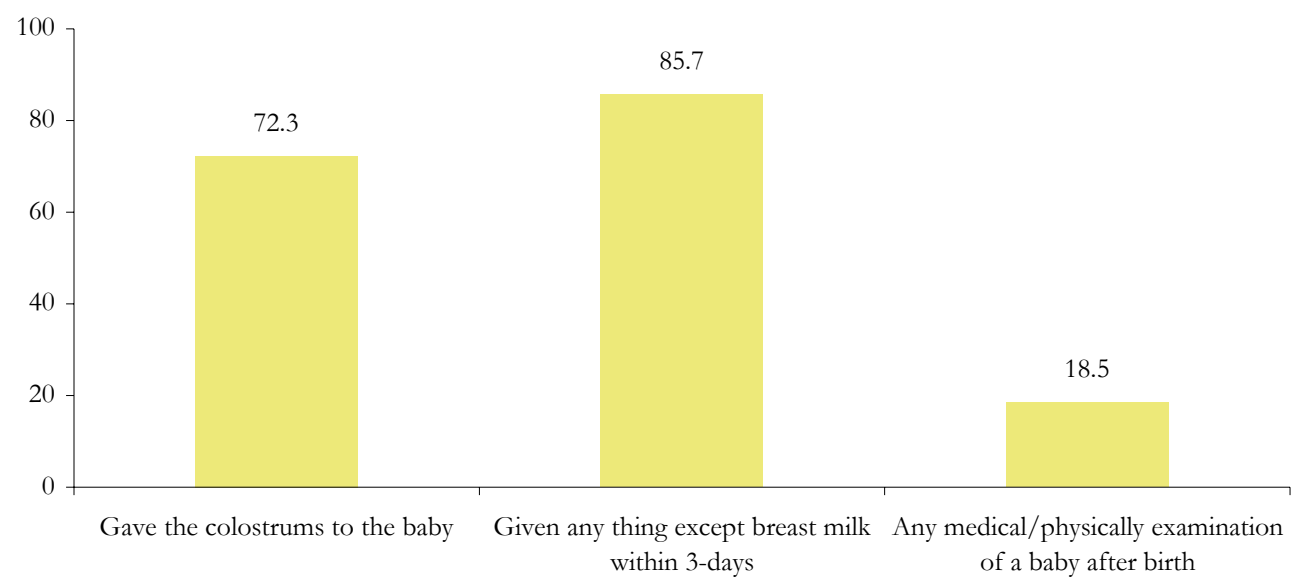


Figure 7.20: $\quad$ Percentage of newborns with danger signs/symptoms soon after delivery

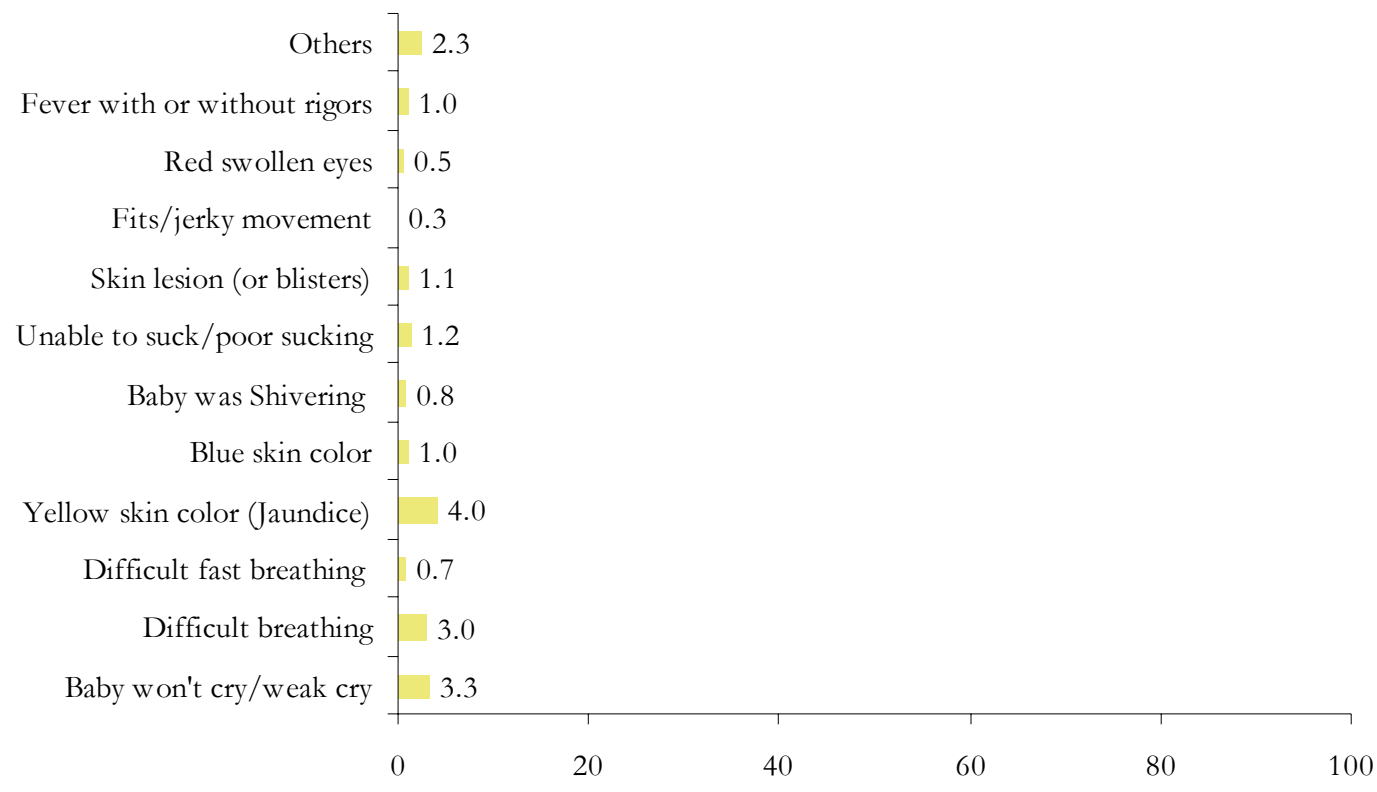

Figure 7.21: $\quad$ Percentage of newborns with danger signs/symptoms within 7-days of delivery

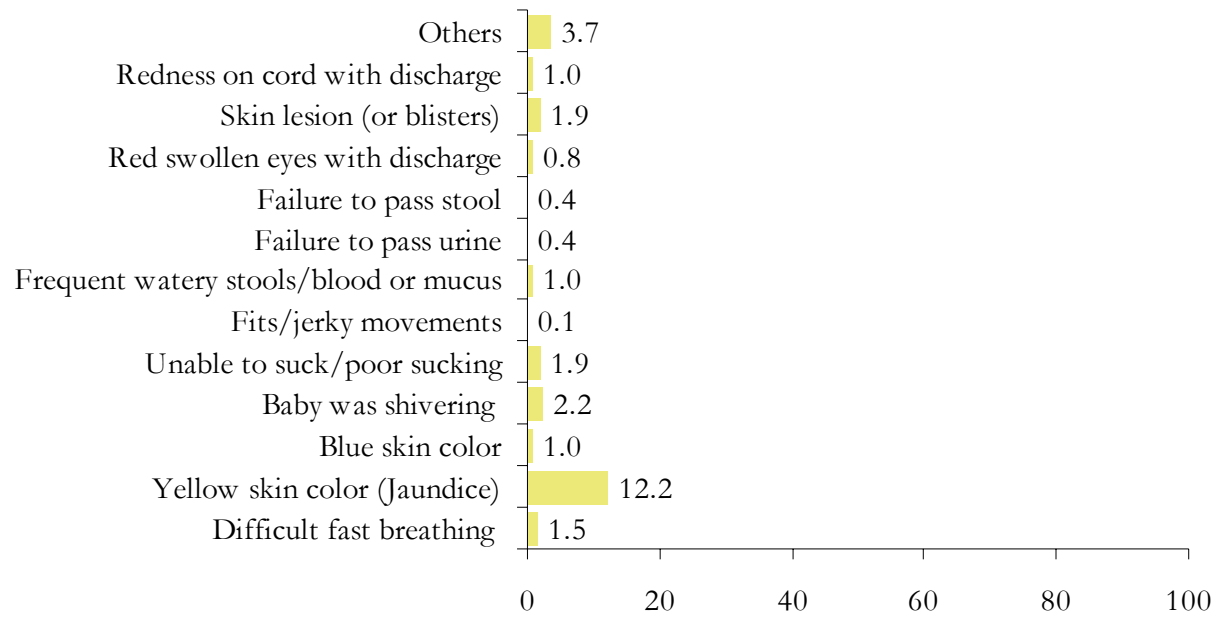


Figure 7.22:

Percentage of newborn with measures taken to have complications treated

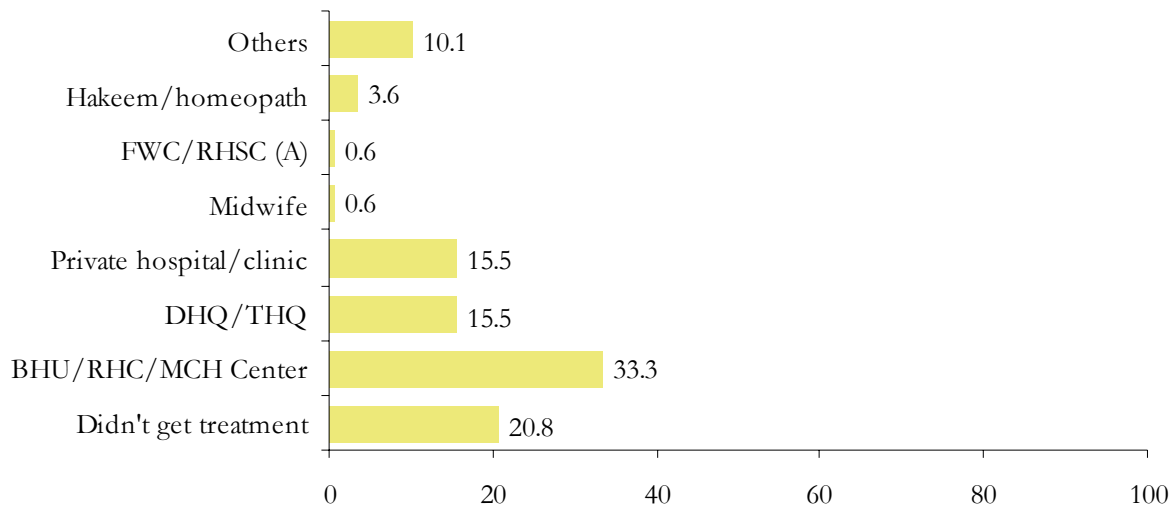

Finally, respondents were also asked to indicate what type of treatment they sought once the above mentioned danger signs and symptoms were noted in their newborns. Figure 7.22 indicates that 33 percent of the respondents sought treatment from a BHU/RHC/MCH center, followed by 16 percent who went to a private hospital/clinic, along with another 16 percent who went to DHQ/THQ. A sizable 21 percent of the population did not get any treatment at all. This may be due to a lack of financial resources required to seek assistance, or due to a lack of education which would result in families failing to realize the magnitude of such complications especially within the first seven days of birth.

Respondents were asked to indicate the status of health of their last child. About 97 percent indicated that their child was still alive, while 79 percent were currently breastfeeding their children.

Figure 7.23: $\quad$ Status and bealth of last birth

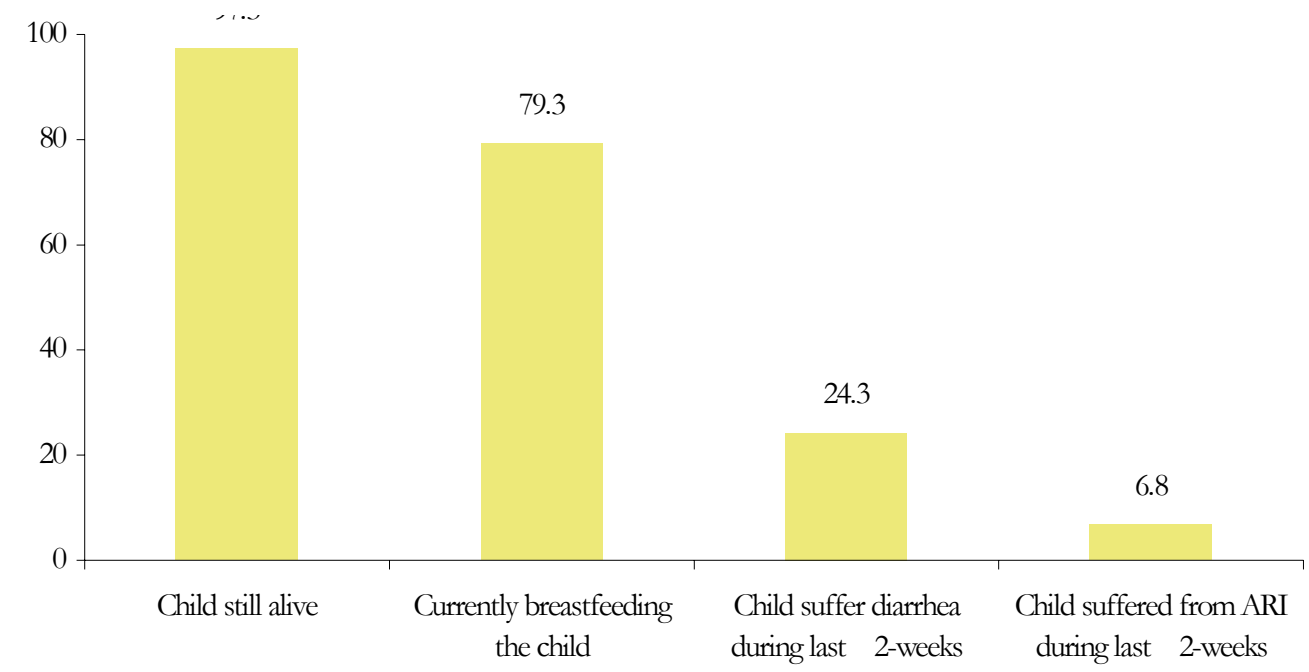

Finally, respondents were asked if their children suffered from diarrhea within the last two weeks. Figure 7.23 shows that a quarter ( 24 percent) of the women said that their child had had at least one episode of diarrhea. As well, 6.8 percent indicated that their children had suffered from ARI within the past two weeks. 



\section{Chapter \\ 8}

\section{Conclusions}

The baseline household survey conducted in Buner is an essential tool in the process of understanding the different attitudes towards and misconceptions regarding pregnancy and neonatal care. Since PAIMAN is intended to improve the health of all pregnant women as well as their newborn children, it is important to understand the obstacles that stand in the way of good health. Since the baseline survey is based largely on the opinions and experiences of married women of reproductive age (MWRA), the information obtained is from the very individuals are to be the primary recipients of the work done through PAIMAN.

This data not only suggests a higher level of poverty, but also low hygiene, sanitation and living standards in Buner thus making it an undesirable environment for expectant and new mothers alike, along with their newborn children. Findings also show only about 22.5 percent of the respondents in the district of Buner have access to some sort of media whether it is television, radio or newspapers. However, even reaching out to this small portion of the population would be difficult as there are some obstacles that stand in the way including the lack of decision-making power for women and the infrequency of access of the media. As well, the other 77.5 percent of the respondents that do not have access to any media must also be reached by other means. Finally, a majority of the people interviewed believed that television was the most trustworthy form of media, even though the highest percent (64.9 percent) had no answer to that question.

Regarding antenatal care, an overwhelming majority ( 69.4 percent) believed it necessary for women to receive antenatal check-ups, while only about 18 percent of the married women felt it was not necessary. The findings show that a 30 percent of the pregnant women receive antenatal care during their last pregnancy. However, only 17 percent of the women interviewed indicated that they received 3 or more antenatal check-ups only when needed.

Respondents were asked to indicate which complications they believed were dangerous and required medical attention. Surprisingly, a very small percent believed that most complications required a doctor's care. The findings show that nearly half the respondents were unable to name a single danger sign, while only 16 percent were able to name three or more signs. The situation is aggravated for women who were unable to name a single sign or complication during pregnancy (percentage?).

Baseline findings show that over 47 percent of the respondents did not receive any TT shots during their pregnancy, while 68.9 percent did not take any iron/folate supplements.

The findings also show that even though a sizable portion of the women interviewed believed that services during childbirth should be obtained from a hospital, 64.8 percent delivered at home. While 
it seems that many women do deliver through health professionals, it may also be said that not all women are allowed to deliver with the help of health professionals even if they want to. One reason, which explains why some women still want to deliver at home, is that many are not able to make decisions independently. Often, women are dependant upon their husbands or in-laws when it comes to major decisions. However, most of the respondents claimed that they had arranged for transport, money, and hospital fees etc. prior to the time of delivery, therefore eradicating any major delays.

Most deliveries were normal vaginal deliveries ( 90.8 percent). The percentage of Caesarean section deliveries was not very high ( 0.4 percent). Normally Caesarean sections are generally performed only for certain medical indications and for complicated deliveries. Severe abdominal pain was a widely reported complication by many women in the region of Buner. Premature ruptures of membranes, excessive bleeding and prolonged labor were some other complications that were reported.

Married women in Buner seem to underestimate the value and importance of postnatal care. Surprisingly, the percentage of those who did not feel postnatal care was necessary was very high, sitting at 92.9 percent.

As in the case of pregnancy, many women were not aware of the complications that may arise during delivery. The baseline findings show that only about 9 percent of the women recognize at least three danger signs during delivery. Deliveries can only be made safe if married women are made educated regarding the danger signs during the delivery, so that they can decide when to seek treatment. Innovative approaches are therefore needed to make these communities more aware of issues regarding maternal and newborn health.

Although baseline survey findings indicate that excessive vaginal bleeding is the most known danger sign during the postpartum period, not all women are aware of this fact. Unfortunately, many women are unaware of danger signs that may appear in newborns, especially in the first seven days after delivery. The postpartum period is a critical time for mother and newborn, and it is necessary that the health of both be monitored closely during this period.

A very large percentage of respondents in Buner indicated that they received their pregnancy-related information from their in-laws, family members and friends. Only 2 percent in rural Buner indicated that a Lady Health Worker was the source of their information while less than 1 percent got their information from a hospital or clinic. $\mathrm{BHU} / \mathrm{RHC} / \mathrm{MCH}$ centers were also a source of information for approximately 6 percent of the population.

Lack of transport to a health facility is a major cause of delay and can often lead to maternal and newborn mortality. It is very important to arrange transport ahead of time in order to eliminate that delay. Unfortunately, many households are unable to do so due to a lack of transportation in their communities. Most communities do not have any arrangement for transport, provision of blood and finances for women at the time of need during delivery. This is a major obstacle to safe birth practices, as women are then forced to deliver at home, and may be exposed to infections and complications. Birth preparedness promotes the arrangement of such aspects.

We hope that these data may be used by health officials, NGOs, and other concerned stakeholders to improve the situation regarding maternal and newborn health in Buner. PAIMAN will use this information to guide its own interventions and to monitor its progress. 


\section{References}

Caldwell, J., Routes to Low Mortality in Poor Countries. Population and Development Review, Vol. 12, No. 2. (Jun., 1986), pp. 171-220.

Federal Bureau of Statistics, "Socio-Economic Indicators at District Level, Punjab," Statistics Division, Government of Pakistan, (2002).

Hollander, D., Antenatal Education Helps Turkish Women Adopt Health-Promoting Behaviour. International Family Planning Perspectives, Vol. 30, No. 1. (Mar., 2004), pp. 45-46.

JHPIEGO/Maternal and Neonatal Health Program, "Monitoring Birth Preparedness and Complication Readiness: Tools and Indicators for Maternal and Newborn Health,” (2004).

Mahmood, Arshad, Determinants of Neonatal and Post-Neonatal Mortality in Pakistan. The Pakistan Development Review, Vol. 41, No. 4, Part II (Winter 2002), pp. 723-744.

Mahmood, Arshad, Socioeconomic Factors, Personal Illness Control and Infant and Child Mortality in Pakistan. Pakistan Population Review, Vol. 3, No. 1 (1992), pp. 67-86.

Martin, Linda G.; J. Trussell; Florentina Reyes Salvail; Nasra M. Shah, Co-variates of Child Mortality in the Philippines, Indonesia, and Pakistan: An Analysis Based on Hazard Models. Population Studies, Vol. 37, No. 3. (Nov., 1983), pp. 417-432.

Nawaz, Shuja, The Mass Media and Development in Pakistan. Asian Survey, Vol. 23, No. 8. (Aug., 1983), pp. 934-957.

Ringheim, Karin, When the Client is Male: Client-Provider Interaction from a Gender Perspective, International Family Planning Perspectives, Vol. 28, No. 3 (Sept., 2002), pp. 170-175.

Robbins, P.T., Global Approaches to Development. Sociology of Development, University of London, (2001), pp. 29-37.

Sathar, Zeba; Nigel Crook; Christine Callum; Shahnaz Kazi, Women's Status and Fertility Change in Pakistan. Population and Development Review, Vol. 14, No. 3. (Sep., 1988), pp. 415432.

Simmons, George B., Family Planning Programs or Development: How Persuasive is the New Wisdom? International Family Planning Perspectives, Vol. 5, No. 3. (Sep., 1979), pp. 101-110.

Syed, Sabiha H., Communications Channels and Family Planning in Pakistan. Studies in Family Planning, Vol. 10, No. 2. (Feb., 1979), pp. 53-60.

www.unesco.org 